University of Louisville

ThinkIR: The University of Louisville's Institutional Repository

Electronic Theses and Dissertations

$5-2012$

\title{
Size- and shape-dependent electrochemistry of gold nanoparticles.
}

Irina V. Khachian

University of Louisville

Follow this and additional works at: https://ir.library.louisville.edu/etd

\section{Recommended Citation}

Khachian, Irina V., "Size- and shape-dependent electrochemistry of gold nanoparticles." (2012). Electronic Theses and Dissertations. Paper 740.

https://doi.org/10.18297/etd/740

This Master's Thesis is brought to you for free and open access by ThinkIR: The University of Louisville's Institutional Repository. It has been accepted for inclusion in Electronic Theses and Dissertations by an authorized administrator of ThinkIR: The University of Louisville's Institutional Repository. This title appears here courtesy of the author, who has retained all other copyrights. For more information, please contact thinkir@louisville.edu. 


\title{
SIZE- AND SHAPE-DEPENDENT ELECTROCHEMISTRY OF GOLD NANOPARTICLES
}

\author{
By
}

Irina V. Khachian

\begin{abstract}
A Thesis
Submitted to the Faculty of the

College of Arts and Sciences of the University of Louisville in Partial Fulfillment of the Requirements for the Degree of
\end{abstract}

\author{
Master of Science
}

Department of Chemistry

University of Lousiville

Louisville, Kentucky

May 2012 
Copyright 2012 by Irina V. Khachian

All rights reserved 


\title{
SIZE- AND SHAPE-DEPENDENT ELECTROCHEMISTRY OF GOLD NANOPARTICLES
}

\author{
By
}

Irina V. Khachian

A Thesis Approved on

April 24, 2012

by the following Dissertation Committee:

Dissertation Director: Dr. Francis P. Zamborini

Dr. Richard P. Baldwin

Dr. Gamini Sumanasekera 


\section{DEDICATION}

This thesis is dedicated to my parents

Galina and Vladimir Plotnikov 


\section{ACKNOWLEDGEMENTS}

First of all I would like to acknowledge my supervisor, Dr. Francis P. Zamborini. His advices and guidance helped me in this study. He supported me in difficult times, believed in me and in the success of this work and told me - "Never give up!" when I had some challenges in the research.

I want to also acknowledge all my research group of fellow students, especially Dr. Olga S. Ivanova, who gave me excellent advice on how to work in the lab and described all the peculiarities of this type of the research, Rafael Masitas Castillo, who trained me the first few months in the lab and taught me the basic principles of the electrochemical techniques, explained how to use lab equipment, showed me where all the chemicals are located, and trained me on scanning electron microscopy (SEM), Lanlan Bao, who helped me with Atomic Force microscopy, Ultraviolet-Visible Spectroscopy, and with the preparation of gold nanoparticles, and Dr. Radhika Dasari, who always supported me and gave good advice.

I would like to acknowledge Joseph Williams from the ElectroOptics Research

Institute and Nanotechnology Center at the University of Louisville for assistance with SEM.

I want to express special words of thanks to my family and friends who always were with me, supported me in every situation I had. I thank my parents Galina and Vladimir 
Plotnikov for endless love, believing in me and supported all my decisions especially when I decided to start my education in the US. A special thanks to my husband Eduard Khachian who understands me and patiently assists me with achieving my goals. Without all those people this work would not exist. 


\title{
ABSTRACT \\ SIZE- AND SHAPE-DEPENDENT ELECTROCHEMISTRY OF GOLD NANOPARTICLES
}

\author{
Irina V. Khachian
}

April 24, 2012

This dissertation describes 1) size-dependent electrochemical oxidation/stripping of chemically synthesized gold nanoparticles (Au NPs), 2) copper underpotential deposition (Cu-UPD) on different sized chemically-synthesized and electrochemically-deposited $\mathrm{Au}$ NPs attached to glass/indium-tin-oxide (ITO) electrodes, and 3) electrochemical synthesis of Au nanoplates directly on glass/ITO electrodes. The motivation of this work was to better understand the characteristics and electrochemical properties of metal nanostructures with different sizes and shapes.

We synthesized Au nanoparticles with average diameters ranging from 5 to $45 \mathrm{~nm}$ by a chemical seed-mediated growth method and electrostatically attached them to amino-functionalized glass/ITO electrodes. Linear sweep voltammograms (LSVs) obtained on electrodes coated with $\mathrm{Au}$ NPs in $0.01 \mathrm{M}$ potassium bromide plus $0.1 \mathrm{M}$ $\mathrm{HClO}_{4}$ showed a positive shift in oxidation potential from $680 \pm 1 \mathrm{mV}$ 
to $773 \pm 6 \mathrm{mV}$ with increasing Au NP diameter, consistent with increasing NP stability with increasing size.

In copper underpotential deposition (UPD) studies, Au NPs were chemicallysynthesized in solution by seed-mediated growth, and Au NPs were electrochemically deposited directly on the glass/ITO electrode from $\mathrm{HAuCl}_{4}$ in $\mathrm{H}_{2} \mathrm{SO}_{4}$ by chronocoulometry. Potentials used were $-0.2 \mathrm{~V}, 0.4 \mathrm{~V}$, and $0.8 \mathrm{~V}$ versus $\mathrm{Ag} / \mathrm{AgCl}$ and charges employed well $6 \times 10^{-4}$ Coulombs (C), $1 \times 10^{-3} \mathrm{C}$, and $6.6 \times 10^{-3} \mathrm{C}$. Cyclic voltammograms (CVs) obtained on the electrodes in $0.01 \mathrm{M} \mathrm{Cu}\left(\mathrm{ClO}_{4}\right)_{2}$ plus $0.1 \mathrm{M}$ $\mathrm{HClO}_{4}$ in the region from 0.1 to $1.6 \mathrm{~V}$ vs. $\mathrm{Hg} / \mathrm{HgO}$ showed that the UPD-peak is highly sensitive to the size of the Au NPs. The amount of $\mathrm{Cu}$ deposited onto the Au surface was inversely proportional to the size of the NP. This shows that a more dense Cu UPD layer forms on smaller NPs, likely due to a greater number of defects with decreasing NP size. CVs obtained in the region from 0.8 to $-0.7 \mathrm{~V}$ revealed a decrease in the reduction potential of $\mathrm{Cu}^{2+}$ from $-508 \mathrm{mV}$ to $-553 \mathrm{mV}$ with increasing NP size. This directly shows that smaller NPs are better catalysts for metal deposition.

We also electrochemically deposited Au NPs directly on the surface of the glass/ITO electrode from $\mathrm{HAuCl}_{4}$ in $\mathrm{H}_{2} \mathrm{SO}_{4}$ at a potential of $0.8 \mathrm{~V}$ versus $\mathrm{Ag} / \mathrm{AgCl}$ using chronocoulometry for $\sim 3 \times 10^{-3} \mathrm{C}, 6 \times 10^{-3} \mathrm{C}, 9 \times 10^{-3} \mathrm{C}$, and $1.2 \times 10^{-2} \mathrm{C}$. We compared the yield of nanoplates formed under the different conditions and studied the mechanism of their growth. In addition, we obtained UV-vis spectra of the Au NPs and Au nanoplates. The growth mechanism involves: formation of uniformly distributed flower-like nanostructures, smashing into an irregular-shaped nanoplate and their growing, then 
etching and aggregation of the nanoplates with the nanoparticles. The maximum yield was observed $40-50 \%$.

In this thesis, we describe the experimental setup used in this research and the results. The results of this research are very important for understanding the fundamental electrochemical properties of NPs, which could lead to applications in several different fields. It is very important to study the dependence of the properties of NPs on their size, shape, and composition as they possess a very different reactivity. Metal NPs can also be used as label in electrochemical analysis. 
TABLE OF CONTENTS

PAGE

ACKNOWLEDGEMENTS

iv

ABSTRACT

TABLE OF CONTENTS

LIST OF TABLES

LIST OF FIGURES

ix

$\mathrm{xi}$

xii

CHAPTER

I. INTRODUCTION

1.1 MAIN GOAL AND SUMMARY 1

1.2 MOTIVATION/OBJECTIVE 2

1.3 IMPORTANCE OF GOLD NANOPARTICLE RESEARCH 2

1.4 ELECTROCHEMICAL STUDIES OF METAL

NANOPARTICLES

1.4.1 Electron-Transfer Studies $\quad 5$

1.4.2 Electrodeposition $\quad 8$

1.5 SUMMARY AND ACCOMPLISHMENTS 11

II. EXPERIMENTAL

2.1 SOLUTIONS 13

2.2 SUBSTRATES $\quad 15$

2.3 CHEMICAL SYNTHESIS OF AU NPS 16

2.4 ASSEMBLY OF AU NPS ON GLASS/ITO 20

2.5 ELECTROCHEMICAL DEPOSITION OF AU NPS 24

2.5.1. Controlled size of Au NPs 24

2.5.2. Au nanoplates deposition $\quad 25$

2.6 CU UPD ON AU NPs 25

2.7 CHARACTERIZATION AND INSTRUMENTATION 26

2.4.1. Electrochemical methods 26

2.4.2. Ultraviolet-Visible Spectroscopy (UV-vis) and Localized Surface Plasmon Resonance (LSPR) 39

2.4.3 Scanning Electron Microscopy (SEM) $\quad 42$

III. SIZE-DEPENDENT ELECTROCHEMICAL OXIDATION OF CHEMICALLY SYNTHESIZED GOLD NANOPARTICLES 46

3.1 INTRODUCTION 46 
3.2 EXPERIMENTAL DETAILS $\quad 48$

3.3 RESULTS AND DISCUSSION 48

3.3.1. Optical characterization $\quad 48$

3.3.2. Microscopy 51

3.3.4. Electrochemical characterization 51

3.4 CONCLUSIONS 66

IV. SIZE DEPENDENCE OF UNDERPOTENTIAL DEPOSITED COPPER ON GOLD NANOPARTICLES $\quad 67$

4.1 INTRODUCTION $\quad 67$

4.2 EXPERIMENTAL DETAILS $\quad 69$

4.3 RESULTS AND DISCUSSION 69

4.3.1. Electrochemical deposition of Au NPs of different size on Glass/ITO electrodes $\quad 69$

4.3.2. Chemical synthesis and attachment of Au NPs of different size on amino-functionalized Glass/ITO electrodes 73

4.3.3. Copper underpotential deposition measurements on Au NPs 73

4.4 CONCLUSIONS

V. ELECTROCHEMICAL GROWTH OF GOLD TRIANGULAR AND HEXAGONAL SHAPED NANOPLATES DIRECTLY ON A SURFACE OF GLASS/ITO ELECTRODE $\quad 90$

5.1 INTRODUCTION 90

5.2 EXPERIMENTAL DETAILS 92

5.3 RESULTS AND DISCUSSION 94

5.3.1. Electrochemical deposition of Au nanoplates and nanoparticles on glass/ITO electrodes $\quad 94$

5.3.2. Spectroscopy studies 104

5.3.3. Cu underpotential deposition (Cu-UPD) studies 104

$\begin{array}{ll}5.4 \text { CONCLUSIONS } & 115\end{array}$

$\begin{array}{ll}\text { VI. SUMMARY AND CONCLUSIONS } & 117\end{array}$

$\begin{array}{ll}\text { REFERENCES } & 121\end{array}$

$\begin{array}{ll}\text { CURRICULUM VITAE } & 130\end{array}$ 


\section{LIST OF TABLES}

TABLE

PAGE

3.1. Statistical Size and Electrochemical Data for Glass/ITO/APTES/Au NP Electrodes.

3.2. Ep for Au seed NPs as a function of coverage.

3.3. Ep for Au NPs as a function of scan rate.

4.1. Statistical data of size, bulk $\mathrm{Cu}^{2+}$ reduction peak potential, and the ratio of the charge of $\mathrm{Cu}$ UPD peak to $\mathrm{Au}$ reduction peak on electrodes with the same surface area of Au NPs.

4.2. Electrochemical Data of the Oxidation of glass/ITO/APTES/Au NP Electrodes.

5.1. Statistical data of size, coverage, and yield of Au nanoplates obtained by electrochemical deposition at a potential of $0.8 \mathrm{~V}$ from solutions with different $\mathrm{HAuCl}_{4}$ concentration and different charge. 


\section{LIST OF FIGURES}

FIGURE

PAGE

1.1. Different types of electron-transfer studies.

2.1. General scheme of experiments used in this work. 14

2.2. Schematic of Au seed formation by reduction of $\mathrm{AuCl}_{4}{ }_{4}$ with $\mathrm{BH}_{4}{ }^{-}$. 17

2.3. Schematic showing metal nucleation and growth process involved in Au NP 28 formation.

2.4. Schematic of synthesis of citrate-capped spherical Au NPs.

2.5. Schematic of Au NP synthesis by seed-mediate growth using citrate reduction. 21

2.6. Structure of APTES molecule and scheme of chemical functionalization of the 22 Glass/ITO surface with APTES.

2.7. Scheme of functionalization of Glass/ITO with the APTES and attachment of Au NPs to the Glass/ITO functionalized substrate.

2.8. $\mathrm{CV}$ of Glass/ITO/Au $(4 \mathrm{~nm})$ in $0.01 \mathrm{M} \mathrm{Cu}\left(\mathrm{ClO}_{4}\right)_{2}$ plus $0.1 \mathrm{M} \mathrm{HClO}_{4}$ at 20 $\mathrm{mV} / \mathrm{s}$.

2.9. The processes of oxidation Au NPs (A) and deposition of a $\mathrm{Cu}$ UPD 28 monolayer (B).

2.10. Electrochemical set-up.

2.11. The excitation waveform in a LSV experiment.

2.12. LSV of Glass/ITO/APTES/Au NPs $(\sim 4 \mathrm{~nm})$ in $10 \mathrm{mM} \mathrm{KBr}$ plus $0.1 \mathrm{M} 34$ $\mathrm{HClO}_{4}$ electrolyte at $1 \mathrm{mV} / \mathrm{s}$. Arrows indicate the direction of the scan.

2.13. Scheme of the oxidation of Au NPs. 
2.14. The excitation waveform in a CV experiment.

2.15. Typical CC plot of the experiment of electrochemical deposition of $\mathrm{Au}$ NPs from the solution of $0.5 \mathrm{M} \mathrm{H}_{2} \mathrm{SO}_{4}$ plus $5 \times 10^{-5} \mathrm{M} \mathrm{HAuCl}_{4}$ at a potential step from $1.0 \mathrm{~V}$ to $-0.2 \mathrm{~V}$ with a passed charge of $6 \times 10^{-4} \mathrm{C}$.

2.16. Scheme of the process of electrochemical deposition of Au NPs using Chronocoulometry (CC) applying different charge (Q).

2.17. Typical UV-vis spectra of Au NPs $(11 \mathrm{~nm})$ attached to the surface of glass/ITO/APTES electrode.

2.18. Scheme of beam/sample interactions and typical SEM image of Au NPs attached to the surface of a glass/ITO electrode.

3.1. Optical picture of the Au NP solutions synthesized by different methods. The more intensive color corresponds to the bigger size of NP.

3.2. UV-visible spectra of the solutions with Au NPs.

3.4. SEM images of Glass/ITO/APTES-functionalized electrodes coated with $\mathrm{Au}$ NPs prepared by different methods: (A) Au seeds of $4 \pm 1$ nm diameter; (B) Au NPs synthesized by seed-mediated growth using $\mathrm{Au}^{+} / \mathrm{Au}$ seed ratio of 10 and (D) 100 with average diameter of $15 \pm 7$ $\mathrm{nm}$ and $73 \pm 19 \mathrm{~nm}$, respectively; (C) Au NPs grown from $\mathrm{HAuCl}_{4}$ with trisodium citrate with an average diameter of $31 \pm 14 \mathrm{~nm}$. The scale bars for frames (B), (C), (D) are $200 \mathrm{~nm}$, for (A) $20 \mathrm{~nm}$ and in the insets in (C) and (D) they are $50 \mathrm{~nm}$.

3.5. Background LSV of glass/ITO/APTES electrode in $0.1 \mathrm{M} \mathrm{HClO}_{4}$ only and in $10 \mathrm{mM} \mathrm{KBr}$ plus $0.1 \mathrm{M} \mathrm{HClO}_{4}$.

3.6. Linear Sweep Voltammograms obtained in $10 \mathrm{mM} \mathrm{KBr}$ plus $0.1 \mathrm{M}$ $\mathrm{HClO}_{4}$ electrolyte at $1.0 \mathrm{mV} / \mathrm{s}$ of $1.4 \mathrm{~cm}^{2} \mathrm{Glass} / \mathrm{ITO} / \mathrm{APTES}$ electrodes coated with chemically synthesized Au NPs as indicated.

3.7. Experimentally measured shift in oxidation potential (blue triangles) for Au NPs versus bulk $\mathrm{Au}$ as a function of radius as compared to electrochemically-deposited Au NPs (red squares) and to theory (dashed line). Blue dashed line ( 1 electron process), red dashed line (1.5 electron process). 
3.8. $\mathrm{LSV}$ in $10 \mathrm{mM} \mathrm{KBr}$ plus $0.1 \mathrm{M} \mathrm{HClO}_{4}$ electrolyte at $1 \mathrm{mV} / \mathrm{s}$ from $0 \mathrm{~V}$ to $1.0 \mathrm{~V}$ of Glass/ITO/APTES electrodes coated with $4 \pm 1 \mathrm{~nm}$ diameter Au NPs by soaking in the solution for $1 \mathrm{~min}$ (blue), $3 \mathrm{~min}$ (red) and 15 min (black). Inset shows the plot of Ep versus ln (Q), which is expected to be linear for reversible kinetics.

3.9. $\mathrm{LSVs}$ in $10 \mathrm{mM} \mathrm{KBr}$ plus $0.1 \mathrm{M} \mathrm{HClO}_{4}$ from $0.6 \mathrm{~V}$ to $1.0 \mathrm{~V}$ of Glass/ITO/APTES electrodes coated with Au seed NPs (soaking time 15 minutes obtained at different scan rates: $100 \mathrm{mV} / \mathrm{s}$ (green), 10 $\mathrm{mV} / \mathrm{s}$ (blue), $1 \mathrm{mV} / \mathrm{s}$ (red), $0.1 \mathrm{mV} / \mathrm{s}$ (black). Inset shows the zoomed in area of the Figure 3.9.

3.10. Plot of peak potential (Ep) versus (A) scan rate and (B) $\ln$ (scan rate) for Glass/ITO/APTES electrodes covered with Au seed NPs.

4.1. Cyclic voltammogram of glass/ITO electrode in a solution of $5 \times 10^{-3} \mathrm{M}$ $\mathrm{HClO}_{4}$ plus $0.5 \mathrm{M} \mathrm{H}_{2} \mathrm{SO}_{4}$ at a scan rate of $100 \mathrm{mV} / \mathrm{s}$ with a potential range from $1.5 \mathrm{~V}$ to $-1.0 \mathrm{~V}$. The red dashed box indicates the range of potentials where the Au NP deposition was made.

4.2. SEM images of Glass/ITO/Au NPs deposited at different potentials and coulombs (C): (A) $-0.2 \mathrm{~V}, 6 \times 10^{-4} \mathrm{C}$; (B) $0.4 \mathrm{~V}, 1 \times 10^{-3} \mathrm{C}$; (C) 0.8 $\mathrm{V}, 6.5 \times 10^{-3} \mathrm{C}$. The scale bar is $200 \mathrm{~nm}$ in the large images and $50 \mathrm{~nm}$ in the inset.

4.3. CVs of Glass/ITO/APTES and Glass/ITO/APTES/Au NPs in $0.01 \mathrm{M}$ $\mathrm{Cu}\left(\mathrm{ClO}_{4}\right)_{2}$ and $0.1 \mathrm{M} \mathrm{HClO}_{4}(\mathrm{~A}),(\mathrm{B})$ and $(\mathrm{C})$ - blow up regions of the Figure $4.3(\mathrm{~A})$.

4.4. CVs of Glass/ITO and Glass/ITO/Au NPs deposited at potentials from $-0.2 \mathrm{~V}$ to $0.8 \mathrm{~V}$ and a charge of $6 \times 10^{-4} \mathrm{C}$ to $6.6 \times 10^{-3} \mathrm{C}$ in $0.01 \mathrm{M}$ $\mathrm{Cu}\left(\mathrm{ClO}_{4}\right)_{2}$ and $0.1 \mathrm{M} \mathrm{HClO}_{4}(\mathrm{~A}),(\mathrm{B})$ and $(\mathrm{C})-$ blow up regions of the Figure $4.4(\mathrm{~A})$.

4.5. $\mathrm{CV}$ of chemically-synthesized glass/ITO/APTES/Au NPs in $0.01 \mathrm{M}$ $\mathrm{Cu}\left(\mathrm{ClO}_{4}\right)_{2}$ and $0.1 \mathrm{M} \mathrm{HClO}_{4}$.

4.6 CV of electrochemically-deposited glass/ITO/Au NPs in $0.01 \mathrm{M}$ $\mathrm{Cu}\left(\mathrm{ClO}_{4}\right)_{2}$ and $0.1 \mathrm{M} \mathrm{HClO}_{4}$.

4.7. $\mathrm{Cu}$-UPD dependence of size of Au NPs.

4.8. Dependence of the Au reduction peak potential on the size of the Au NP. 
Au NPs.

4.10. Linear Sweep Voltammograms obtained in $10 \mathrm{mM} \mathrm{KBr}$ plus $0.1 \mathrm{M}$

$\mathrm{HClO}_{4}$ electrolyte at $1.0 \mathrm{mV} / \mathrm{s}$ of $1.4 \mathrm{~cm}^{2}$ glass/ITO/APTES

electrodes coated with chemically synthesized Au NPs. The surface area of the Au NPs was kept constant as determined by Au oxide reduction peak obtained in $\mathrm{H}_{2} \mathrm{SO}_{4}$.

4.11. $\mathrm{CV}$ of glass/ITO/APTES/Au ${ }_{4 \mathrm{~nm}}$ in $0.01 \mathrm{M} \mathrm{Cu}\left(\mathrm{ClO}_{4}\right)_{2}$ and $0.1 \mathrm{M}$ $\mathrm{HClO}_{4}$ with different coverage of Au NPs.

4.12. Plot of $\mathrm{Cu}: \mathrm{Au}$ ratio in different deposition time of $\mathrm{Au}$ seeds.

5.1. Scheme of setup for the electrochemical deposition of Au nanoplates.

5.2. Cyclic Voltammogram (CV) of a glass/ITO electrode obtained in $5 \times 10^{-3} \mathrm{M} \mathrm{HAuCl}_{4}$ plus $0.5 \mathrm{M} \mathrm{H}_{2} \mathrm{SO}_{4}$ at a scan rate of $100 \mathrm{mV} / \mathrm{s}$. The arrows show the direction of the forward and reverse scan beginning at $1.5 \mathrm{~V}$ and ending at $-1.0 \mathrm{~V}$. The deposition was made at $0.8 \mathrm{~V}$ for all synthesis.

5.3. SEM images of glass/ITO electrodes after Au deposition at a potential of $0.8 \mathrm{~V}$ with a different amount of passed charge: (A) $3 \times 10^{-3} \mathrm{C}$; (B) $6 \times 10^{-3} \mathrm{C}$; (C) $9 \times 10^{-3} \mathrm{C}$; (D) $1.2 \times 10^{-2} \mathrm{C}$. The charge was passed in increments of $3 \times 10^{-3} \mathrm{C}$ and a $\mathrm{CV}$ was obtained from 0 to $1.6 \mathrm{~V}$ in $0.01 \mathrm{M} \mathrm{Cu}\left(\mathrm{ClO}_{4}\right)_{2}$ plus $0.1 \mathrm{M} \mathrm{HClO}_{4}$ solution (as described in the text) between each increment. The scale bars are $200 \mathrm{~nm}$.

5.4. SEM images of glass/ITO/Au nanostructures deposited at a potential of $0.8 \mathrm{~V}$ with different amount of charge: (A) $6 \times 10^{-4} \mathrm{C}$; (B) $6 \times 10^{-3} \mathrm{C}$; and $(\mathrm{C}) 1.2 \times 10^{-2} \mathrm{C}$. The scale bars are $2 \mu \mathrm{m}$.

5.5. SEM images of glass/ITO/Au nanostructures deposited by a potential step from $1.0 \mathrm{~V}$ to $0.8 \mathrm{~V}$ from a solution with different concentrations of $\mathrm{HAuCl}_{4}$ (as indicated in each image) and constant $0.5 \mathrm{M}$ concentration of $\mathrm{H}_{2} \mathrm{SO}_{4}$ with different amounts of charge: (A), (B),

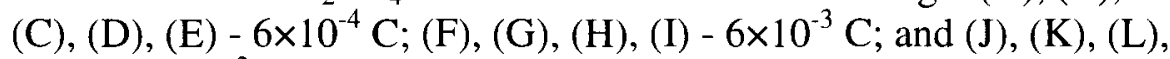
(M) $-1.2 \times 10^{-2} \mathrm{C}$.

5.6. SEM images of glass/ITO/Au nanostructures deposited by stepping the potential from $1.0 \mathrm{~V}$ to $0.8 \mathrm{~V}$ in a $5 \times 10^{-5} \mathrm{M} \mathrm{HAuCl}_{4}$ plus $0.5 \mathrm{M}$ $\mathrm{H}_{2} \mathrm{SO}_{4}$ solution with a charge of $1.2 \times 10^{-2} \mathrm{C}$ under different conditions: (A)without cycling between $3 \times 10^{-3} \mathrm{C}$ intervals; (B) with cycling in $0.1 \mathrm{M} \mathrm{HClO}_{4}$ between $3 \times 10^{-3} \mathrm{C}$ intervals, and $(\mathrm{C})$ with cycling in $0.01 \mathrm{M} \mathrm{Cu}\left(\mathrm{ClO}_{4}\right)_{2}$ plus $0.1 \mathrm{M} \mathrm{HClO}_{4}$ between $3 \times 10^{-3} \mathrm{C}$ intervals. 
5.7. UV-vis spectra of glass/ITO/Au electrodes deposited at $0.8 \mathrm{~V}$ with a charge of (A) $3 \times 10^{-3} \mathrm{C}$ (blue), (B) $6 \times 10^{-3} \mathrm{C}$ (purple), (C) $9 \times 10^{-3}$ $\mathrm{C}$ (green), and (D) $1.2 \times 10^{-2} \mathrm{C}(\mathrm{red})$. The absorbance increased with increasing $\mathrm{Au}$ deposition charge in all cases.

5.8. Cyclic voltammogram (CV) of $\mathrm{Cu}$ UPD on glass/ITO electrodes deposited with $3 \times 10^{-3} \mathrm{C}$ (black), $6 \times 10^{-3} \mathrm{C}$ (green), $9 \times 10^{-3} \mathrm{C}$ (red) and $1.2 \times 10^{-2} \mathrm{C}$ (blue) of Au.

5.9. Scheme of nanoplates formation.

5.10. Cyclic voltammograms of $\mathrm{Cu}$ UPD on glass/ITO/Au obtained from $0.01 \mathrm{M} \mathrm{Cu}\left(\mathrm{ClO}_{4}\right)_{2}$ plus $0.1 \mathrm{M} \mathrm{HClO}_{4}$ before (black) and after (red) oxidation of $\mathrm{Au}$. Scan rate $20 \mathrm{mV} / \mathrm{s}$.

5.11. Linear Sweep Voltammograms (LSVs) of glass/ITO coated with electrochemically deposited Au NPs and nanoplates obtained in 10 $\mathrm{mM} \mathrm{KBr}$ plus $0.1 \mathrm{M} \mathrm{HClO}_{4}$ electrolyte at $1 \mathrm{mV} / \mathrm{s}$. Black - full oxidation, red - partial oxidation.

5.12. SEM images of glass/ITO/Au deposited at a potential of $0.8 \mathrm{~V}$ before (A) and after (B) oxidation in $10 \mathrm{mM} \mathrm{KBr}$ plus $0.1 \mathrm{M} \mathrm{HClO}_{4}$. The scale bars are $1 \mu \mathrm{m}$.

5.13. SEM images of Glass/ITO/Au NPs (A) and Glass/ITO/Au NPs plus nanoplates (B). Scale bars $200 \mathrm{~nm}$. Cyclic voltammograms of $\mathrm{Cu}$ UPD on Glass/ITO/Au NPs (black) and Glass/ITO/Au nanoplates

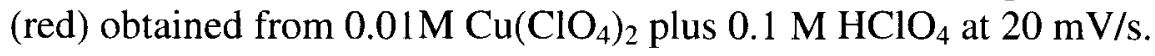




\section{CHAPTER I}

\section{INTRODUCTION}

\subsection{MAIN GOAL AND SUMMARY}

The main goal of this research was to study the electrochemical properties of Au nanoparticles (NPs) in different processes such as oxidation, underpotential deposition of $\mathrm{Cu}$, and electrodeposition as a function of size and shape. In Chapter I, I describe background information about metal NPs and underpotential deposition (UPD). Chapter II includes a description of the experimental procedures and instrumentation used in this research. Chapter III describes studies on the size-dependent oxidation properties of $\mathrm{Au}$ NPs which were chemically prepared and attached on the surface of glass/ITO electrodes. In Chapter IV, I describe our research on the size dependence of Cu UPD on Au NPs. Chapter $\mathrm{V}$ describes the electrochemical growth of triangular and hexagonal $\mathrm{Au}$ nanoplates directly on a glass/ITO electrode. Chapter VI summarizes the results of this research and suggests future directions for it. 


\subsection{MOTIVATION/OBJECTIVE}

The motivation of this research was to better understand the electrochemical properties of $\mathrm{Au}$ NPs synthesized by chemical and electrochemical methods. The study will provide information about the oxidation of nanoparticles with different sizes and shapes, interactions of NPs with copper under underpotential deposition conditions, and the size and shape of NPs grown under different electrochemical conditions. This knowledge can be very useful for future studies about the interaction of Au NPs with other metals and transformation of their shape under various electrochemical conditions. Understanding of these properties can lead to applications in catalysis, sensing, and other areas of electrochemistry.

\subsection{IMPORTANCE OF GOLD NANOPARTICLE RESEARCH}

Nanosized particles of noble metals, especially gold nanoparticles (Au NPs), which have been known for 2500 years, have received great scientific interest because they are remarkably different from the bulk materials. In particular, their high-specific surface area makes them extremely reactive at small dimensions. ${ }^{1,2}$ In addition, they possess unique optical, ${ }^{3,4}$ magnetic, ${ }^{5}$ thermal, ${ }^{6}$ electronic, ${ }^{7,8}$ catalytic, ${ }^{9}, 10,11,12$ and electrochemical ${ }^{13}$ properties, which depend critically on their size, shape, the interparticle distance, and the nature of the protecting stabilizer. ${ }^{14}$

Metal nanomaterials have potential applications in the fields of physics, biology, medicine, chemistry, and material science as well as different interdisciplinary fields. ${ }^{15}$ Also, the synthesis and characterization of Au NPs is attractive from a fundamental point of view. Numerous methods have been developed for the preparation of Au NPs. They 
include chemical synthesis by reduction with citrate and ascorbic acid (Turkevich method), ${ }^{16}$ the reaction of a chlorauric acid with tetraoctylammonium bromide (TOAB) and sodium borohydride in toluene as an anti-coagulant and reducing agent, respectively (Brust method), ${ }^{17}$ reaction between hydroquinone and $\mathrm{HAuCl}_{4}$ (Perrault method), ${ }^{18}$ generation of "naked" $\mathrm{Au}$ NPs in water by reducing $\mathrm{HAuCl}_{4}$ with $\mathrm{NaBH}_{4}$ (Martin method), ${ }^{19}$ electrochemical deposition from $\mathrm{HAuCl}_{4}$ solution directly on the surface of a working electrode, ${ }^{62}$ photochemical methods (UV, ${ }^{20,21}$ Near IR $^{22}$ ), sonochemical methods, ${ }^{23,24}$ radiolysis, ${ }^{25,26}$ and thermolysis. ${ }^{27,28}$ There has been great progress in controlling the size and shape of the nanoparticles, and the surface chemistry is important for the protection of Au NPs from aggregation and oxidation and for the development of different applications.

Au NPs are highly active catalysts for $\mathrm{CO}$ and $\mathrm{H}_{2}$ oxidation, ${ }^{29} \mathrm{NO}$ reduction, ${ }^{30}$ the water-gas shift reaction, ${ }^{31}$ and $\mathrm{CO}_{2}$ hydrogenation. ${ }^{32} \mathrm{Au}$ NPs have a large third-order nonlinear susceptibility and near-resonance nonlinear response, and glass with a large amount of dispersed $\mathrm{Au}$ NPs is a promising material for use in nonlinear optical devices. ${ }^{33}$ In electroanalytical chemistry, Au NPs are promising materials due to their excellent conductivity, biological compatibility, ability to facilitate electron transfer, and high surface-to-volume ratio. ${ }^{34}$ Development of nanomaterials offers the opportunity to use them in electrochemical applications, such as the modification of electrode surfaces, which generates functional electrochemical sensing interfaces. Some examples include the direct electrochemistry of redox proteins on Au NPs, third generation electrochemical biosensors, ${ }^{35}$ genosensors, ${ }^{36}$ immunosensors, ${ }^{37,38}$ electrocatalysis, ${ }^{39}$ and electrochemical sensing. ${ }^{40}$ 
Clearly, a large variety of structures, properties, and applications of Au NPs are connected with other fields, including biology, physics, medicine, and engineering.

\subsection{ELECTROCHEMICAL STUDIES OF METAL NANOPARTICLES}

Since this work is based on electrochemical methods, such as electrochemical deposition and electrochemical oxidation of Au NPs, we review previous electrochemical studies involving metal NPs.

Since the development of methods of synthesis and isolation of NPs in purified forms, several innovations in the field of electrochemistry have appeared. Direct voltammetric measurements are able to study solutions of NPs or solid NPs attached to the substrate. The electrochemical experiments, which were done directly on metal NPs, give various electrochemical responses, which can be classified as: bulk-continuum, quantized double layer charging, and molecule-like. ${ }^{41}$

In all electrified metal/electrolyte solutions, the NPs have a double layer with ionic surface excesses on the solution side that balance any net electronic charge residing on the metal NP surface. ${ }^{42}$ In this case, the metal-like nanoparticles are very electroactive and behave as electron donor/acceptors to the quantitative measure of their double-layer capacitances. ${ }^{42}$ Mulvaney and co-workers were the first to study bulk-continuum voltammetry of an isolated $10 \mathrm{~nm}$ diameter $\mathrm{Ag}$ nanoparticle that was protected by a layer

of polyacrylic acid. ${ }^{43}$ The authors scanned a working electrode to positive and negative potentials and observed currents for oxidation and ultimate dissolution of NPs whose associated currents were controlled by 
mass transport of the Ag NP. ${ }^{43}$ They determined the number of electrons $(n)$ transferred from the working electrode to the NP.

The electrochemical studies of Au NPs involve the processes of deposition, oxidation, reduction and dissolution of the Au atoms in the NPs. One of the main techniques is voltammetry. The other well-known technique for monitoring the sizes of NPs, especially during the process of oxidation under potential control, is electrochemical scanning tunneling microscopy (STM). ${ }^{44,45,46,47,48}$

\subsubsection{Electron-Transfer Studies}

Electron-transfer studies include: quantized double-layer (QDL) charging, molecular clusters, stripping (oxidation) processes, and electron-transfer reduction (Figures 1.1).

Murray's research group conducted electrochemical experiments of Au NPs which were monolayer-protected ${ }^{49}$ with mixed-ligands, thiolates or trimethyl (mercaptoundecyl) ammonium (TMA) ${ }^{50}$ and attached to the Au electrode surface coated with carboxylate bridges ${ }^{51,52,53}$ or dissolved in $\mathrm{CH}_{2} \mathrm{Cl}_{2}$ solutions. ${ }^{41,54,55,56}$ The average diameter of $\mathrm{Au}$ NPs, which were attached to the electrode surface, was $1.6 \mathrm{~nm}$. They used cyclic voltammetry, alternating impedance, and potential step techniques to study the oxidation and reduction of the Au NPs and measured the rate of electron transfer between the attached NPs and the electrode. The process involved single-electron charging of the metal nanoparticle during the processes of oxidation or reduction. These events are known as quantized double-layer (QDL) charging. The Au NPs, which were dissolved in solution, were much smaller $-1.1 \mathrm{~nm}$ in diameter. ${ }^{54}$ They revealed the energy gaps 


\section{NP Charging}

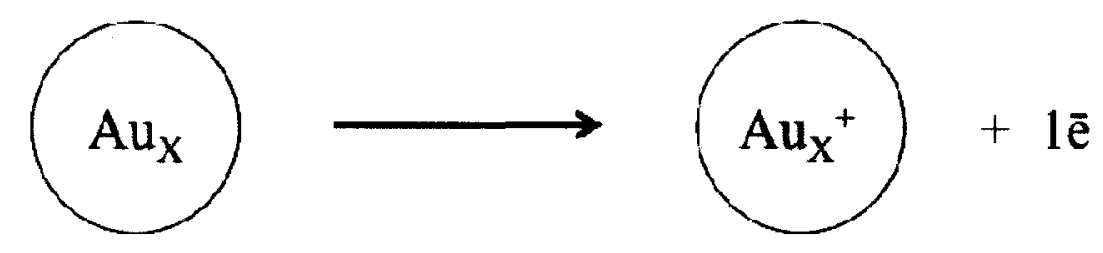

\section{Metal atom oxidation (Dissolution)}

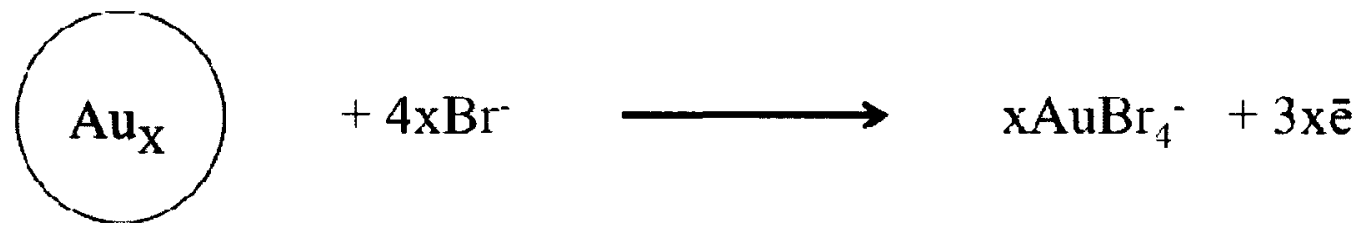

Figure 1.1. Different types of electron-transfer studies. 
between the first one-electron oxidation and the first reduction, indicating the gap of highest occupied molecular orbital (HOMO) - lowest unoccupied molecular orbital (LUMO) using voltammetry. Also, Au NPs were characterized via scanning transmission electron microscopy, which allowed determination of $\mathrm{Au}_{13}$ clusters. $^{55}$

The problem of size-dependence of metal NPs is studied in a lot of different aspects. According to theory and experimental data, the standard redox potential of metal NPs decreases with decreasing size. ${ }^{13}$ According to Henglein's and Plieth's theories, with a decreasing number of atoms in the metal, the redox potential will be negatively shifted. ${ }^{57.58}$ Plieth explained this by the difference in the surface free energy between the atoms of bulk metal and the NPs with small size. ${ }^{58}$ Henglein calculated the standard reduction potential for $\mathrm{Ag}$ particles with different amounts of atoms, showing a large change from $-1.8 \mathrm{~V}$ to $-1.0 \mathrm{~V}$, for 1 and 2 atoms, respectively to $+0.799 \mathrm{~V}$ for bulk $\mathrm{Ag}$ (vs. NHE).

Compton described the electrochemical oxidation (stripping) of different-sized $\mathrm{Ag}$ NPs which were attached to a basal plane pyrolytic graphite electrode in $0.1 \mathrm{M} \mathrm{NaClO}_{4}{ }^{59}$ The diameter of the NPs varied from 25 to $100 \mathrm{~nm}$. There was no dependence of oxidation on the size of the NP in this size range. Compton and co-workers also described the oxidation of hemispherical deposits of bismuth attached to a single crystal $\mathrm{Au}(111)$ electrode under electrochemically irreversible conditions. ${ }^{60}$ They concluded that the difference in the voltammetry was mainly due to the morphology/orientation of deposits, which leads to differences in the kinetics and thermodynamics of the process of stripping. ${ }^{60}$ 
Brainina and co-workers described the theoretical study of metal NP oxidation ${ }^{61}$ and Compton with co-workers also studied theoretically and experimentally the oxidation of metal NPs in solution. Ivanova recently showed for the first time the size-dependent oxidation of chemically-synthesized Ag NPs which were electrostatically attached to an amino-functionalized glass/ITO working electrode ${ }^{13}$ and Au NPs electrochemically deposited on glass/ITO electrodes. ${ }^{62}$ The amount of metal was kept constant in both cases. The size of Ag NPs varied from 8 to $50 \mathrm{~nm}$, and the oxidation potential shifted negatively from 391 to $278 \mathrm{mV}$ with decreasing NPs size. ${ }^{13}$ The same general behavior occurred for electrochemically-deposited $\mathrm{Au}$ NPs, but the shift in oxidation potential agreed better with the predicted shift in redox potential based on Plieth's theory. This is explained by the change in free energy associated with the difference in surface energy as a function of the size of the particle. ${ }^{62}$ Plieth predicted a shift that has a $1 / \mathrm{r}$ dependence on radius $(r)$.

\subsubsection{Electrodeposition}

In this study we will discuss two aspects of the deposition of Au NPs: metal UPD and electrochemical deposition of metal NPs.

\section{UNDERPOTENTIAL DEPOSITION STUDIES ON METALS}

Chapter IV describes studies of underpotential deposition (UPD) of $\mathrm{Cu}$ on different sized $\mathrm{Au}$ NPs and Chapter V describes $\mathrm{Cu}$ UPD on Au nanoplates. Accordingly, I define UPD and discuss previous Cu UPD studies on Au and UPD studies on metal NPs.

Underpotential Deposition (UPD) is a well-known phenomenon which occurs when adsorbate atoms, predominantly metal adatoms, are more strongly bound to the different 
substrate than to the substrate of their own kind. ${ }^{63}$ The process of UPD involves the deposition of one (possible up to three) monolayer(s) at a potential more positive than for bulk deposition of multilayers and more positive than the reversible Nernst potential, ${ }^{64,65}$ and has a variety of structures. ${ }^{66}$ The UPD layers play a significant role in fuel cell studies, ${ }^{67}$ in electrocatalysis of oxidation of organic compounds, ${ }^{68,69}$ and in oxygen reduction ${ }^{70,71,72}$ and hydrogen evolution reactions. ${ }^{73}$ There are many studies of UPDbased systems, including studies of temperature effects on metal UPD processes ${ }^{74}$ and of self-assembled monolayers. ${ }^{75}$ Examples of common UPD systems are $\mathrm{Cu}$ on $\mathrm{Au}, \mathrm{Pb}$ on $\mathrm{Ag}, \mathrm{Pb}$ on $\mathrm{Au}, \mathrm{Ag}$ on $\mathrm{Au}$, and others.

\section{Cu UPD on Au.}

One of the most widely studied systems is $\mathrm{Cu}$ UPD on single crystal Au surfaces. $\mathrm{Cu}$ UPD on $\mathrm{Au}$ (111) occurs in two stages. ${ }^{76}$ In sulfuric acid electrolyte, step one is the random deposition of $\mathrm{Cu}$ adatoms and sulfate ions on the electrode surface followed by the formation of an ordered honeycomb $(\sqrt{ } 3 \times \sqrt{ } 3) \mathrm{R} 30^{\circ}$ structure in which the surface coverage of $\mathrm{Cu}$ is 0.67 and the sulfate anions occupy the centers of the honeycomb (coverage of anions is 0.33$).^{77}$ The second stage corresponds to the formation of a full monolayer of $\mathrm{Cu}$ with $(1 \times 1)$ structure and sulfate ions adsorbed on top of the copper adlayer. ${ }^{78}$ The adlattice structure of $\mathrm{Cu}$ depends on the potential, the presence and amount of adsorbed anions, and the crystal phase of $\mathrm{Au}$. A $(5 \times 5)$ structure forms in the presence of chloride anions or a $(2 \times 2)$ structure forms with a $0.75 \mathrm{Cu}$ coverage at concentrations below $10^{-5} \mathrm{M}$ and potentials below $0.14 \mathrm{~V}$ vs. SCE. ${ }^{79}$ The adlattice is similar in perchloric 
acid solution. Cu UPD also depends on the Au crystal phase. Au (110) and Au (100) both have a $(1 \times 1)$ structure in sulfuric acid media..$^{80,81,82}$

\section{Metal UPD on NPs.}

Recently, Crooks and co-workers studied Cu UPD on Pt NPs immobilized on glassy carbon electrodes with different number of atoms (55, 147 and 225). The cyclic voltammetry showed that the coverage of the $\mathrm{Cu}$ shell $\left(\theta_{\mathrm{Cu}}\right)$ was inversely proportional to the number of Pt atoms in the NP. ${ }^{83}$ Hernandez et al. used Pb UPD on $\mathrm{Au}$ NPs to characterize their shape (cubic) and relative size $(40 \mathrm{~nm}){ }^{85}$ They found that $\mathrm{Pb}$ UPD reveals that the structure of the surface presents wide (100) domains, but also the majority of surface sites have a (111) or (110) symmetry. ${ }^{84}$ Others have used Pd UPD to decorate Pt NPs for formic acid electrooxidation. ${ }^{85}$ Compton and co-workers demonstrated the absence of the UPD of $\mathrm{Pb}, \mathrm{Cd}$ and $\mathrm{Tl}$ on nanoelectrode arrays composed of Ag NPs with diameter less than $50 \mathrm{~nm}^{86}$ as well as on Au NPs with average diameter of $10 \pm 5 \mathrm{~nm} .^{87}$

\section{ELECTROCHEMICAL DEPOSITION OF AU NANOSTRUCTURES}

Noble metal nanoparticles such as gold, silver, platinum and palladium are attractive materials because of their unique optical, ${ }^{3,4}$ magnetic, ${ }^{5}$ thermal, ${ }^{6}$ electronic, ${ }^{7,8}$ catalytic,,$^{9,10,11,12}$ and electrochemical ${ }^{13}$ properties. The properties of metal nanostructures depend on many factors, such as size, ${ }^{88}$ surrounding medium, ${ }^{89}$ structure, ${ }^{90}$ shape of the particle, ${ }^{91,92}$ morphology, and exposed crystal planes. Over the years, researchers have developed different methods to synthesize nanoparticles with different shapes, including cubes, ${ }^{93}$ rings, ${ }^{94}$ prisms, $^{95}$ discs $^{96}$ and rods. ${ }^{97}$ 
Our group recently developed a method to control the size of Au NPs that were electrochemically deposited directly on the surface of a glass/ITO working electrode by controlling the deposition potential while keeping the amount of $\mathrm{Au}$ deposited constant by monitoring the charge with chronocoulometry. ${ }^{62}$ The diameter of the NPs ranged from 8 to $250 \mathrm{~nm}$ at potentials of -0.2 to $0.8 \mathrm{~V}$ versus $\mathrm{Ag} / \mathrm{AgCl}$. Also, electrochemical deposition of $\mathrm{Au}$ nanorods (NRs) was recently performed by Adbelmonti and Zamborini. ${ }^{98} \mathrm{Au}$ NRs were electrodeposited from a solution containing $2.5 \times 10^{-4} \mathrm{M}$ $\mathrm{AuCl}_{4}{ }^{-}$and $0.1 \mathrm{M}$ cetyltrimethylammonium bromide (CTAB) onto Au-nanoparticle (NP)seeded mercaptopropyltrimethoxysilane (MPTMS)-functionalized glass/indium tin oxide (glass/ITO) electrodes. The yield of NRs depends on the presence of Au seeds, the electrode potential, and on deposition time. In general, the length, aspect ratio, and yield of the Au NRs increase with increasing potential and increasing deposition time up to 120 $\min$.

\subsection{SUMMARY AND ACCOMPLISHMENTS}

In the main parts of this dissertation (Chaper III, Chapter IV, and Chapter V), I will present my research on the synthesis, oxidation (stripping) and UPD. The synthesis of $\mathrm{Au}$ NPs occurred by a seed-mediated growth method. Next, we studied the size-dependent oxidation of NPs which were attached to the surface of amino-functionalized glass/ITO electrodes in a solution of $10 \mathrm{mM} \mathrm{KBr}$ plus $0.1 \mathrm{M} \mathrm{HClO}_{4}$ (Chapter III). In Chapter IV, I describe the effect of the size of Au NPs on the monolayer of $\mathrm{Cu}$ deposited at the underpotential deposition conditions. Chapter $\mathrm{V}$ focuses on the charge-controlled electrodeposition of Au nanoplates. The main accomplishments of this research were: 
- In Chapter III, I demonstrate for the first time size-dependent oxidation of the chemically-synthesized Au NPs with an average diameter from 4 to $73 \mathrm{~nm}$. Oxidation was studied in $10 \mathrm{mM} \mathrm{KBr}$ plus $0.1 \mathrm{M} \mathrm{HClO}_{4}$ solution using linear sweep voltammetry. This experiment agreed well with the theoretical prediction that the shift of the redox potential is due to the change of the surface energy associated with the particle size but is different from the electrochemically-deposited Au NPs.

- In Chapter IV I demonstrated size-dependent copper underpotential deposition (UPD) on Au NPs. The size of NPs ranged from 4 to $310 \mathrm{~nm}$ and the amount of $\mathrm{Cu}$, relative to surface $\mathrm{Au}$ atoms, decreased with increasing size of Au NPs.

- In Chapter V for the first time I demonstrated the charge-controlled electrochemical deposition of $\mathrm{Au}$ nanoplates directly on the surface of a glass/ITO electrode. I describe the mechanism of growth, which produced a yield of $40-50 \%$ nanoplates on the surface.

- Chapter VI summarizes and provides future directions of this research.

The work presented in this dissertation can be used in future electrochemical studies of metal nanostructures. The stability of NPs is important in catalysis, sensing, bioapplications, environmental sciences, controlled growth (synthesis), electrochemical reactivity, and metal corrosion. UPD research is important in catalysis and controlling composition, and properties. The controlled synthesis of nanostructures is important for all of the above applications. 


\section{CHAPTER II}

\section{EXPERIMENTAL}

Figure 2.1 shows a general scheme of the experimental procedures used in this work. The experimental route includes the following steps: 1) preparation of the substrate (Glass/Indium-tin-oxide (ITO) electrodes), 2) electrochemical deposition of gold nanoparticles (Au NPs), 3) chemical synthesis of Au NPs in solution and attachments of $\mathrm{Au}$ NPs on the surface of the electrode, 4) characterization of Au NPs by cyclic voltammetry (CV) and linear sweep voltammetry (LSV), and characterization by scanning electron microscopy (SEM) and Ultraviolet-Visible (UV-vis) spectroscopy. All of these steps and techniques will be described in detail in this chapter.

\subsection{SOLUTIONS}

Chemicals. NANOpure water (Barnstead, resistivity = $18 \mathrm{M} \Omega \mathrm{cm}$ ) was used for all aqueous solutions and for rinsing substrates. $\mathrm{HAuCl}_{4} \bullet 3 \mathrm{H}_{2} \mathrm{O}$ was synthesized according to Block's procedure. ${ }^{99}$ Potassium bromide (Fisher Scientific, IR grade), sulfuric acid (VWR, 95-98\%), perchloric acid (Merck, 60\%), Sodium borohydride (sigma-Aldrich, 98\%), Citric acid, trisodium salt (Bio-Rad Laboratories), Copper (II) perchlorate hexahydrate, 98\% (Acros Organics), and Aminopropyltriethoxysilane (APTES) (SigmaAldrich, $\geq 98 \%$ ) were purchased and used as received. 


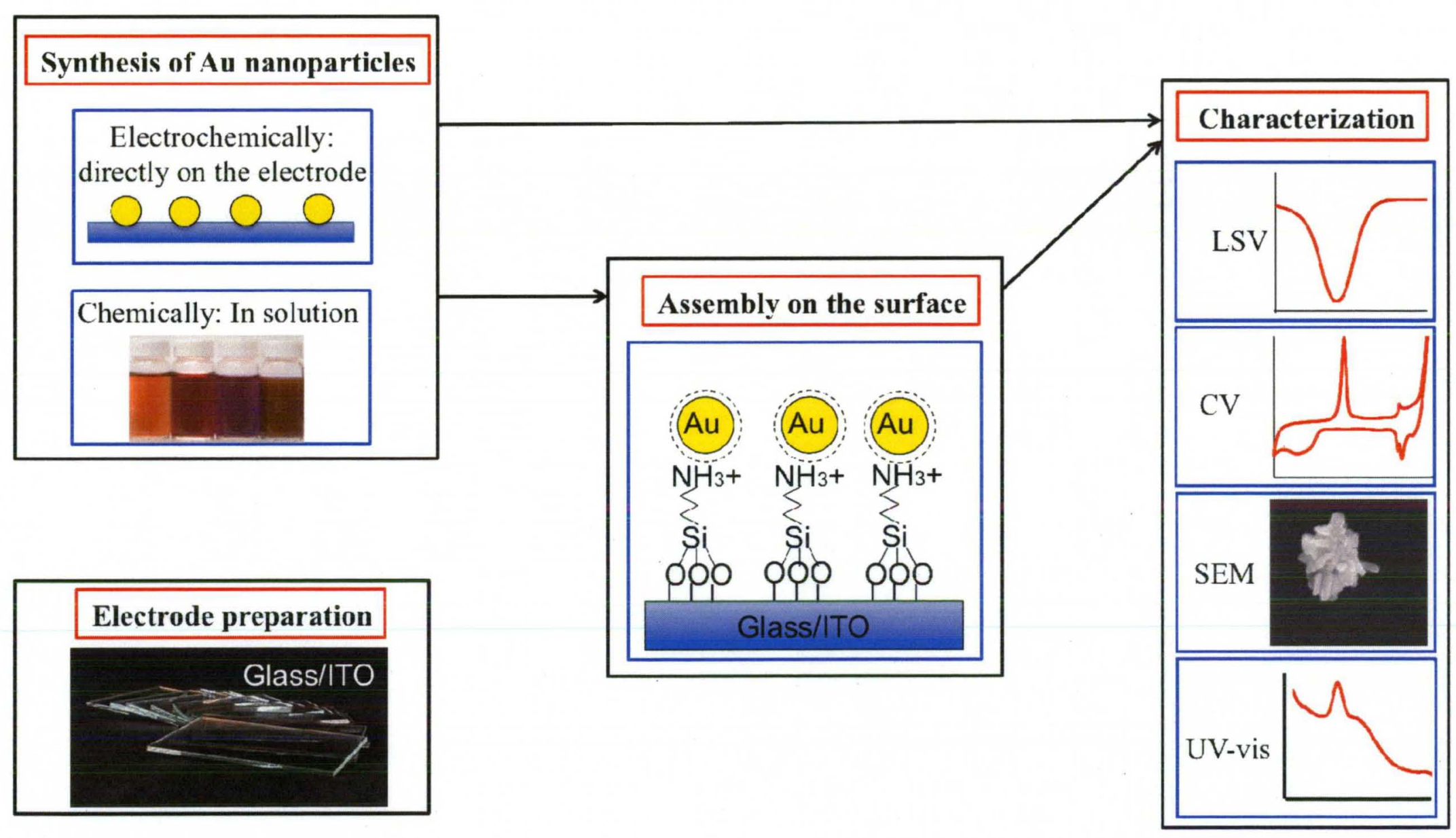

Figure 2.1. General scheme of experiments used in this work. 
Aqua Regia. Aqua regia solution is a mixture of concentrated nitric acid $\left(\mathrm{HNO}_{3}\right)$ and Hydrochloric acid $(\mathrm{HCl})$, usually in a 1:3 volume ratio, respectively. It is a highly corrosive mixture of the acids and used for cleaning glassware from the inorganic residues. The solution may be prepared before application or it can be made before and kept in a glass bottle in a fume hood. The glassware was kept in an aqua regia solution for 30 minutes, then rinsed with deionized water, acetone, deionized water, ethanol, deionized water, 2-propanol, deionized water and nanopure water and finally dried and used in the experiments.

\subsection{SUBSTRATES}

Indium Tin Oxide (ITO)-coated glass slides. Indium tin oxide (ITO or tin doped indium oxide) -coated glass slides are covered by the solid tin (IV) oxide $\left(\mathrm{SnO}_{2}\right)$ and indium (III) oxide $\left(\mathrm{In}_{2} \mathrm{O}_{3}\right)$, usually $90 \% \mathrm{In}_{2} \mathrm{O}_{3}$ and $10 \% \mathrm{SnO}_{2}$ by weight. The main properties of these substrates are optical transparency and electrical conductivity, which is why they are widely used. In our electrochemical, microscopic (Scanning electron microscopy (SEM)) and spectroscopic experiments (Ultraviolet-Visible (UV-vis) spectroscopy) the unpolished float glass-coated ITO slides $\left(R_{S}=5-15 \Omega\right.$, Delta Technologies, Limited - Loveland, $\mathrm{CO}$; or $\mathrm{R}_{\mathrm{S}}=8-12 \Omega$, antireflection coated opposing surface, Delta Technologies, Limited $\cdot$ Stillwater, MN) were used as a working electrode or the surface for investigation. Slides were cut by a diamond pen into $25 \times 7 \mathrm{~mm}$ slices, then cleaned by sonication for $20 \mathrm{~min}$ in acetone, ethanol and 2-propanol, and finally dried under a stream of $\mathrm{N}_{2}$. 


\subsection{CHEMICAL SYNTHESIS OF AU NPS}

Synthesis of Au nanparticle (Au NP) seed with $4 \pm 1 \mathrm{~nm}$ average diameter. The procedure of synthesis was described previously by Murphy and co-workers. ${ }^{100}$ For this purpose, I prepared a $20 \mathrm{~mL}$ aqueous solution of $0.25 \mathrm{mM} \mathrm{HAuCl}_{4}$ and $0.25 \mathrm{mM}$ citric acid, trisodium salt in a beaker with intense stirring. Then $0.6 \mathrm{~mL}$ of $10 \mathrm{mM}$ ice-cold $\mathrm{NaBH}_{4}$ was added to the solution with continuous stirring for $2 \mathrm{~h}$. The solution immediately changed its color from slightly yellow to an intense red after adding $\mathrm{NaBH}_{4}$, which indicated the formation of Au NPs. Figure 2.2 shows a scheme of the reaction and Figure 2.3 shows a scheme of the Au nucleation and growth process involved in NP synthesis.

Synthesis of $15 \pm 7 \mathrm{~nm}$ Average Diameter Au NPs. We used the same method as described by Pyatenko et al. to synthesize citrate-capped spherical Au NPs with controlled size. ${ }^{101}$ A solution of $1 \mathrm{~mL}$ of $0.01 \mathrm{M} \mathrm{HAuCl}_{4}$ and $99 \mathrm{~mL}$ of water was boiled and stirred with the addition of $2 \mathrm{~mL}$ of $1 \%$ trisodium citrate solution by weight and 4 $\mathrm{mL}$ of the Au NPs seed solution ( $4 \pm 1 \mathrm{~nm}$ average diameter). After $1 \mathrm{~h}$ of boiling with stirring, the solution was cooled to room temperature. The mole ratio of $\mathrm{Au}^{\mathrm{III}} / \mathrm{Au}$ seed was 10:1. The mol of Au seed refers to total atoms of Au in the seed NPs, not mol of NPs.

Synthesis of $31 \pm 14 \mathbf{~ n m}$ Average Diameter Au NPs. I added $19 \mathrm{~mL}$ of nanopure water, $0.5 \mathrm{~mL}$ of $0.01 \mathrm{M}$ citric acid, trisodium salt and $0.5 \mathrm{~mL}$ of $0.01 \mathrm{M} \mathrm{HAuCl}_{4}$ to a 50 $\mathrm{mL}$ beaker. The solution was heated to $80-90^{\circ} \mathrm{C}$ for $20-25 \mathrm{~min}$ with rapid stirring and then cooled back to room temperature. Figure 2.4 shows a scheme of the synthesis of citrate-capped spherical Au NPs of this size. 


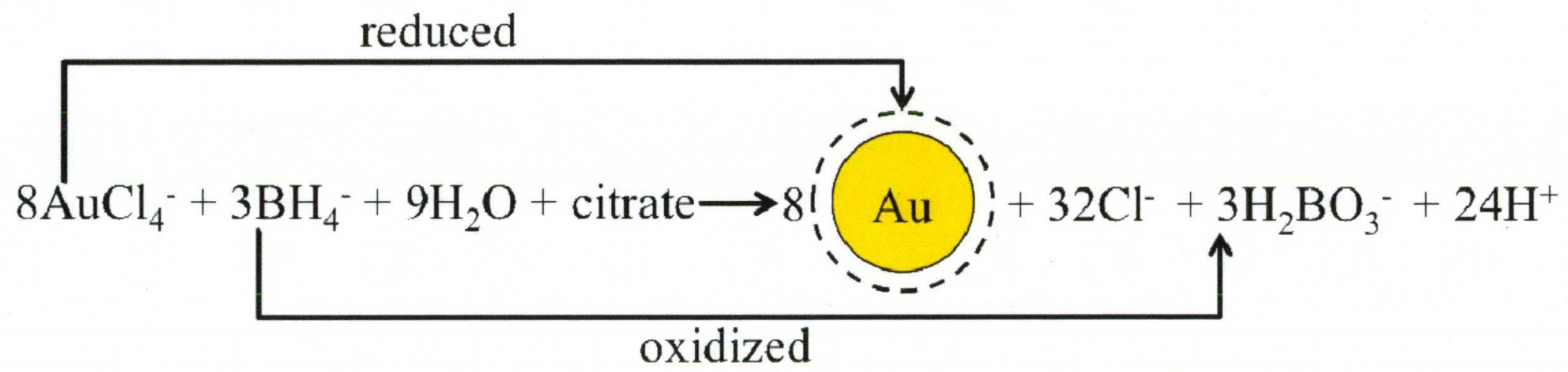

Figure 2.2. Schematic of Au seed formation by reduction of $\mathrm{AuCl}_{4}{ }^{-}$with $\mathrm{BH}_{4}{ }^{-}$. 


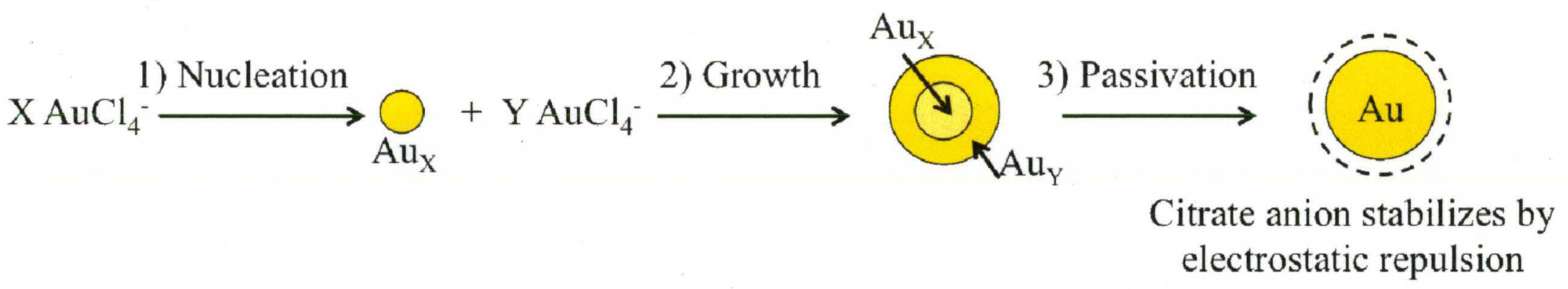

Figure 2.3. Schematic showing metal nucleation and growth process involved in Au NP formation. 


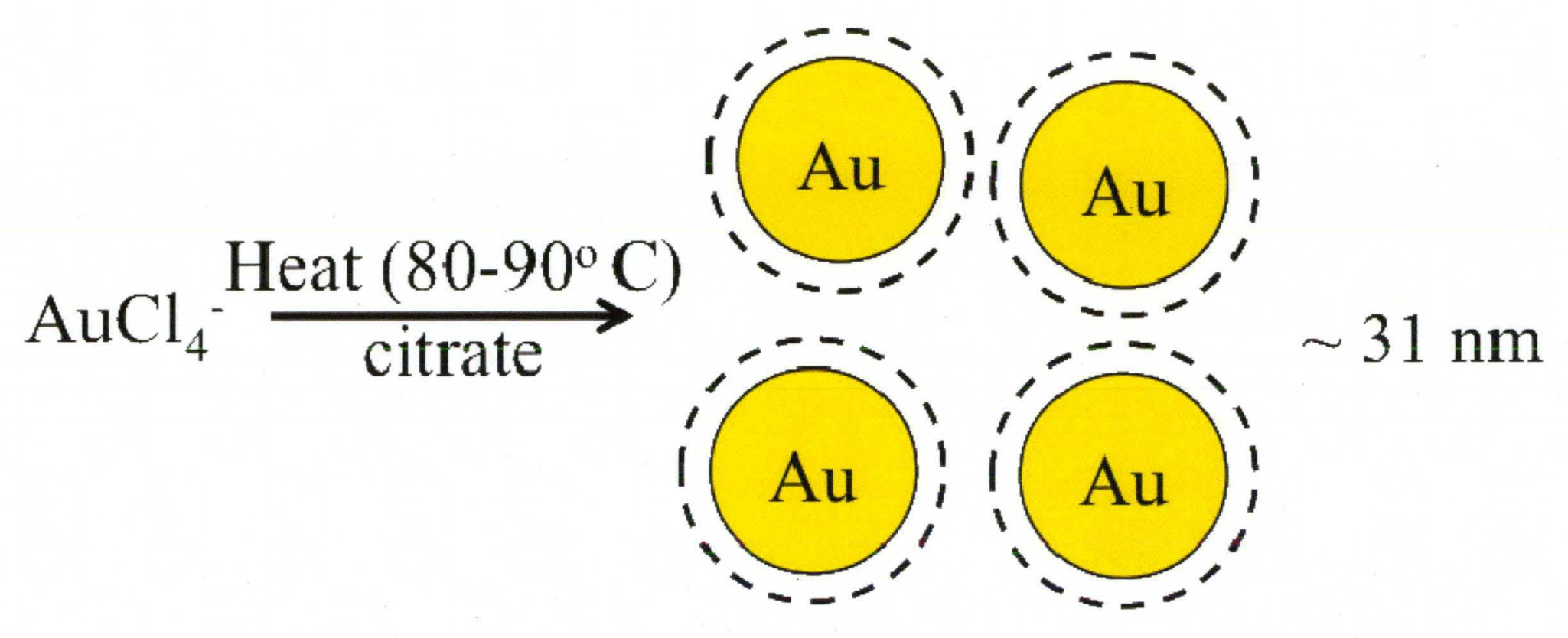

Figure 2.4. Schematic of synthesis of citrate-capped spherical Au NPs. 
Synthesis of $73 \pm 19 \mathrm{~nm}$ Average Diameter Au NPs. A solution of $10 \mathrm{~mL}$ of 0.01 $\mathrm{M} \mathrm{HAuCl}_{4}$ and $90 \mathrm{~mL}$ of water was boiled and stirred followed by the addition of $2 \mathrm{~mL}$ $1 \%$ trisodium citrate solution by weight and $4 \mathrm{~mL}$ of the Au NPs seed solution $(4 \pm 1 \mathrm{~nm}$ average diameter), which was prepared as already described. After $1 \mathrm{~h}$ of boiling with stirring, the solution was cooled back to room temperature. Figure 2.5 shows a scheme of the Au NP seed-mediated growth method using citrate reduction.

\subsection{ASSEMBLY OF AU NPS ON GLASS/ITO}

Functionalization of Glass/ITO Electrodes. Glass/ITO electrodes were aminofunctionalized by immersion into a solution of $10 \mathrm{~mL}$ 2-propanol, $100 \mu \mathrm{L}$ of aminopropyltriethoxysilane (APTES), and 4-5 drops of water and by heating just below boiling for $\sim 30$ minutes. In this step, the surface hydroxyl groups $\left(\mathrm{OH}^{-}\right)$react with the ethoxy $\left(-\mathrm{O}-\mathrm{CH}_{2}-\mathrm{CH}_{3}\right)$ groups of APTES to covalently form a monolayer. As a result, the substrate surface was modified with amino $\left(\mathrm{NH}_{2}\right)$ groups, which are likely protonated as $\mathrm{NH}_{3}{ }^{+}$. The electrodes were then removed and rinsed with 2-propanol, nanopure water, and dried under a stream of $\mathrm{N}_{2}$. The structure of the APTES molecule and scheme of chemical functionalization of the Glass/ITO surface with APTES is shown in Figure 2.6.

Electrostatic Attachment of Au NPs to the Glass/ITO/APTES. Au NPs were attached to the glass/ITO/APTES electrode by electrostatic interactions between the negatively-charged (citrate capped) Au NPs and positively-charged $\mathrm{NH}_{3}{ }^{+}$groups of APTES by immersion of the electrode into a colloidal solution of the Au NPs as shown in Figure 2.7. The coverage of Au NPs on the electrode was controlled by varying the soaking time and by dilution of the colloidal solution of Au NPs. Typical soaking times 


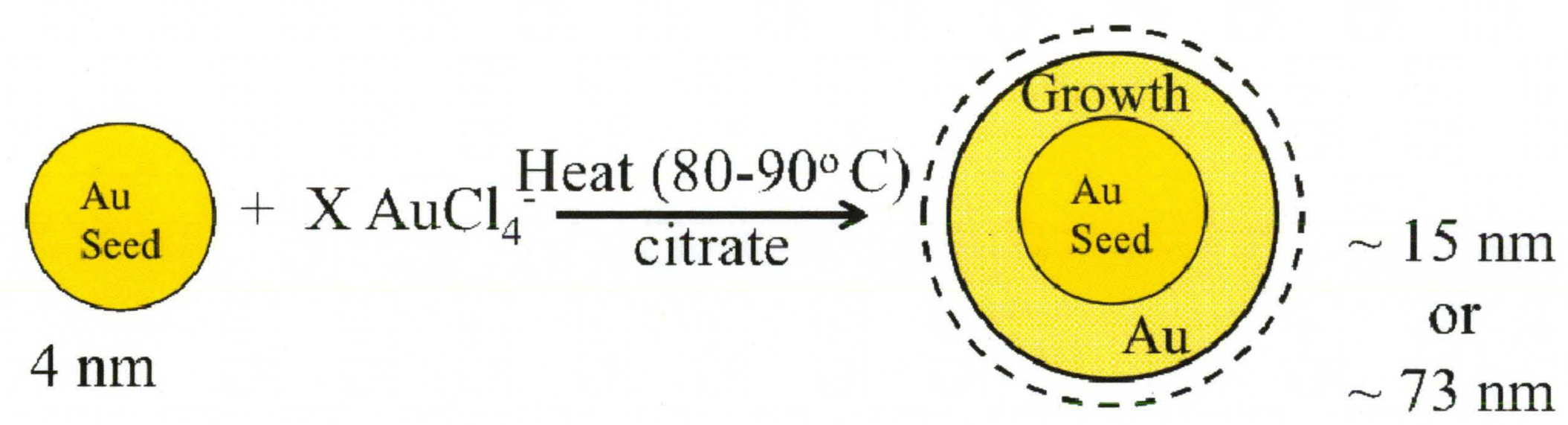

Figure 2.5. Schematic of Au NP synthesis by seed-mediate growth using citrate reduction. 


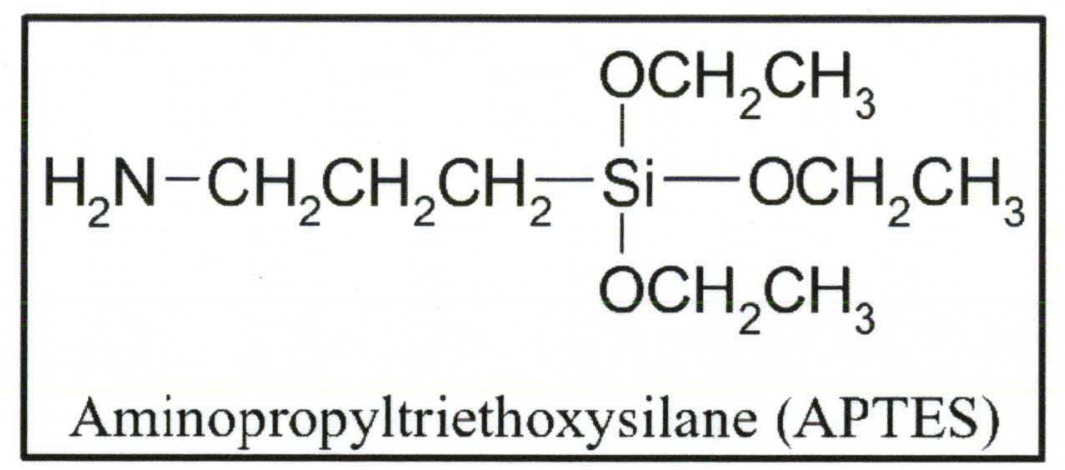

N
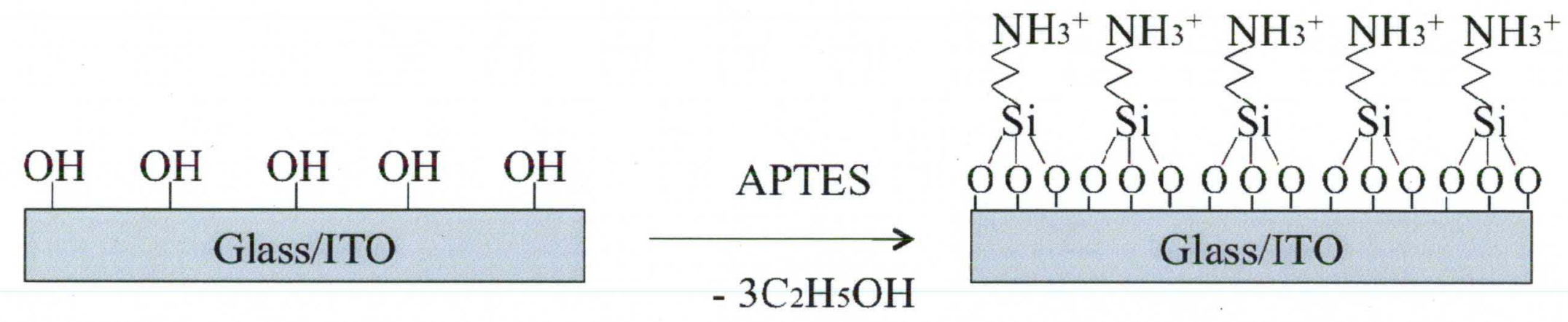

$\mathrm{OH}^{-}$and Si groups covalently form a monolayer

Figure 2.6. Structure of APTES molecule and scheme of chemical functionalization of the Glass/ITO surface with APTES. 


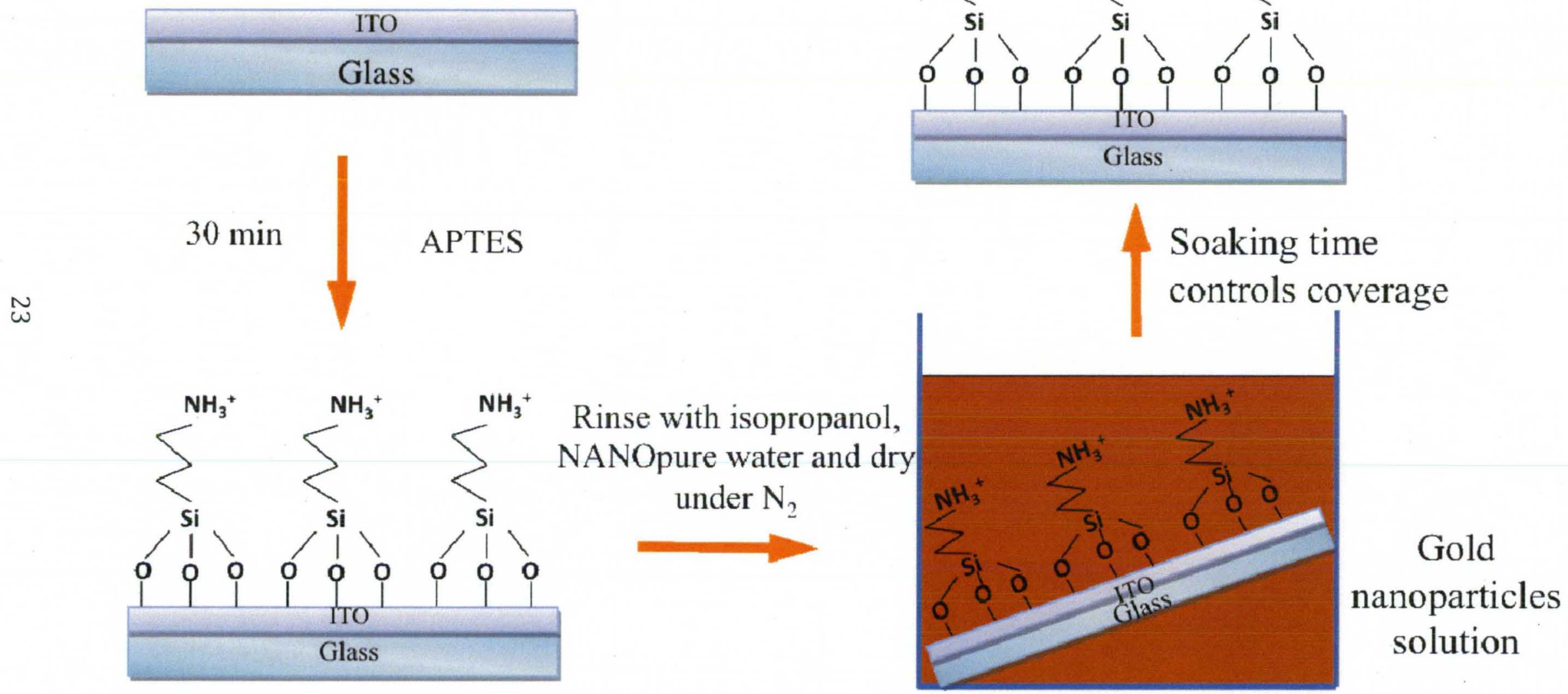

Figure 2.7. Scheme of functionalization of Glass/ITO with the APTES and attachment of Au NPs to the Glass/ITO functionalized substrate. 
ranged from 5 to $16 \mathrm{~min}$ and the solution of $4 \pm 1 \mathrm{~nm}$ average diameter Au NPs was often diluted by a factor of 10 .

\subsection{ELECTROCHEMICAL DEPOSITION OF AU NPS.}

Au solution for electrochemical deposition. A gold solution was used for the electrochemical deposition of Au NPs directly onto the Glass/ITO surface. This solution contained: $0.5 \mathrm{M} \mathrm{H}_{2} \mathrm{SO}_{4}$ and $5^{*} 10^{-3}-5^{*} 10^{-6} \mathrm{M} \mathrm{HAuCl}_{4}$. Glass/ITO slides were immersed to this solution and different potentials were applied for growing by chronocoulometry. This led to the growth of Au NPs, nanorods (NRs), nanotriangles, nanohexagons, and other shape nanostructures.

\subsubsection{Controlled size of Au NPs.}

Electrochemical Deposition of Gold Nanoparticles (Au NPs). Before Au NPs were electrochemically deposited onto the clean Glass/ITO working electrodes using a $\mathrm{CH}$ Instruments (Austin, TX) 660C electrochemical workstation in chronocoulometry mode with an $\mathrm{Ag} / \mathrm{AgCl}(3 \mathrm{M} \mathrm{KCl})$ reference electrode and a $\mathrm{Pt}$ wire counter electrode, Glass/ITO electrodes were cleaned by sonication for $20 \mathrm{~min}$ in acetone, ethanol, and 2propanol and then dried under a stream of $\mathrm{N}_{2}$. Different sizes of $\mathrm{Au}$ NPs were produced by applying different conditions such as 1) the same concentration and charge but varying the deposition potential (stepped from $1 \mathrm{~V}$ to $-0.2 \mathrm{~V}, 0.4 \mathrm{~V}$, and $0.8 \mathrm{~V}$ ), 2) the same concentration and various potential $(-0.2 \mathrm{~V}, 0.4 \mathrm{~V}$, and $0.8 \mathrm{~V})$ and charge $\left(6 \times 10^{-4}\right.$

Coulombs (C), $1 \times 10^{-3}$, and $\left.6.6 \times 10^{-3} \mathrm{C}\right)$, and 3) various concentration of $\mathrm{AuCl}_{4}{ }^{-}\left(5 \times 10^{-3}\right.$ 
M, $5 \times 10^{-4} \mathrm{M}, 5 \times 10^{-5} \mathrm{M}, 2.5 \times 10^{-5} \mathrm{M}$, and $\left.5 \times 10^{-6} \mathrm{M}\right)$. The surface coverage of Au NPs was kept constant. After the desired charge was achieved the Glass/ITO/Au NPs electrode was removed from the cell, gently rinsed with water and dried under $\mathrm{N}_{2}$. The deposition time ranged between 1 and $35 \mathrm{~min}$, and the average Au NP diameter ranged from 14 to $312 \mathrm{~nm}$.

\subsubsection{Au nanoplates deposition}

Electrochemical deposition of Gold Nanoplates (Au NPLs). Glass/ITO electrodes were used as working electrodes after cleaning them in three solutions - acetone, ethanol and 2-propanol 20 minutes in each by sonication. Then they were dried under a stream of $\mathrm{N}_{2}$. Au NPLs were electrochemically deposited onto the clean Glass/ITO working electrode using a $\mathrm{CH}$ Instruments (Austin, TX) 660C electrochemical workstation in chronocoulometry mode with an $\mathrm{Ag} / \mathrm{AgCl}(3 \mathrm{M} \mathrm{KCl})$ reference electrode and $\mathrm{Pt}$ counter electrode to complete the cell. The electrolyte solution used for the deposition Au NPs with different sizes was from $5 \times 10^{-3}$ to $5 \times 10^{-6} \mathrm{M} \mathrm{HAuCl}_{4}$ plus $0.5 \mathrm{M} \mathrm{H}_{2} \mathrm{SO}_{4}$. The potential was stepped from $1.0 \mathrm{~V}$ to $0.8 \mathrm{~V}$. The amount of charge passed during the deposition was varied from $3 \times 10^{-3}$ Coulombs (C) to $1.2 \times 10^{-2} \mathrm{C}$ with the time of deposition from approximately $1000 \mathrm{sec}$ to $4000 \mathrm{sec}$, respectively.

\subsection{CU UPD ON AU NPS}

An electrochemical cell with a glass/ITO/Au NPs or glass/ITO/APTES/Au NP working electrode, $\mathrm{Pt}$ wire counter electrode, and $\mathrm{Hg} / \mathrm{HgO}$ or $\mathrm{Ag} / \mathrm{AgCl}$ reference electrode was used for UPD studies. The electrolyte solution was $0.01 \mathrm{M} \mathrm{Cu}\left(\mathrm{ClO}_{4}\right)_{2}$ plus 
$0.1 \mathrm{M} \mathrm{HClO}_{4}$ and the scan rate was $20 \mathrm{mV} / \mathrm{s}$. For $\mathrm{Cu}$ UPD measurements the potential range was from $0.0 \mathrm{~V}$ to $1.6 \mathrm{~V}$ and for bulk $\mathrm{Cu}$ deposition the potential range was from $0.8 \mathrm{~V}$ to $-0.7 \mathrm{~V}$ using cyclic voltammetry.

After electrochemical deposition of Au NPs on the surface of the working electrode, the working electrode was immersed into the $\mathrm{Cu}_{2}{ }^{+}$solution and the phenomenon of $\mathrm{Cu}-$ UPD was observed and studied by CV. Figure 2.8 shows a typical CV on Au NPs. The peak at $1.4 \mathrm{~V}$ is due to $\mathrm{Au}$ oxide formation with the reduction near $900 \mathrm{mV}$. The peaks near $360 \mathrm{mV}$ are due to $\mathrm{Cu}$ UPD deposition and oxidation. Figure 2.9 shows the processes of the oxidation of Au NPs (A) and deposition of the monolayer of Cu UPD (B).

\subsection{CHARACTERIZATION AND INSTRUMENTATION}

\subsubsection{Electrochemical methods}

Electrochemical techniques are the branch of chemical techniques that study chemical reactions which occur in a solution at the interface of an electrode and electrolyte and which involve electron transfer between the electrode and the electrolyte or species in solution. This section will describe the electrochemical cell, set-up, and techniques which were used in this research. Figure 2.10 presents the basic electrochemical set-up used in these studies. It includes an electrochemical cell with working, counter and reference electrodes, a beaker, the electrolyte solution, potentiostat, and computer for the acquisition and analysis of the data. 


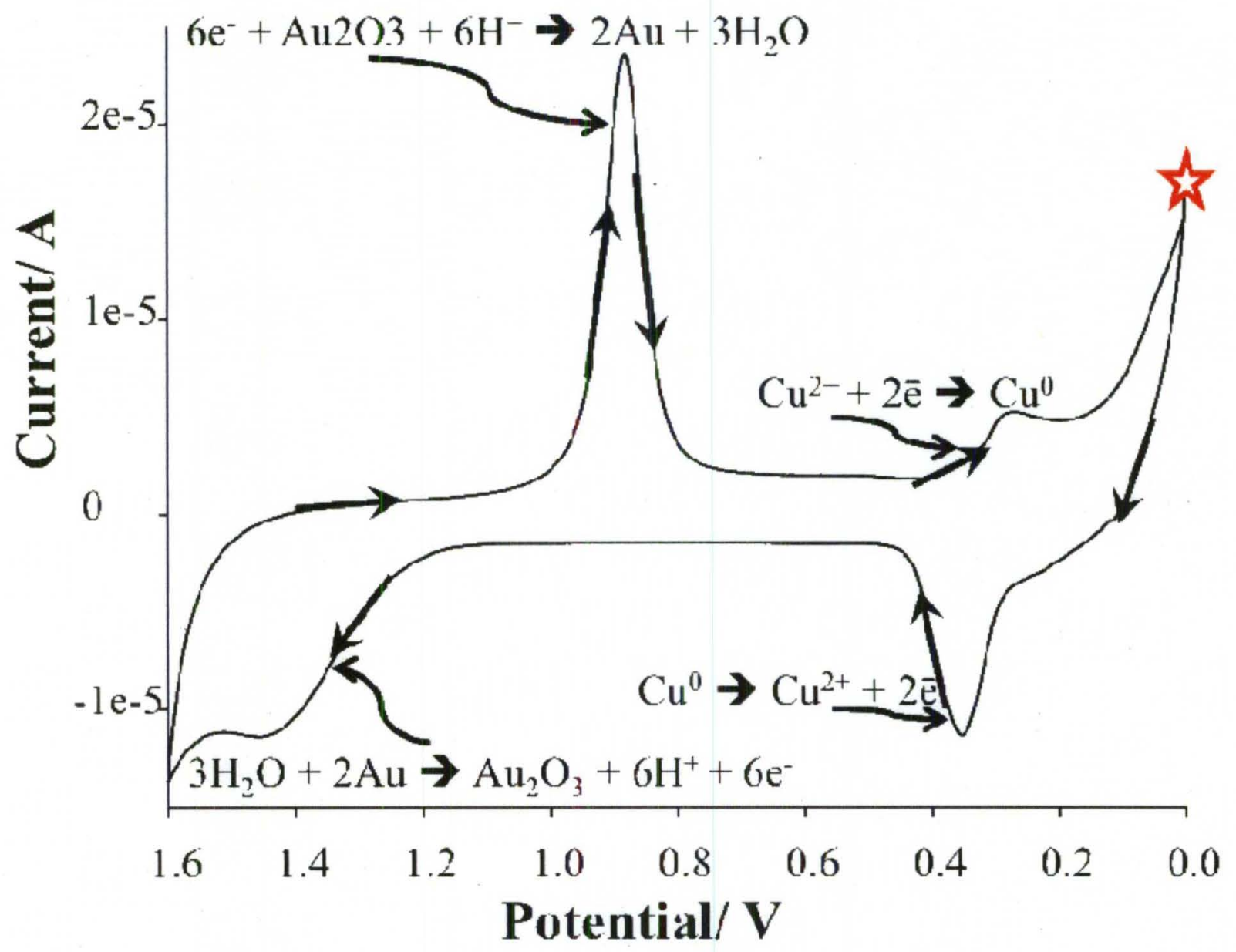

Figure 2.8. $\mathrm{CV}$ of Glass/ITO/Au $(4 \mathrm{~nm})$ in $0.01 \mathrm{M} \mathrm{Cu}\left(\mathrm{ClO}_{4}\right)_{2}$ plus $0.1 \mathrm{M} \mathrm{HClO}_{4}$ at $20 \mathrm{mV} / \mathrm{s}$. 

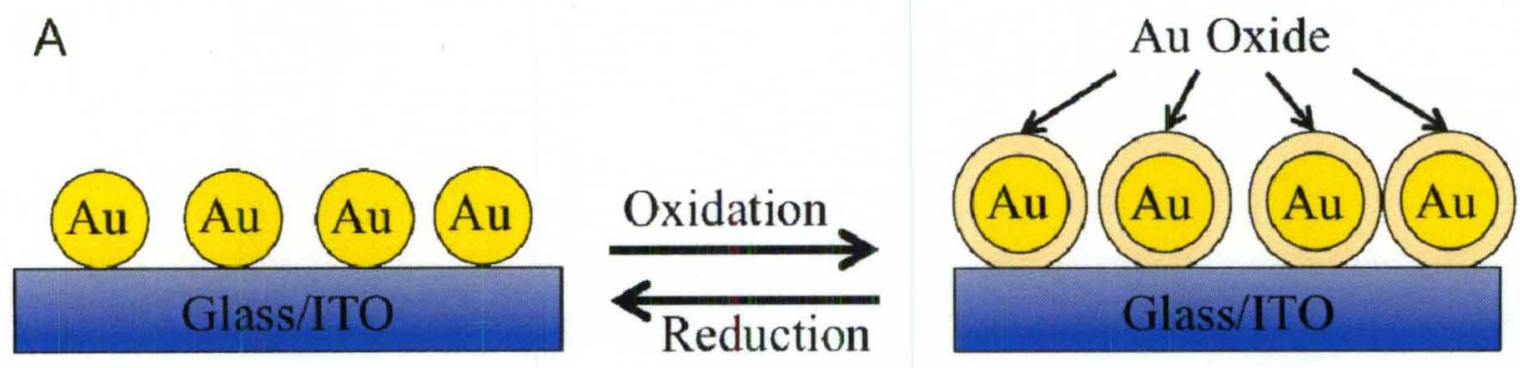

B

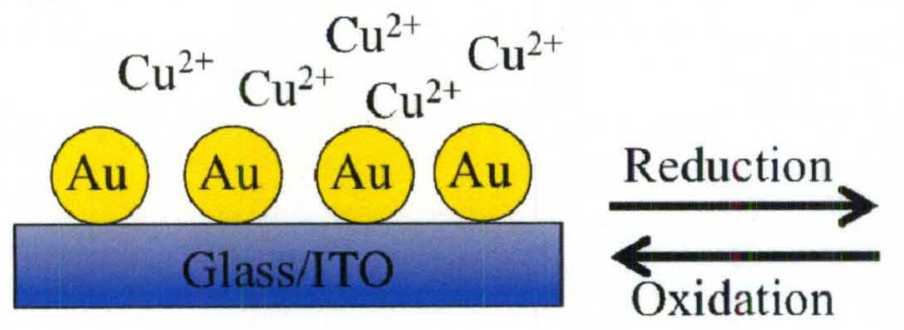

Monolayer of $\mathrm{Cu}$ UPD

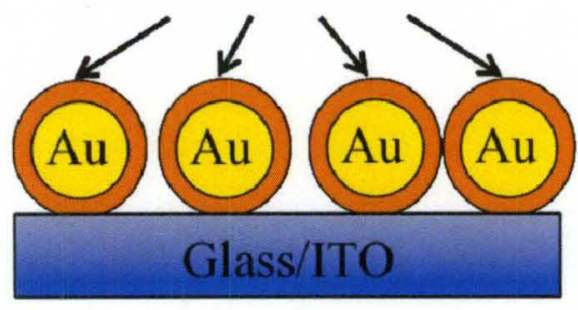

Figure 2.9. The processes of oxidation Au NPs (A) and deposition of a Cu UPD monolayer (B). 


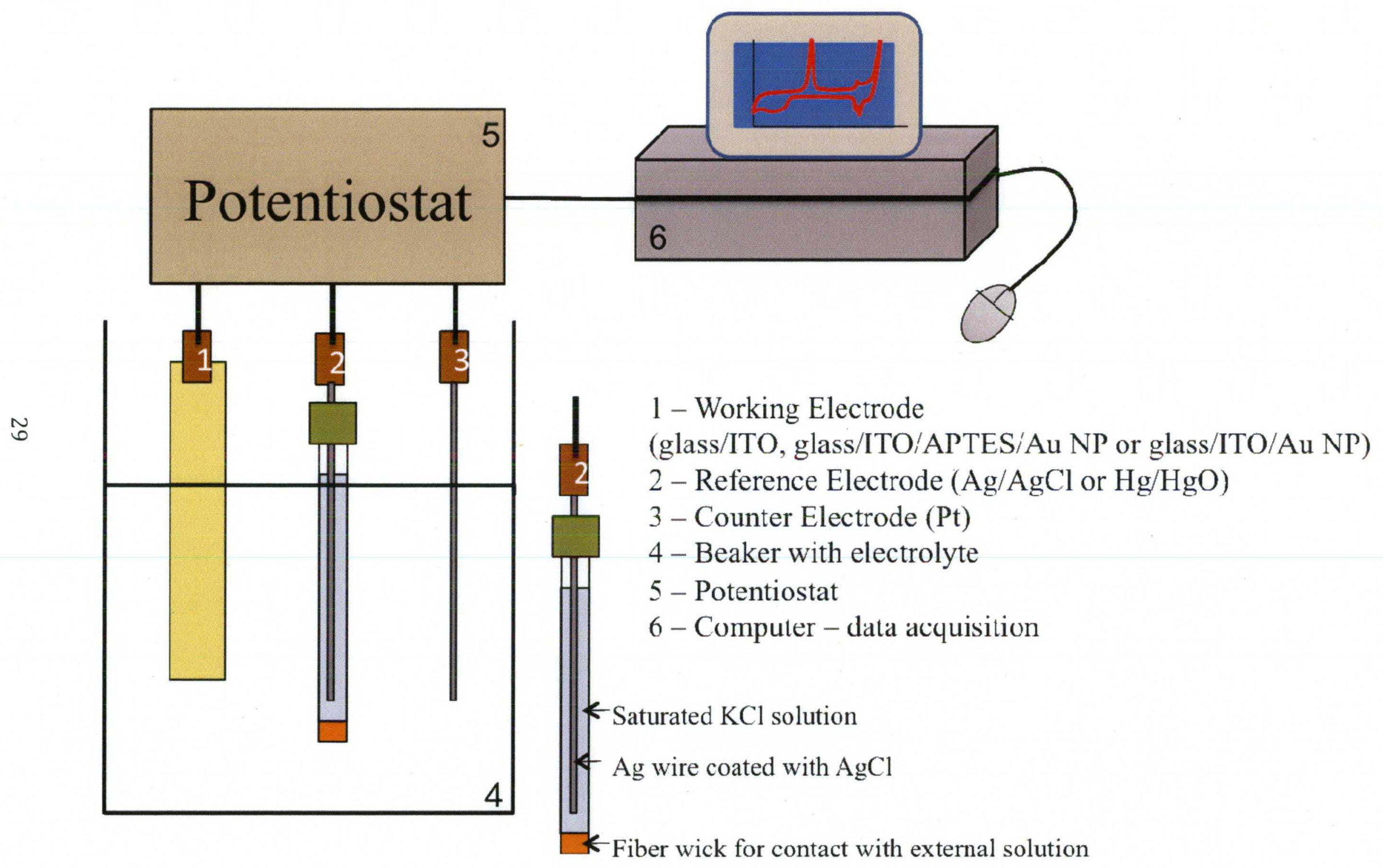

Figure 2.10. Electrochemical set-up. 
Electrochemical cell. In this research we used a three-electrode system:

1. The working electrode is an electrode were the chemical reaction occurs. In our work, glass/ITO, glass/ITO/APTES/Au or glass/ITO/Au served as a working electrode.

2. The reference electrode is an electrode, which has a stable and well-known electrode potential. It serves as a reference to control and know the potential of the working electrode and doesn't pass any current. In our studies we used an $\mathrm{Ag} / \mathrm{AgCl}$ ot $\mathrm{Hg} / \mathrm{HgO}$ reference electrode. It consists of a silver wire electrode coated with solid $\mathrm{AgCl}$ and immersed in a solution of $3 \mathrm{M}$ potassium chloride.

\section{$\mathrm{Ag}|\mathrm{AgCl}, \mathrm{KCl}(3 \mathrm{M})| \mid$}

The electrode potential is determined by the half-reaction

$$
\mathrm{AgCl}(\mathrm{s})+\mathrm{e}^{-} \rightarrow \mathrm{Ag}(\mathrm{s})+\mathrm{Cl}^{-} \quad(\mathrm{Rxn} 2.1)
$$

Also, this electrode has a fiber wick for contact with the external solution.

The second reference electrode used in this research was a mercury/mercury oxide $(\mathrm{Hg} / \mathrm{HgO})$ electrode, which is immersed into a solution of potassium hydroxide $(\mathrm{KOH})$.

3. The counter electrode, also known as an auxiliary electrode, is used for the connection in the electrolyte. It closes the circuit and balances the current observed at the working electrode by acting as an electron sink. In this work, a Pt wire served as the counter electrode.

Electrolyte solutions used in this work were different depending on the purpose of the experiment, and they will be specified in each particular experiment in the following 
chapters.

Potentiostat. A potentiostat is an electronic device that controls the three electrode cell by controlling the potential of the working electrode relative to the reference electrode and it measures the current flow between the counter and working electrodes. A CH Instruments (Austin, TX) 660C electrochemical workstation was used for all electrochemical experiments.

\section{Linear sweep voltammetry (LSV) - stripping voltammetry. This is a} voltammetric method where the current at a working electrode is measured while the potential between the working electrode and a reference electrode is swept linearly with time. In LSV, the voltage is scanned from a lower limit to an upper limit. The characteristics of the LSV depend on factors:

- The rate of electron transfer reaction(s)

- The chemical reactivity of the electroactive species

- The voltage scan rate

The current response is plotted as a function of voltage. LSV allowed determining the composition of species present on the electrode surface and the amount of the species. The schematic excitation waveform in LSV is presented in Figure 2.11. The slope of excitation wave is equal:

$$
\text { Slope }=\frac{\Delta E}{\Delta \text { time }}[\text { Volts/time }] \quad \text { (Eq. 2.1) }
$$

The slope of the excitation wave is the scan rate of the experiment. 


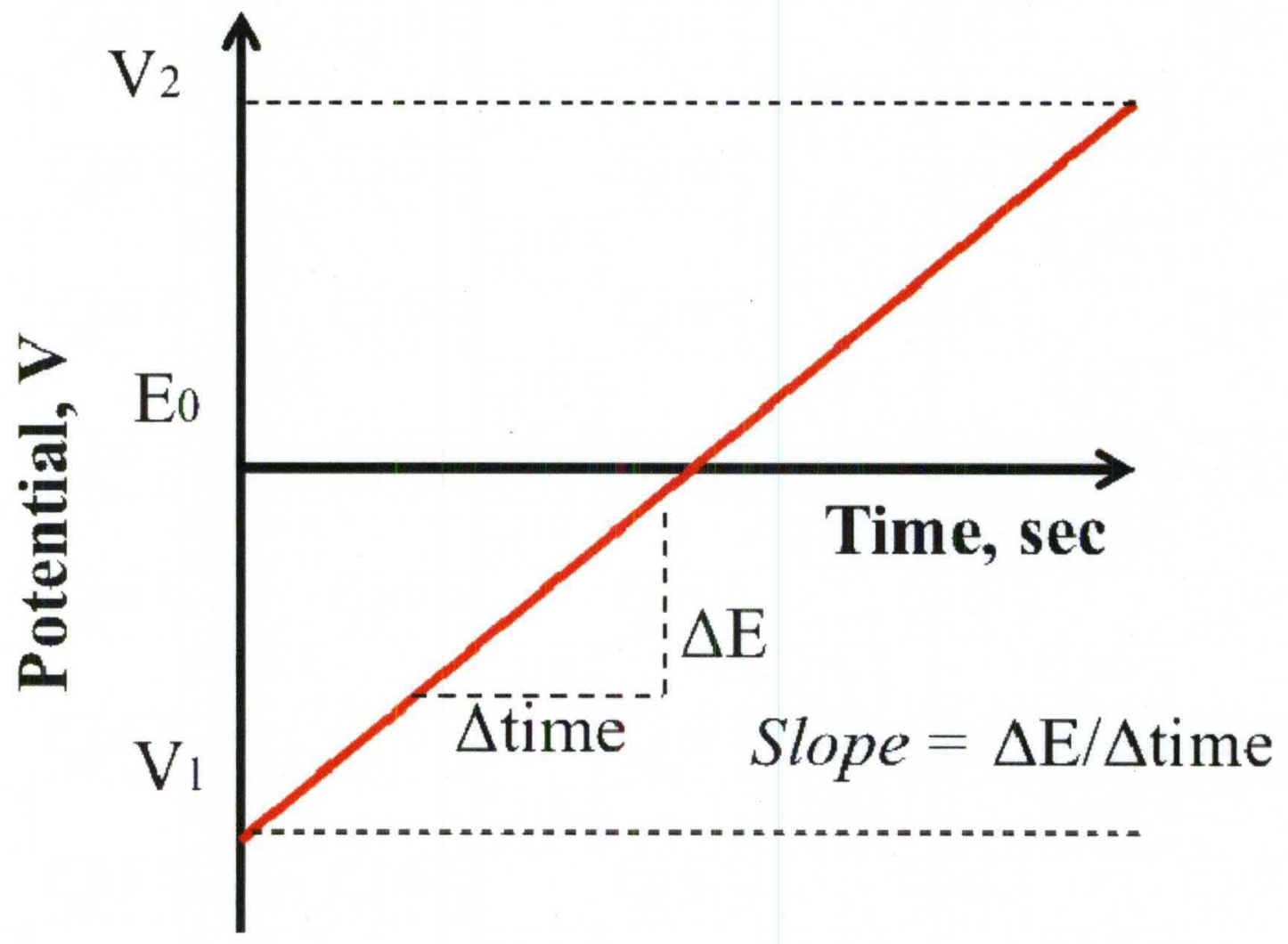

Figure 2.11. The excitation waveform in a LSV experiment. 
The oxidation or reduction of the species is always registered as a peak in the current signal at the potential at which the species begins to oxidize or reduce. According to Faraday's $1^{\text {st }}$ law, the amount of a substance oxidized/reduced at an electrode during the reaction is directly proportional to the quantity of electricity transferred at that electrode, where

$$
m o l=\frac{Q}{n F}(\text { Eq. 2.2) }
$$

In this equation $\mathrm{Q}$ is the charge passed through the working electrode during the reaction in Coulombs, $\mathbf{n}$ is the number of the electrons involved in the reaction, and $\mathrm{F}$ is Faraday's constant $\left(\mathrm{F}=96,485 \mathrm{C} \cdot \mathrm{mol}^{-1}\right)$. The amount of charge per second is the current in Amperes (A).

In this work LSV was used for studying the electrochemical oxidation of Au NPs. Figure 2.12 shows a typical stripping voltammogram of glass/ITO/APTES/Au NPs ( 4 $\mathrm{nm}$ ) at a scan rate of $1 \mathrm{mV} / \mathrm{s}$ in a solution of $0.01 \mathrm{M} \mathrm{KBr}$ plus $0.1 \mathrm{M} \mathrm{HClO}_{4}$.

The initial potential was $0 \mathrm{~V}$ and final potential $1.0 \mathrm{~V}$. The potential was swept positive direction and the current measured. The peak of the oxidation of $\mathrm{Au}$ is at $\sim 750$ $\mathrm{mV}$. The process of oxidation corresponds to two possible reactions:

$$
\begin{array}{ll}
\mathrm{Au}^{0}+2 \mathrm{Br}^{-}=\mathrm{AuBr}_{2}^{-}+\mathrm{e}^{-} & (\text {Rxn. 2.2) } \\
\mathrm{Au}^{0}+4 \mathrm{Br}^{-}=\mathrm{AuBr}_{4}^{-}+3 \mathrm{e}^{-} & \text {(Rxn. 2.3) }
\end{array}
$$

After the current reaches the maximum value, it drops back to the baseline once all of the $\mathrm{Au}$ was oxidized to the $\mathrm{Au}^{\mathrm{I}}$ or to the $\mathrm{Au}{ }^{\mathrm{III}}$ and removed from the electrode. In Figure 2.13 presented the scheme of the process of oxidation of Au NPs. According to the resulting curve, it is possible to determine the amount the oxidized $\mathrm{Au}$ from the area of the oxidation peak as long as the number of electrons is known. 


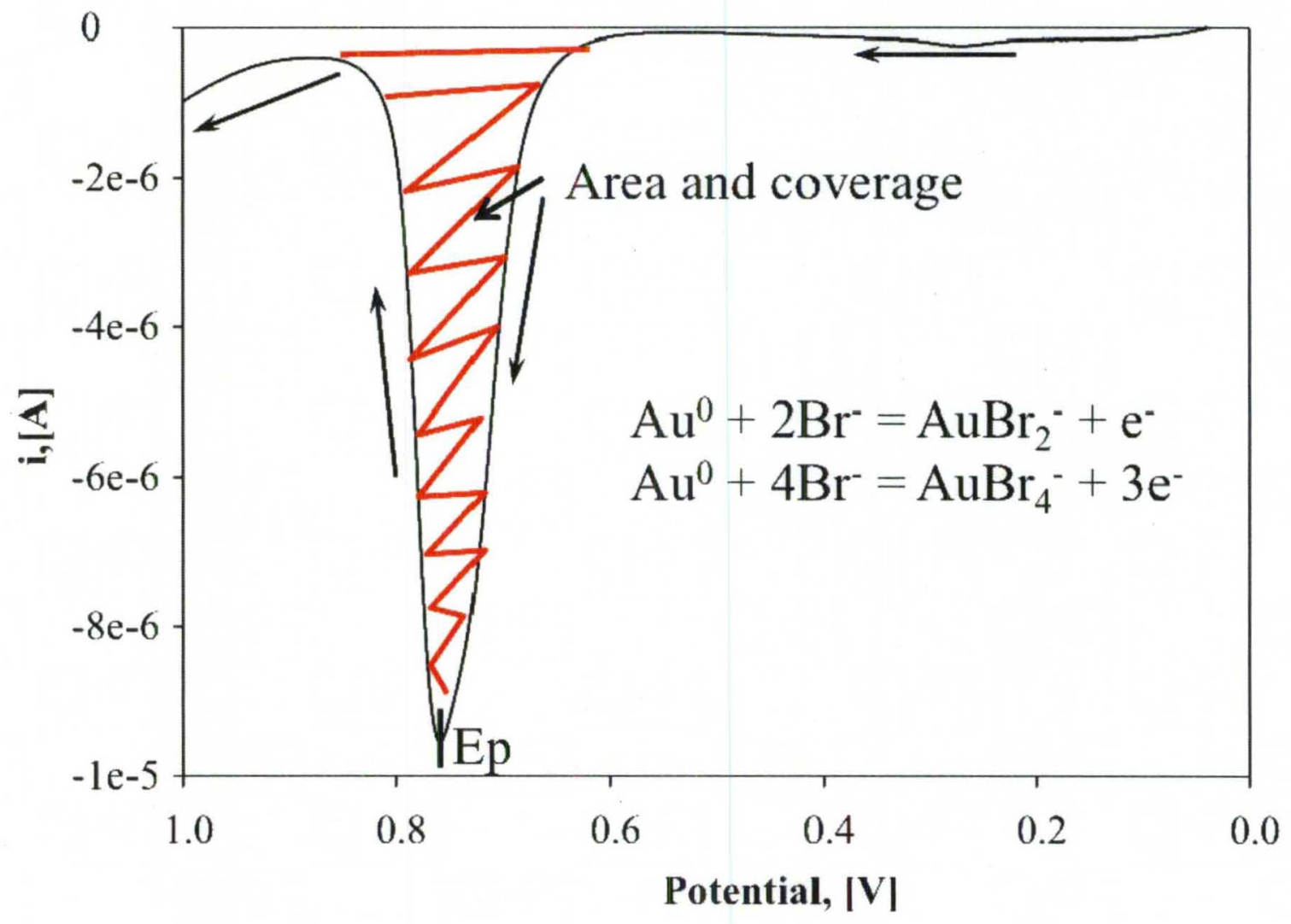

Figure 2.12. LSV of Glass/ITO/APTES/Au NPs $(\sim 4 \mathrm{~nm})$ in $10 \mathrm{mM} \mathrm{KBr}$ plus $0.1 \mathrm{M}$ $\mathrm{HClO}_{4}$ electrolyte at $1 \mathrm{mV} / \mathrm{s}$. Arrows indicate the direction of the scan. 


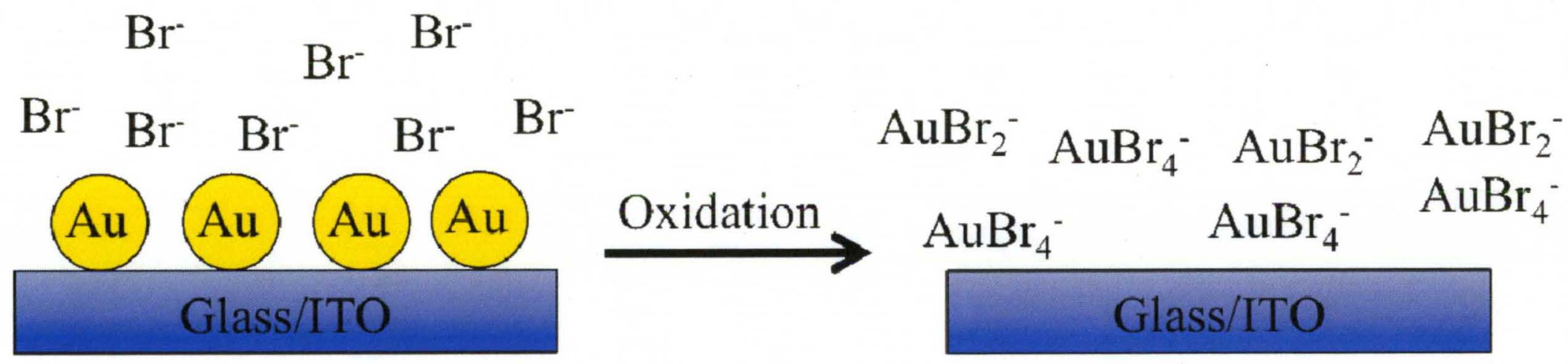


LSV was used in this work in studies of the electrochemical oxidation of chemically synthesized Au NPs and electrochemically deposited Au NPs.

Cyclic voltammetry (CV). CV is a type of potentiodynamic electrochemical measurement. In cyclic voltammetry, the potential of a small, stationary working electrode is changed linearly with time starting from a potential where no electrode reaction occurs and moving to potentials where reduction or oxidation of a solute or electrode bound species occurs. After traversing the potential region in which one or more electrode reactions take place, the direction of the linear sweep is reversed and the electrode reactions of intermediates and products, formed during the forward scan often can be detected.

A typical expected response of a reversible redox couple during the single scan is shown in Figure 2.14. Initially molecule $\mathrm{O}$ is reduced. The forward scan produces an identical response as seen in LSV. During the reverse scan, the R molecule becomes oxidized back to $\mathrm{O}$.

There is several types of information which you can obtain from a CV.

1. The cathodic $\left(i_{p, c}\right)$ and anodic peak current $\left(i_{p, c}\right)$ is related to concentration, the diffusion coefficient, electrode area, number of electrons (n), scan rate, and electron transfer rate.

2. The potential of the cathodic peak $\left(\mathrm{E}_{\mathrm{p}, \mathrm{c}}\right)$ and potential of the anodic peak $\left(\mathrm{E}_{\mathrm{p}, \mathrm{a}}\right)$ are related to thermodynamics of the reaction, other solutions species, and electron transfer rate.

3. The cathodic half-peak potential $\left(\mathrm{E}_{\mathrm{p} / 2}\right)$ is related to the $\mathrm{E}^{0}$.

4. The half-wave potential $\left(E_{1 / 2}\right)$. 


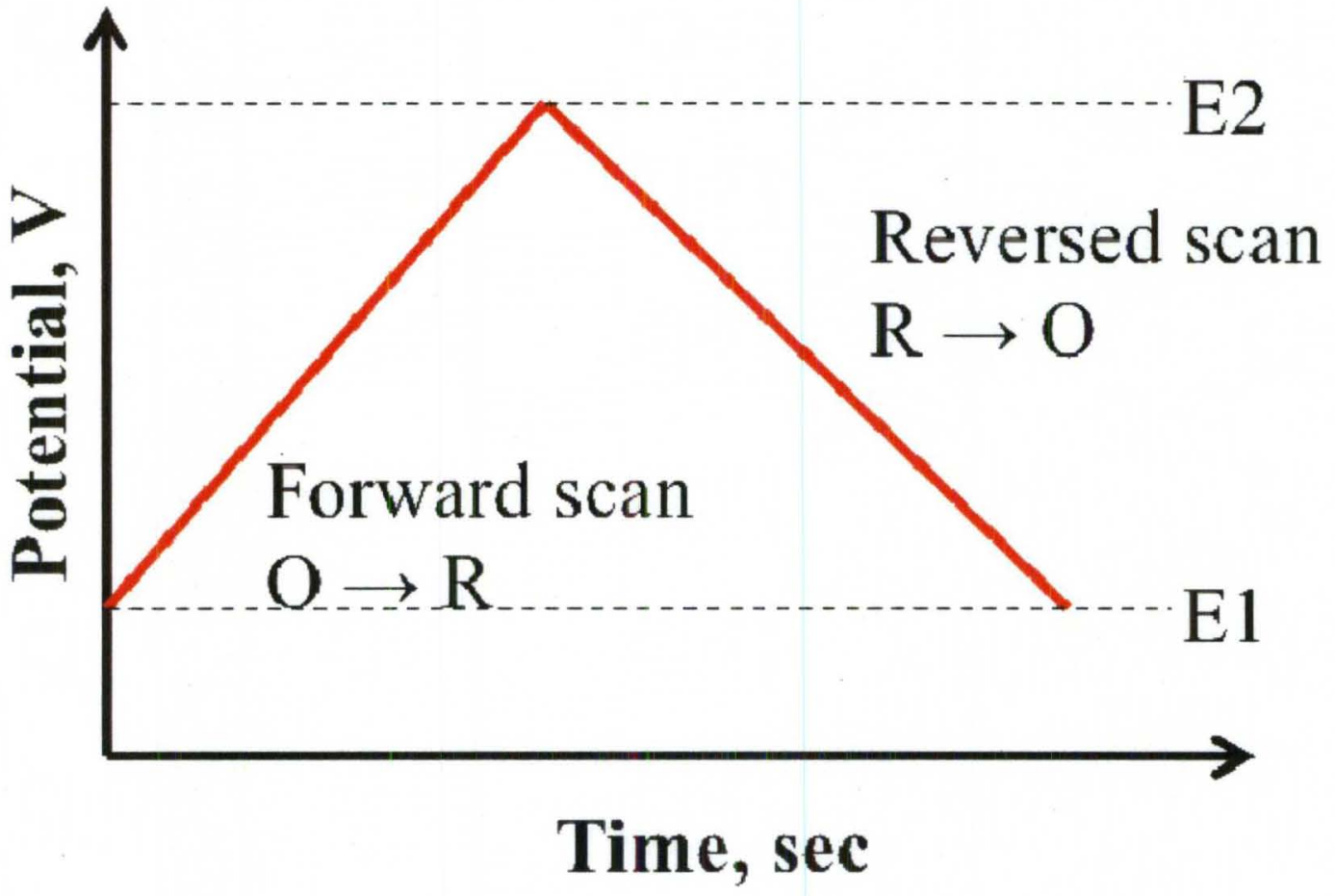

Figure 2.14. The excitation waveform in a CV experiment. 
From a reversible electrochemical reaction:

1. The voltage separation between the current peaks:

$$
\Delta E=E_{p}^{a}-E_{p}^{c}=\frac{59}{n} m V
$$

2. The positions of the peak voltage does not change as a function of voltage scan rate

3. The ratio of the peak currents is equal to one

$$
\frac{i_{p, c}}{i_{p, a}}=1
$$

4. The peak currents are proportional to the square root of the scan rate.

In this research $\mathrm{CV}$ was used in order to study the electrochemical oxidationreduction of $\mathrm{Au}^{3+}$ for the Au nanostructures, and also for the studying of $\mathrm{Cu}-\mathrm{UPD}$.

Chronocoulometry (CC). Chronocoulometry is a technique, in which the chargetime behavior of an electrode in a solution is observed. CC uses a potential step waveform. The typical experiment starts at some initial potential where is no electrolysis. Then it is changed (stepped) instantaneously to the other value, which leads to the oxidation or reduction of species in the electrolyte. The potential is held for some period of time, depending on the experiment. ${ }^{102}$

The effect of the changes in potential used in the $\mathrm{CC}$ experiment can be understood by the Nernst equation, which is for the redox couple $\mathrm{O}+\mathrm{n} \overline{\mathrm{e}}=\mathrm{R}$ is:

$$
E=E^{0^{\prime}}+\frac{0.059}{n} \log \frac{c_{O}^{S}}{c_{R}^{S}}
$$


where $\mathrm{n}$ is the number of transferred electrons, $\mathrm{E}$ is the applied potential $(\mathrm{V}), \mathrm{E}^{0}$, is the formal redox potential, and $\mathrm{C}^{\mathrm{S}}$ is the surface concentration of the electroactive species.

$\mathrm{CC}$ is widely applicable to measuring the electrode surface area, concentration, kinetics of heterogeneous electron transfer reaction and chemical reactions coupled to electron transfer, diffusion coefficients, adsorption, and the effective time constant of an electrochemical cell.

In this research, $\mathrm{CC}$ was used in a single potential step experiment. $\mathrm{CC}$ was used during the electrochemical deposition of Au nanostructures with different size and shape from the solution of $0.5 \mathrm{M} \mathrm{H}_{2} \mathrm{SO}_{4}$ plus $5 \times 10^{-5} \mathrm{M} \mathrm{HAuCl}_{4}$. By varying the final potential, the amount of charge, and the concentration of $\mathrm{HAuCl}_{4}$ solutions, we were able to deposit NPs with controlled size and shape. Figure 2.15 shows a typical plot of the $\mathrm{CC}$ of electrochemical deposition of Au NPs from a solution of $0.5 \mathrm{M} \mathrm{H}_{2} \mathrm{SO}_{4}$ plus $5 \times 10^{-5} \mathrm{M}$ $\mathrm{HAuCl}_{4}$ during a step from $1.0 \mathrm{~V}$ to $-0.2 \mathrm{~V}$ with the passed charge of $6 \times 10^{-4} \mathrm{C}$. Figure 2.16 shows a scheme of the process of electrochemical deposition of Au NPs using CC applying different charge (Q). Charge is a critical variable in the controlled-size and shape deposition processes. With the increasing of the passing charge, the size of NPs increases.

\subsubsection{Ultraviolet-Visible Spectroscopy (UV-vis) and Localized Surface Plasmon Resonance (LSPR)}

UV-vis spectroscopy measures the absorbance of light in the ultraviolet-visible spectral region by a sample. UV-vis data were obtained using a Varian Cary 50 Bio UVvisible Spectrophotometer. This instrument analyzed compounds in the ultraviolet (UV) 


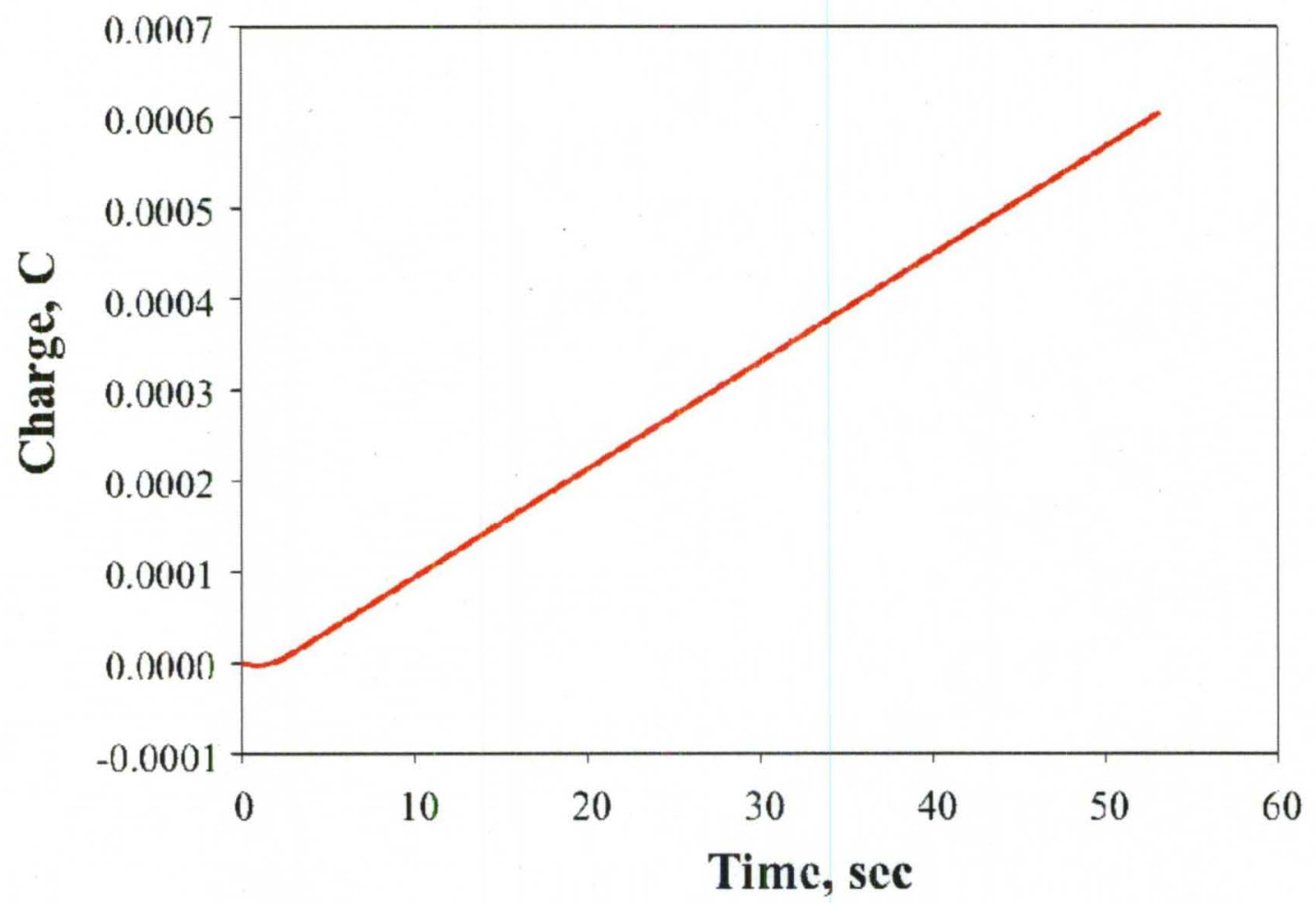

Figure 2.15. Typical CC plot of the experiment of electrochemical deposition of $\mathrm{Au}$ NPs from the solution of $0.5 \mathrm{M} \mathrm{H}_{2} \mathrm{SO}_{4}$ plus $5 \times 10^{-5} \mathrm{M} \mathrm{HAuCl}_{4}$ at a potential step from $1.0 \mathrm{~V}$ to $-0.2 \mathrm{~V}$ with a passed charge of $6 \times 10^{-4} \mathrm{C}$. 


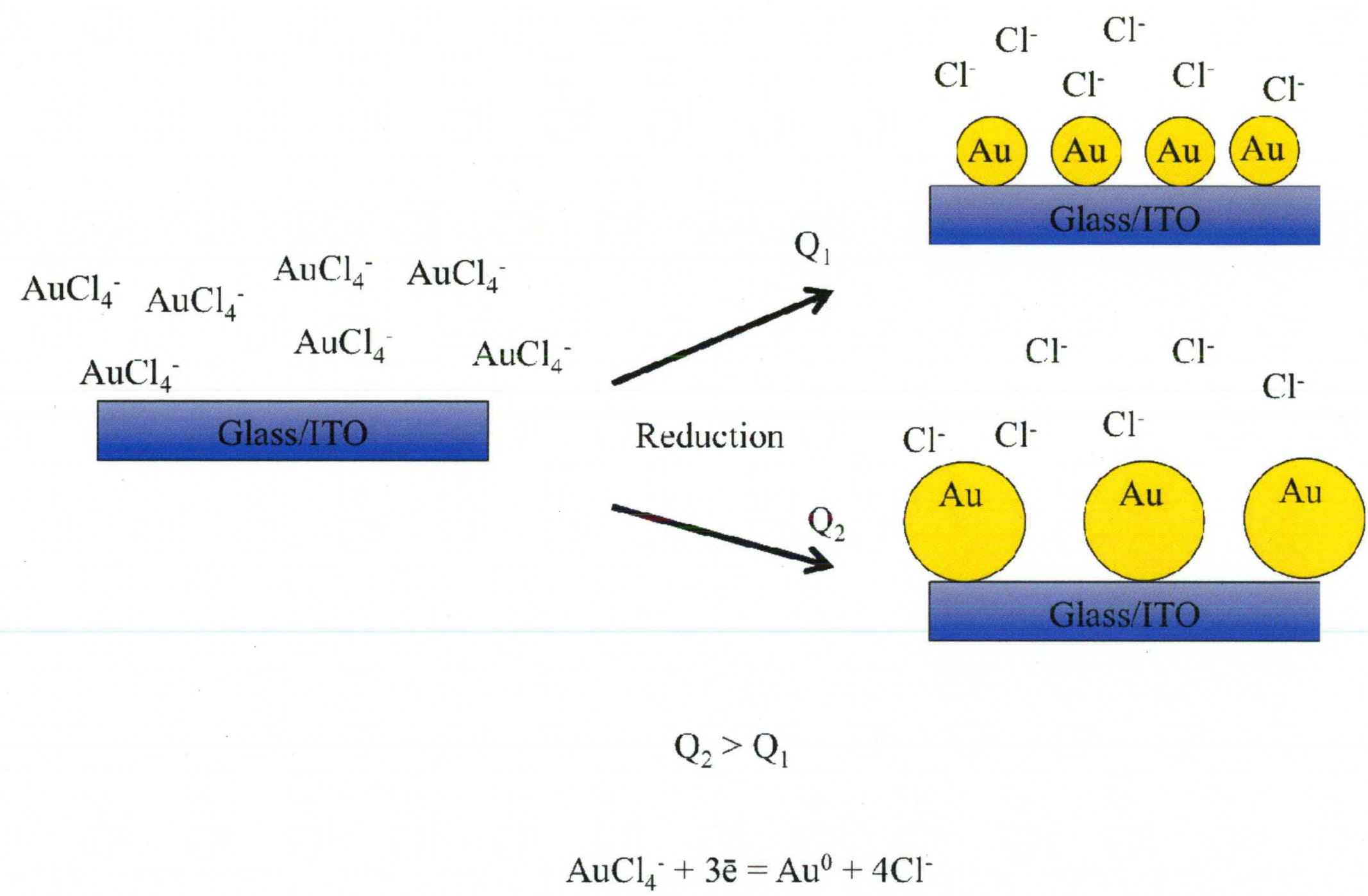

Figure 2.16. Scheme of the process of electrochemical deposition of Au NPs using Chronocoulometry (CC) applying different charge (Q). 
and visible (Vis) regions of the electromagnetic spectrum. It determines the transmittance of the sample by calculating the ratio of the intensity of the light passed through the sample $(I)$ and the light intensity before it passed through the sample $\left(I_{0}\right)$. The absorbance A is based on the transmittance:

$$
\mathrm{A}=-\log (\mathrm{T}) \quad(\mathrm{Eq} .2 .7)
$$

UV-vis spectroscopy also allows one to determine the wavelength and maximum absorbance of compounds.

In this research, we measured the absorbance of the $\mathrm{Au}$ nanostructures in solutions and also attached to the substrate, either glass/ITO or glass/ITO/APTES electrodes. They absorb strongly in the visible region due to the localized surface plasmon resonance $(\mathrm{LSPR})$ band at $\sim 520-550 \mathrm{~nm}$. The dimensions of the nanoparticles are much smaller than the incident wavelength, which leads to the oscillation of the plasmon around the nanoparticle. A typical UV-vis spectrum of Au NPs $(11 \mathrm{~nm})$ attached to the surface of a glass/ITO/APTES electrode is presented in Figure 2.17.

\subsubsection{Scanning Electron Microscopy (SEM)}

The scanning electron microscope uses a focused beam of high-energy electrons to generate a variety of signals at the surface of a solid conductive specimen. The signal reveals information about the topography, morphology, and some information about the electronic conductance of the specimen. It can give 3D images with the spatial resolution to $5 \mathrm{~nm}$.

The scanning electron microscope consists of: ${ }^{103}$

- Electron gun 


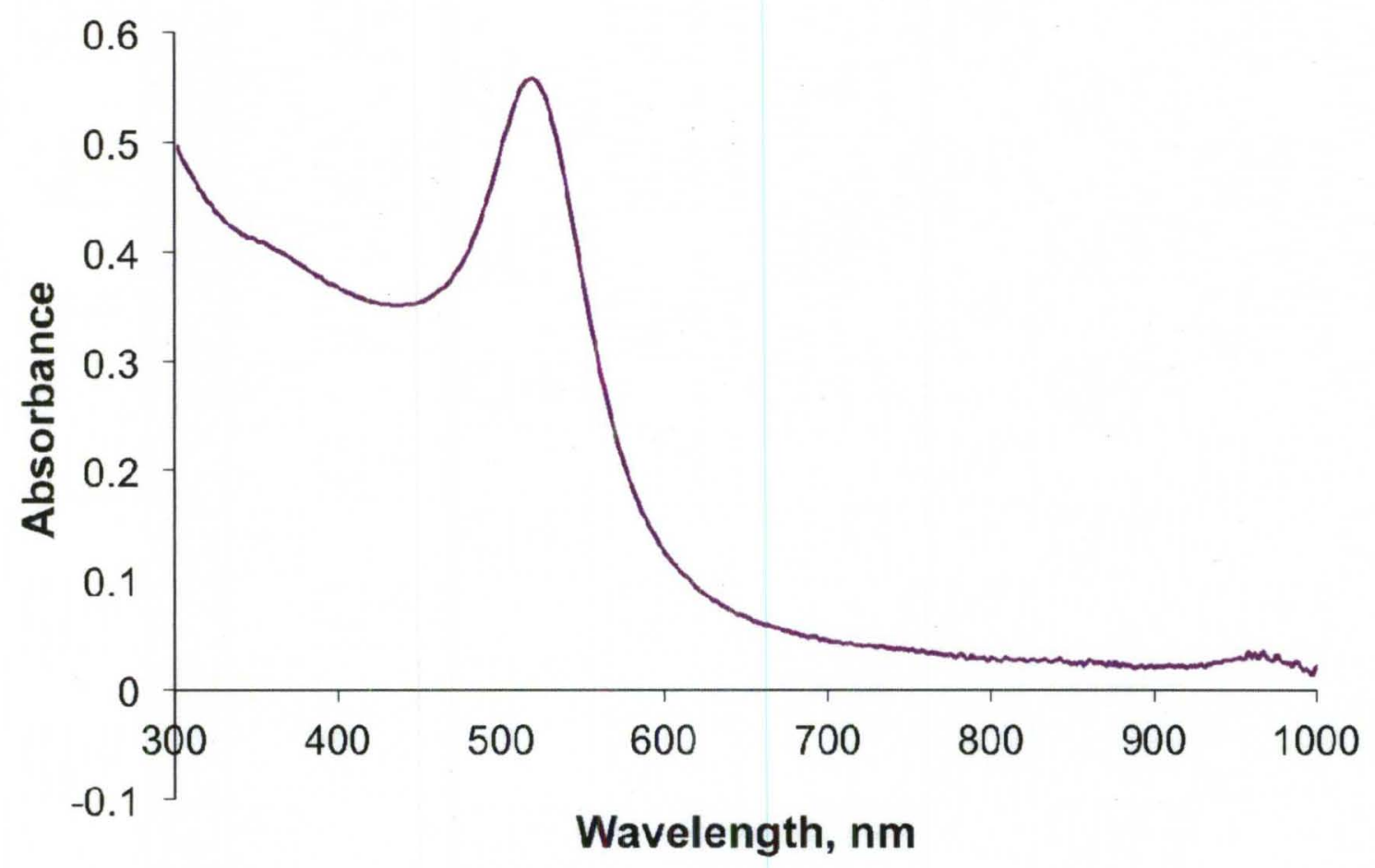

Figure 2.17. Typical UV-vis spectra of Au NPs $(11 \mathrm{~nm})$ attached to the surface of glass/ITO/APTES electrode. 
- Lenses (condenser and objective)

- Apertures

- Controls for specimen position

- An area of beam/specimen interaction

- Detectors for all signals of interest

Infrastructure Requirements:

- Power supply

- Vacuum system

- Cooling system

- Vibrational-free floor

- Room free of ambient magnetic and electric fields

The electron beam follows a vertical path through the microscope, which is held within a vacuum. The beam goes through electromagnetic fields and lenses. Then the beam is focused down toward the sample and electrons and X-rays are ejected from the sample. Figure 2.18 shows a scheme of the interaction of the electron beam with a sample and a typical SEM image of Au NPs deposited on the surface of a glass/ITO electrode. The SEM detects secondary electrons, and backscattered electrons and converts them into a signal which is transferred to a screen and produces the final image.

In this work, SEM images of Au NPs attached to the substrate (glass/ITO or glass/ITO/APTES) were collected by a Carl Zeiss STM AG Supra 35VP field emission scanning electron microscope (FESEM) operating at an acceleration voltage of $20 \mathrm{kV}$ and using an in-lens ion annular secondary electron detector. 

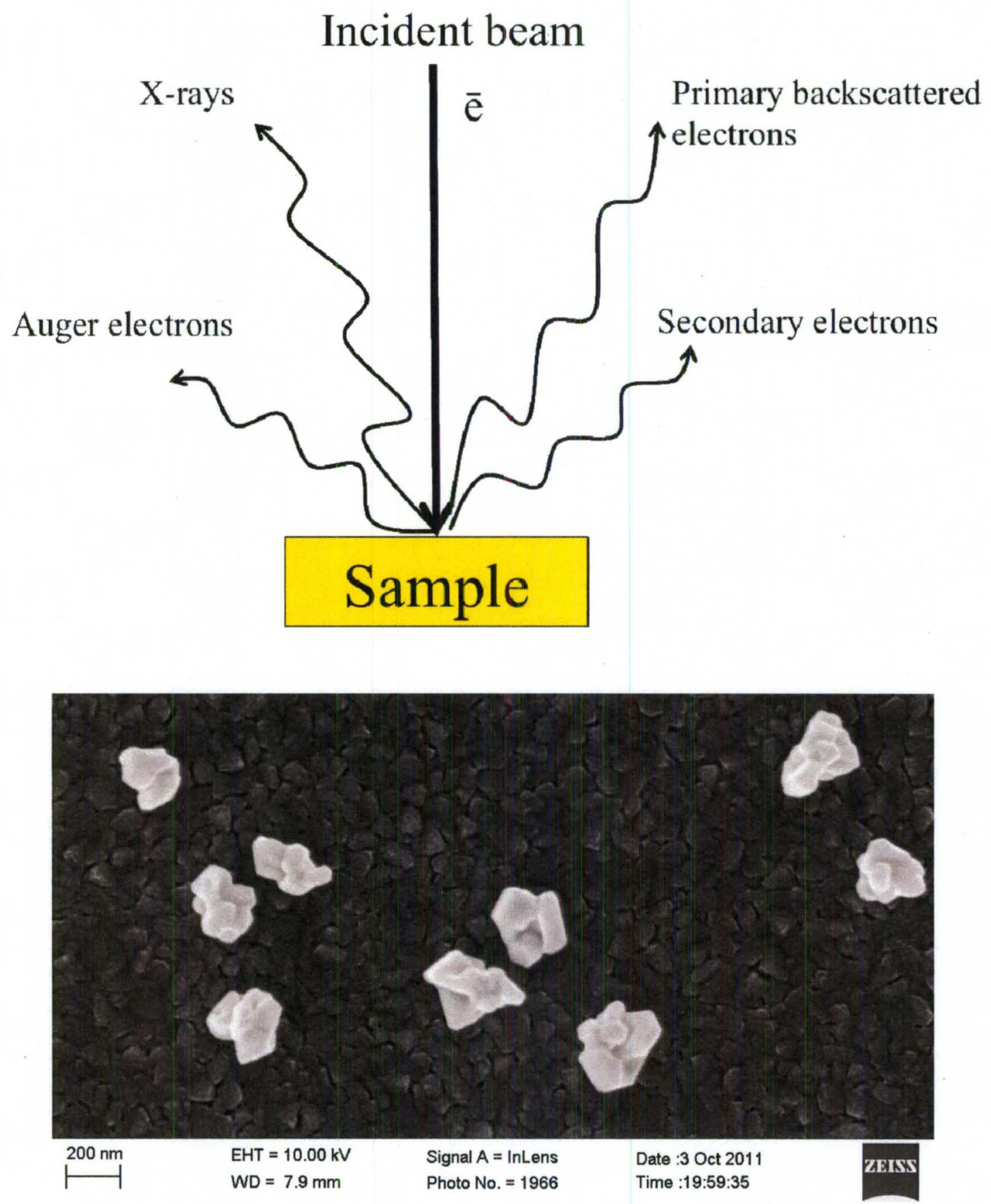

Figure 2.18. Scheme of beam/sample interactions and typical SEM image of Au NPs attached to the surface of a glass/ITO electrode. 


\section{CHAPTER III}

\section{SIZE-DEPENDENT ELECTROCHEMICAL OXIDATION OF CHEMICALLY SYNTHESIZED GOLD NANOPARTICLES}

\subsection{INTRODUCTION}

Here we describe the electrochemical oxidation of Au NPs as a function of size. Au NPs were prepared chemically in solution with average diameters from 4 to $73 \mathrm{~nm}$. They were electrostatically attached to amino-functionalized glass/ITO electrodes. Linear sweep voltammograms (LSVs) from 0.0 to $1.6 \mathrm{~V}$ in $0.01 \mathrm{M} \mathrm{KBr}$ plus $0.1 \mathrm{M} \mathrm{HClO}_{4}$ showed a positive shift in the oxidation Au peak potential (Ep) from $741 \pm 3 \mathrm{mV}$ to $843 \pm 12 \mathrm{mV}$ with increasing Au NP diameter at a constant coverage. Understanding the size-dependent thermodynamics of metal oxidation is very important, considering the numerous applications of metal nanostructures. Understanding the kinetic and thermodynamic properties of metal nanostructures is very important due to their numerous applications in catalysis, sensing, plasmonics and nanoelectronics. One of the important parameters on which the properties of nanoparticles (NPs) depend is their size. Many scientists all over the world are studying various size-dependent properties of metal NPs, including optical properties, conductivity, hardness, melting point, 
and quantum effects. The redox potential of a metal $\left(\mathrm{M}^{0} / \mathrm{M}^{\mathrm{n}+}\right)$ is one important property that has been predicted to shift negative with decreasing NP size. It was theoretically described and proven experimentally. ${ }^{13,62}$ In the theories of Henglein and Plieth, the redox potential will be negatively shifted with a decreasing number of atoms in the metal clusters. ${ }^{57,58}$ It can be explained by the difference in the surface free energy between the atoms of bulk metal and NPs with a small size. ${ }^{58}$ Also, Henglein provided calculations of the standard reduction potential for Ag clusters with different numbers of atoms based on sublimation energies. It was found that there is a big difference in $\mathrm{E}^{0}$ of $-1.8 \mathrm{~V},-1.0 \mathrm{~V}$, and $+0.799 \mathrm{~V}$ vs. $\mathrm{NHE}$, for $\mathrm{Ag}_{1}, \mathrm{Ag}_{2}$, and $\mathrm{Ag}$ bulk, respectively.

Compton and co-workers described oxidative stripping of Ag NPs from 25 to 100 $\mathrm{nm}$ attached to a basal plane pyrolytic graphite electrode in $0.1 \mathrm{M} \mathrm{NaClO}_{4},{ }^{59}$ but found no dependence of oxidation on the size of the NPs over this range. Another Compton study of stripping voltammetry described the potential shift of hemispherical deposits of bismuth attached to a single crystal $\mathrm{Au}(111)$ electrode under electrochemically irreversible conditions. ${ }^{60}$ It was concluded that the difference in voltammetry was caused mainly by the morphology/orientation of deposits, which leads to differences in the kinetics and thermodynamics of the process of stripping. ${ }^{60}$

Our group recently described the size-dependent oxidation of 1) chemically synthesized Ag NPs which were electrostatically attached to the surface of an aminefunctionalized glass/ITO working electrode, ${ }^{13}$ 2) Au NPs electrochemically deposited on glass/ITO electrodes, ${ }^{62}$ and 3) chemically synthesized Au NPs below $4 \mathrm{~nm}$ attached to glass/ITO. ${ }^{104}$ The potential of oxidation shifted negative with decreasing NPs size as 
predicted by Plieth with a 1/radius dependence. Agreement with theory was better for Au than Ag.

Here we describe the oxidation of chemically-synthesized Au NPs with diameter 4 to $73 \mathrm{~nm}$. We previously described the oxidation of electrochemically-deposited Au NPs from 8 to $250 \mathrm{~nm}^{62}$ and chemically-synthesized Au NPs below $4 \mathrm{~nm}^{104}$ The range covered here will allow us to fill the gap for chemically-synthesized Au NPs from $4 \mathrm{~nm}$ to bulk and determine if chemically-synthesized Au NPs behave different than electrochemically-synthesized Au NPs of the same size.

\subsection{EXPERIMENTAL DETAILS}

The chemical synthesis of Au NPs, their oxidation and their characterization by UV-vis and SEM is described in Chapter II.

\subsection{RESULTS AND DISCUSSON}

3.3.1. Optical Characterization. Figure 3.1 shows a photograph of the solutions of different-sized Au NPs synthesized by the different methods. The color of the solution changed from light pink to a cloudy reddish-brown with increasing Au NP size. We characterized the different Au NPs in solution by UV-vis spectroscopy as shown in Figure 3.2 where the solution of $4 \mathrm{~nm}$ Au NPs was diluted by a factor of 3. Samples were prepared and placed into $1 \mathrm{~cm}$ glass cuvettes for measurement of their absorbance spectrum. Figure 3.2 shows that the localized surface plasmon band (LSPR) of Au NPs shifts and becomes more intense with increasing NPs size. The peak appeared at $518 \mathrm{~nm}$ 


\section{$4 \pm 1 \mathrm{~nm} \quad 15 \pm 7 \mathrm{~nm} \quad 31 \pm 14 \mathrm{~nm} \quad 73 \pm 19 \mathrm{~nm}$}

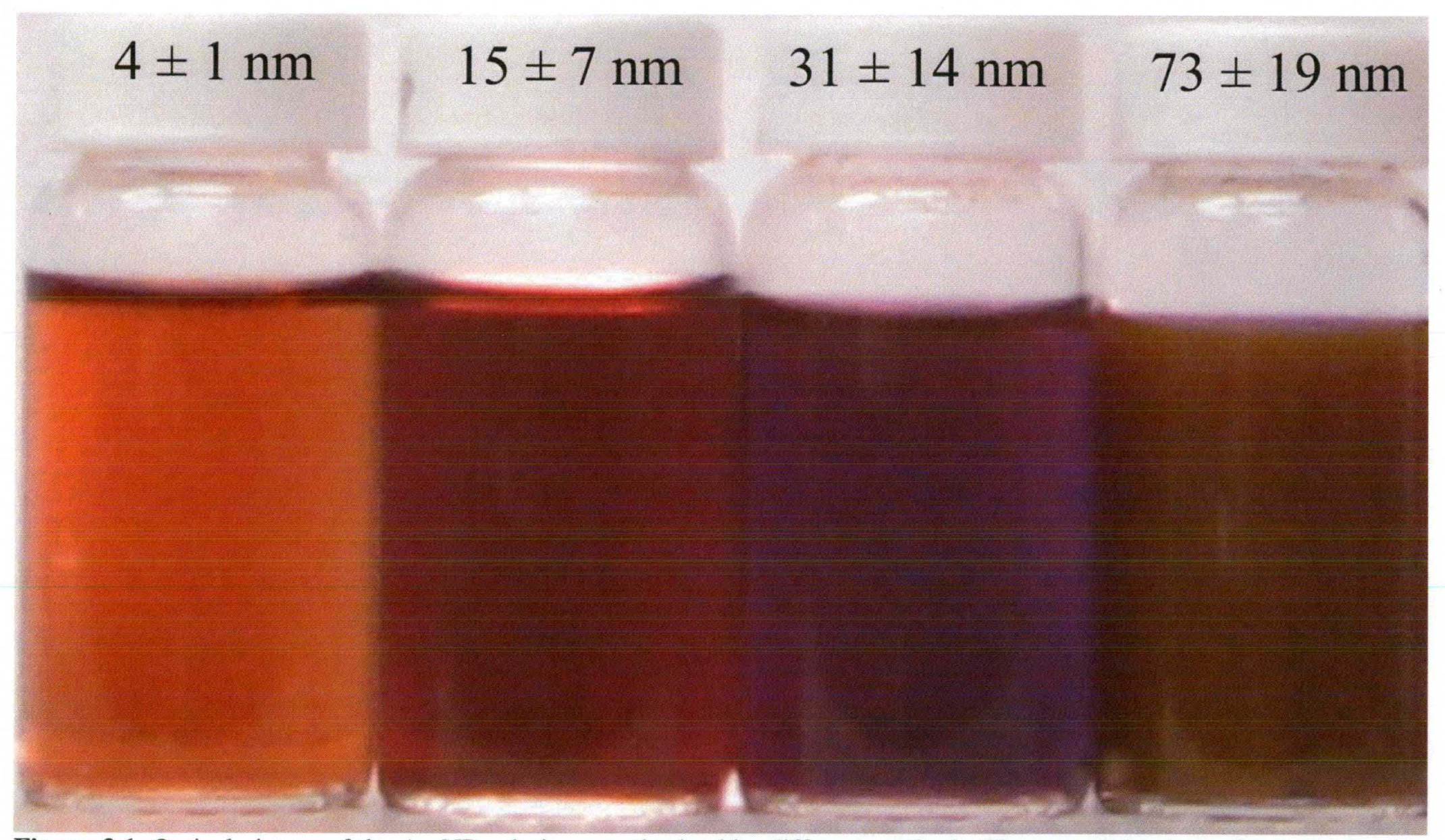

Figure 3.1. Optical picture of the Au NP solutions synthesized by different methods. The more intensive color corresponds to the bigger size of NP. 


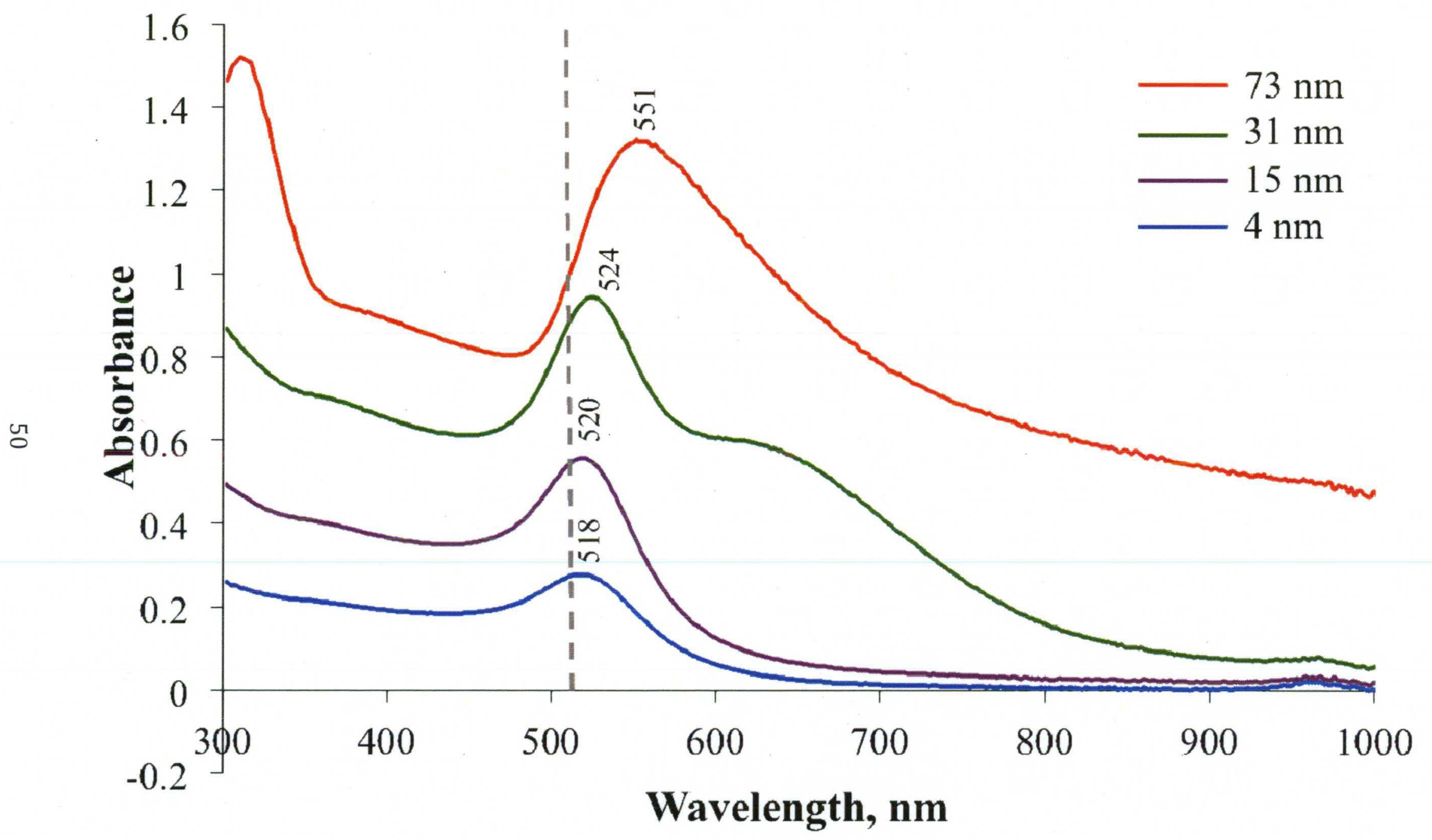

Figure 3.2. UV-visible spectra of the solutions with Au NPs. 
for the seeds and $551 \mathrm{~nm}$ for particles with average diameter $73 \mathrm{~nm}$. The LSPR band significantly broadens for the NPs of $31 \mathrm{~nm}$ and $73 \mathrm{~nm}$ and is more red-shifted. It can be explained by the formation of NPs with different sizes. This data corresponds well to Mie's theory about the absorbance/scattering of nanoparticles with spherical shape as a function of size. ${ }^{105}$

3.3.2. Microscopy. The average size of synthesized Au NPs was determined by SEM after electrostatic attachment to the surface of a glass/ITO/APTES electrode. Figure 3.4 shows typical SEM images of four different samples with different sizes. Frame A shows a SEM image of $4 \pm 1 \mathrm{~nm}$ Au "seeds". They are almost invisible because the SEM resolution is larger than the average size of the seed. Frames B and D show samples with average sizes of $15 \mathrm{~nm}$ and $73 \mathrm{~nm}$, respectively, prepared with a $\mathrm{Au}^{+} / \mathrm{Au}$ ratio of 10 and 100, respectively. In Frame $C$ the average size of the Au NPs is $31 \mathrm{~nm}$. They were prepared by heating $\mathrm{HAuCl}_{4}$ and the trisodium cirate salt with no seeds. The Au NPs are isolated and well-spaced, showing no aggregation. Figure 3.3 shows a scheme of the experiment.

3.3.4. Electrochemical Characterization. Figure 3.5 shows the background LSV of a glass/ITO/APTES electrode in the range from $0.0 \mathrm{~V}$ to $1.6 \mathrm{~V}$ at $20 \mathrm{mV} / \mathrm{s}$ in $0.1 \mathrm{M}$ $\mathrm{HClO}_{4}$ only and in $10 \mathrm{mM} \mathrm{KBr}$ plus $0.1 \mathrm{M} \mathrm{HClO}_{4}$. There are no peaks that interfere with Au oxidation in this range of potentials.

Ivanova recently showed for the first time the size-dependent oxidation of Au NPs electrochemically deposited on glass/ITO electrodes. ${ }^{62}$ The amount of metal NPs was kept constant at around $2.86( \pm 0.05) \times 10^{-4} \mathrm{C}$. The size of Au NPs varied from 8 to $250 \mathrm{~nm}$ 

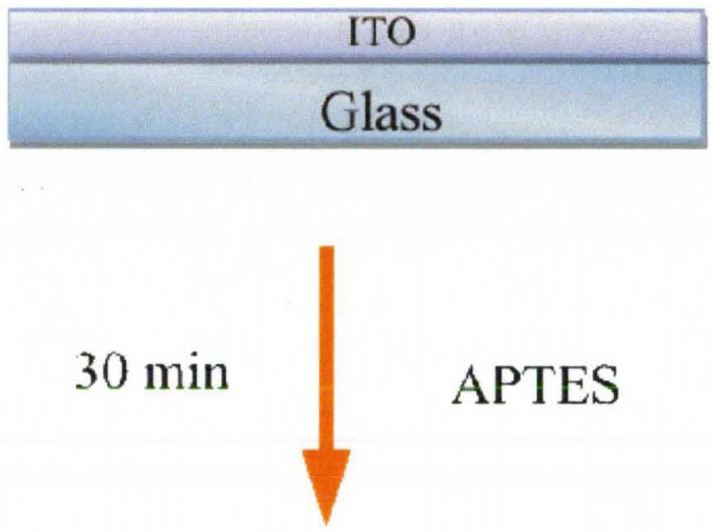

N

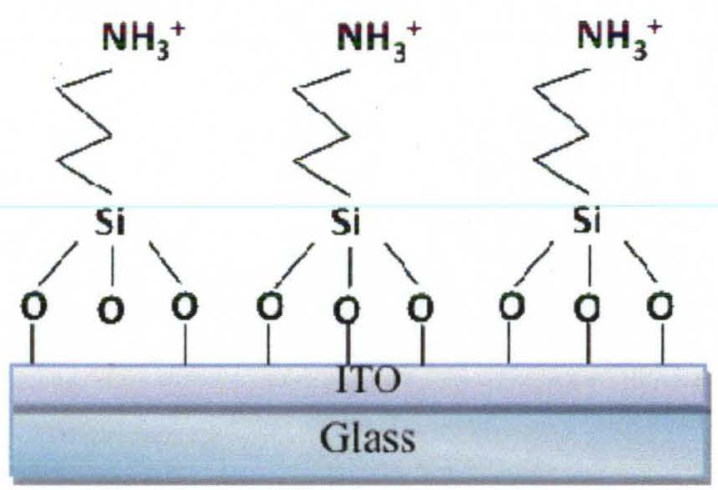

Rinse with isopropanol, NANOpure water and dry under $\mathrm{N}_{2}$, place into $\mathrm{Au}$ NPs solution

Figure 3.3. Scheme of SEM experiment.

\section{SEM}

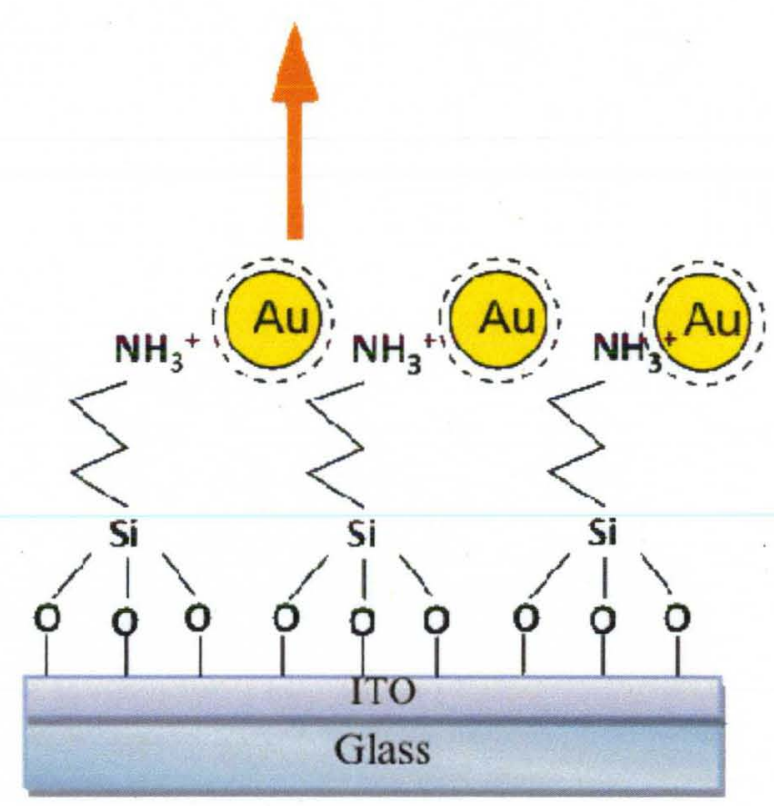




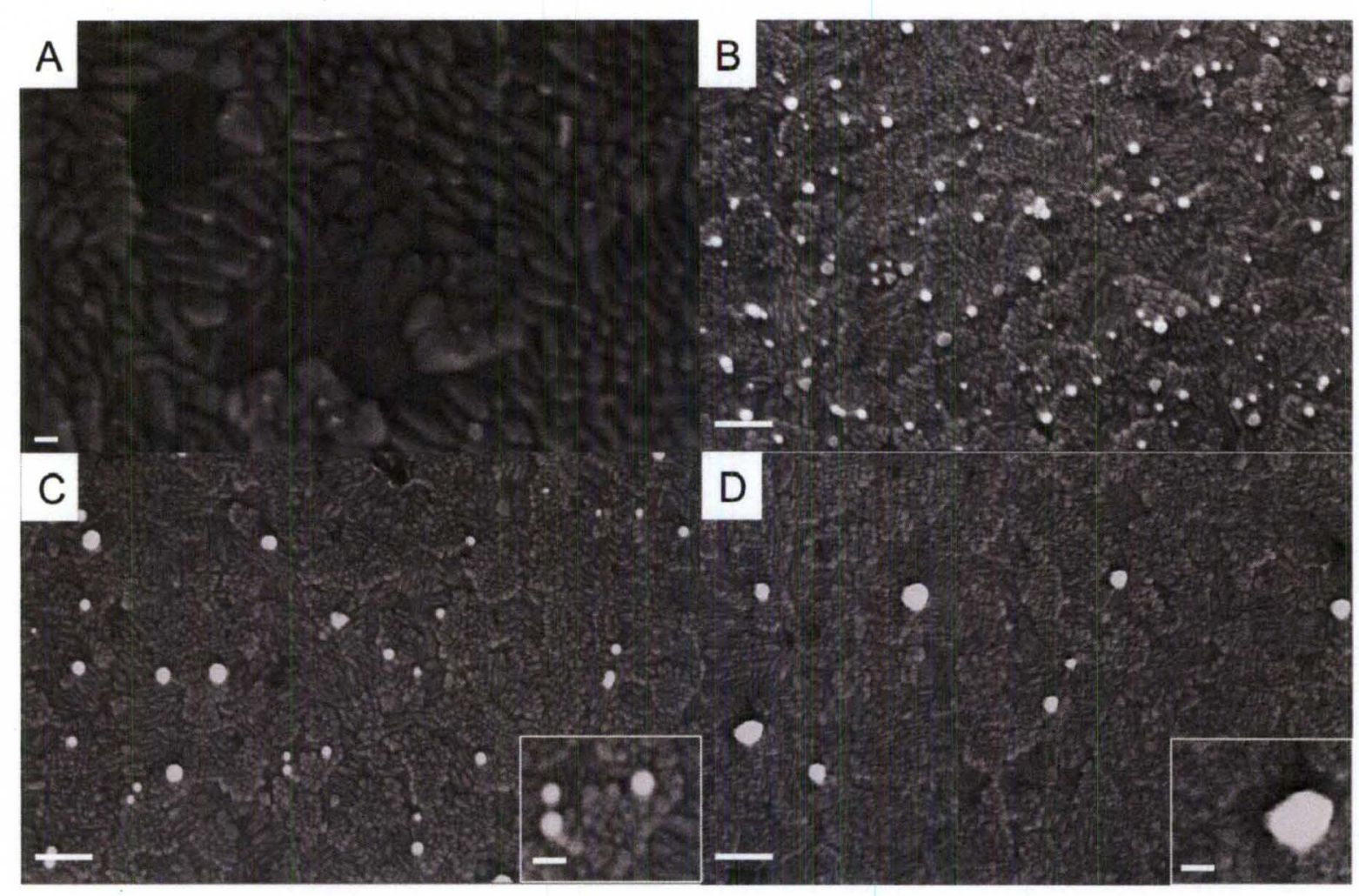

Figure 3.4. SEM images of Glass/ITO/APTES-functionalized electrodes coated with Au NPs prepared by different methods: (A) Au seeds of $4 \pm 1 \mathrm{~nm}$ diameter; (B) Au NPs synthesized by seed-mediated growth using $\mathrm{Au}^{+} / \mathrm{Au}$ seed ratio of 10 and (D) 100 with average diameter of $15 \pm 7 \mathrm{~nm}$ and $73 \pm 19 \mathrm{~nm}$, respectively; (C) Au NPs grown from $\mathrm{HAuCl}_{4}$ with trisodium citrate with an average diameter of $31 \pm 14 \mathrm{~nm}$. The scale bars for frames (B), (C), (D) are $200 \mathrm{~nm}$, for (A) $20 \mathrm{~nm}$ and in the insets in (C) and (D) they are 50 nm. 


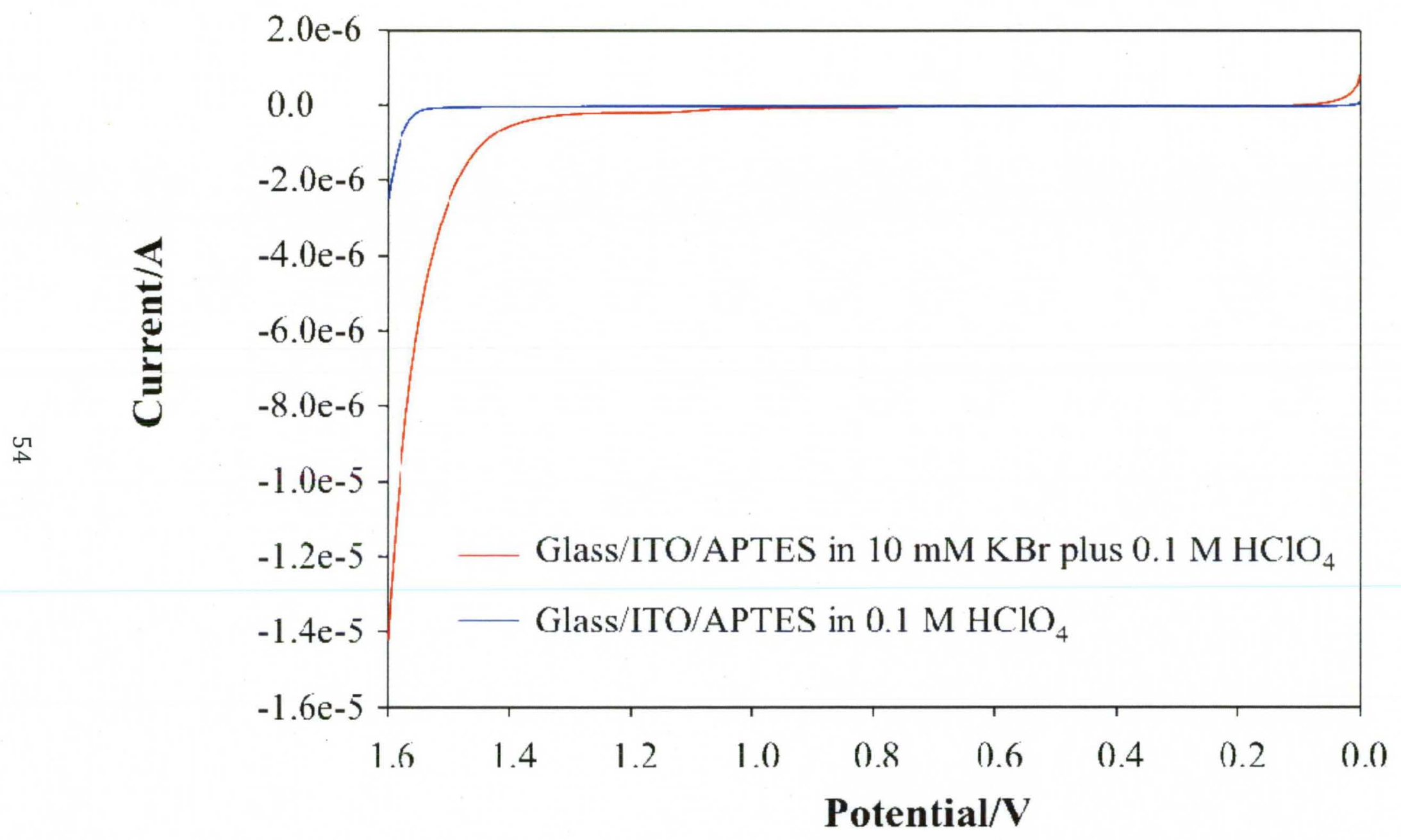

Figure 3.5. Background LSV of glass/ITO/APTES electrode in $0.1 \mathrm{M} \mathrm{HClO}_{4}$ only and in $10 \mathrm{mM} \mathrm{KBr}$ plus $0.1 \mathrm{M} \mathrm{HClO}_{4}$. 
and the potential of oxidation was negatively shifted from 913 to $822 \mathrm{mV}$ with decreasing NP size.

The shift in oxidation potential agreed well with the predicted shift in redox potential based on Plieth's theory. This is explained by the change in free energy associated with the difference in surface energy as a function of the size of the particle.

In this work we kept the same amount of Au NPs on the electrode surface in order to make a comparison of the oxidation potentials of Au NPs chemically-synthesized and electrochemically-deposited. We obtained linear sweep volammograms (LSVs) from 0.0 $\mathrm{V}$ to $1.6 \mathrm{~V}$ in $10 \mathrm{mM} \mathrm{KBr}$ in $0.1 \mathrm{M} \mathrm{HClO}_{4}$ at $1.0 \mathrm{mV} / \mathrm{s}$ of Glass/ITO/APTES electrodes coated with Au NPs with the different sizes. Figure 3.6 shows LSVs in the range $0.0 \mathrm{~V}$ to $1.6 \mathrm{~V}$ for electrodes with different sizes of Au NPs $(4 \pm 1 \mathrm{~nm}, 15 \pm 7 \mathrm{~nm}, 31 \pm 14 \mathrm{~nm}$ and $73 \pm 19 \mathrm{~nm}$ ) with the average oxidation potentials of $741 \mathrm{mV}, 766 \mathrm{mV}, 782 \mathrm{mV}$, and 843 $\mathrm{mV}$, respectively. For the calculation average value were chosen at least three samples with the charge values between $2.7 \times 10^{-4} \mathrm{C}$ to $3.2 \times 10^{-4} \times 10^{-4} \mathrm{C}$. According to the LSV, with increasing of the size of Au NPs the broadness of the oxidation peak increases due to size dispersity in sample. There was a negative shift in the oxidation potential with decreasing Au NP average diameter as predicted and shown previously. The possible oxidation reactions are:

$$
\begin{array}{ll}
\mathrm{Au}^{0}+2 \mathrm{Br}^{-} \rightarrow \mathrm{AuBr}_{2}{ }^{-}+\mathrm{e}^{-} & \mathrm{E}_{\mathrm{Au}(\mathrm{I}) / \mathrm{Au}(0)}^{0}=0.963 \mathrm{~V} \text { vs NHE } \\
\mathrm{Au}^{0}+4 \mathrm{Br}^{-} \rightarrow \mathrm{AuBr}_{4}{ }^{-}+3 \mathrm{e}^{-} & \mathrm{E}_{\mathrm{Au}(\mathrm{III}) / \mathrm{Au}(0)}=0.858 \mathrm{~V} \text { vs NHE }
\end{array}
$$

There is also a possible chemical step:

$$
\mathrm{AuBr}_{4}{ }^{-}+2 \mathrm{Au}^{0}+2 \mathrm{Br}^{-} \rightarrow 3 \mathrm{AuBr}_{2}^{-}
$$




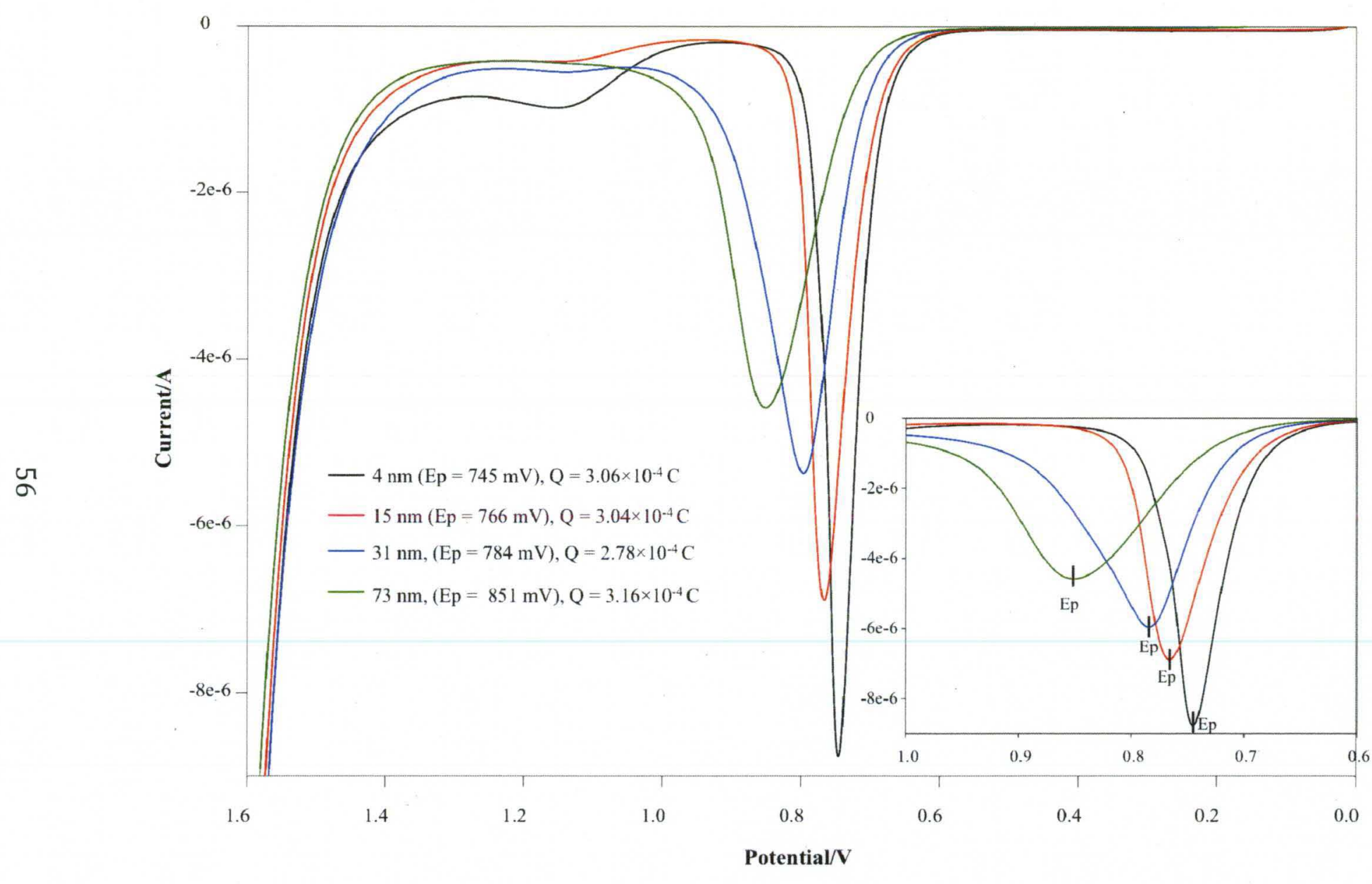

Figure 3.6. Linear Sweep Voltammograms obtained in $10 \mathrm{mM} \mathrm{KBr}$ plus $0.1 \mathrm{M} \mathrm{HClO}_{4}$ electrolyte at $1.0 \mathrm{mV} / \mathrm{s}$ of $1.4 \mathrm{~cm}^{2}$ Glass/ITO/APTES electrodes coated with chemically synthesized Au NPs as indicated. 
This shift was predicted by Plieth ${ }^{58}$ and shown by our group previously for chemically synthesized Ag NPs and electrochemically deposited Au NPs on the glass/ITO surface. According to this experimental data, the oxidation potential of chemically-synthesized Au NPs is lower than the oxidation potential of electrochemically deposited Au NPs with the same sizes and coverage. That means that 1) electrochemically-deposited Au NPs are physically different compared to chemically-synthesized Au NPs or 2) the different oxidation behavior is due to different NP/electrode interactions.

Table 3.1 shows the statistical data such as average diameter measured by SEM of the different sized Au NPs, peak potential, and charge under the peak calculated from the LSVs. At least 3 samples were analyzed. For the statistical calculations of the potential of the oxidation peak, we chose samples which had values of their charge ranging from $2.85 \times 10^{-4} \mathrm{C}$ to $3.10 \times 10^{-4} \mathrm{C}$. Figure 3.7 shows theoretical plots of the difference between the oxidation potential of bulk $\mathrm{Au}(\mathrm{Ep}$, bulk $\mathrm{Au})$ as a function of nanoparticle radius calculated using the following formula derived by Plieth. ${ }^{58}$

$$
\Delta E=E_{p, A u N P}-E_{p, b u l k A u}=\frac{-2 \gamma W_{m}}{z F} \times \frac{1}{r}
$$

where $E_{p, A u N P}$ is the peak potential of Au NPs $[V], E_{p, b u l k}$ Au is the peak potential of bulk

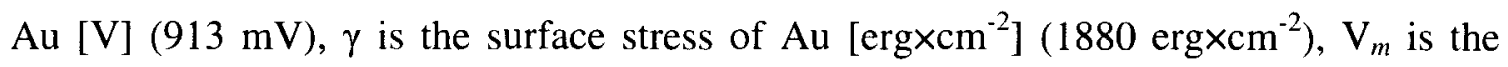
molar volume of $\mathrm{Au}\left[\mathrm{cm}^{3} \times \mathrm{mol}^{-1}\right], z$ is the number of electrons, $F$ is Faraday's constant [96485.34 ${\mathrm{C} \times \mathrm{mol}^{-1}}^{-1}$, and $r$ is the NP radius. We also present the experimental data of electrochemically-deposited Au NPs for comparison. The values of chemicallysynthesized Au NPs and electrochemically-deposited Au NPs are statistically different between each other. All of the average $E_{p}$ values shift positive with increasing Au NP 
Table 3.1. Statistical Size and Electrochemical Data for Glass/ITO/APTES/Au NP Electrodes

\begin{tabular}{|c|c|c|}
\hline $\begin{array}{c}\text { Diameter SEM } \\
(\mathbf{n m})\end{array}$ & $\begin{array}{c}\text { Experimental peak potential, Ep, exp } \\
{[\mathbf{m v}]}\end{array}$ & $\begin{array}{c}\text { Charge under the peak } \\
\left(* \mathbf{1 0} \mathbf{-}^{-4} \mathbf{C}\right)\end{array}$ \\
\hline $4( \pm 1)$ & $741( \pm 3)$ & $2.75( \pm 0.20)$ \\
\hline $15( \pm 7)$ & $766( \pm 2)$ & $3.13( \pm 0.19)$ \\
\hline $31( \pm 14)$ & $781( \pm 3)$ & $2.90( \pm 0.26)$ \\
\hline $73( \pm 19)$ & $842( \pm 11)$ & $2.80( \pm 0.32)$ \\
\hline
\end{tabular}




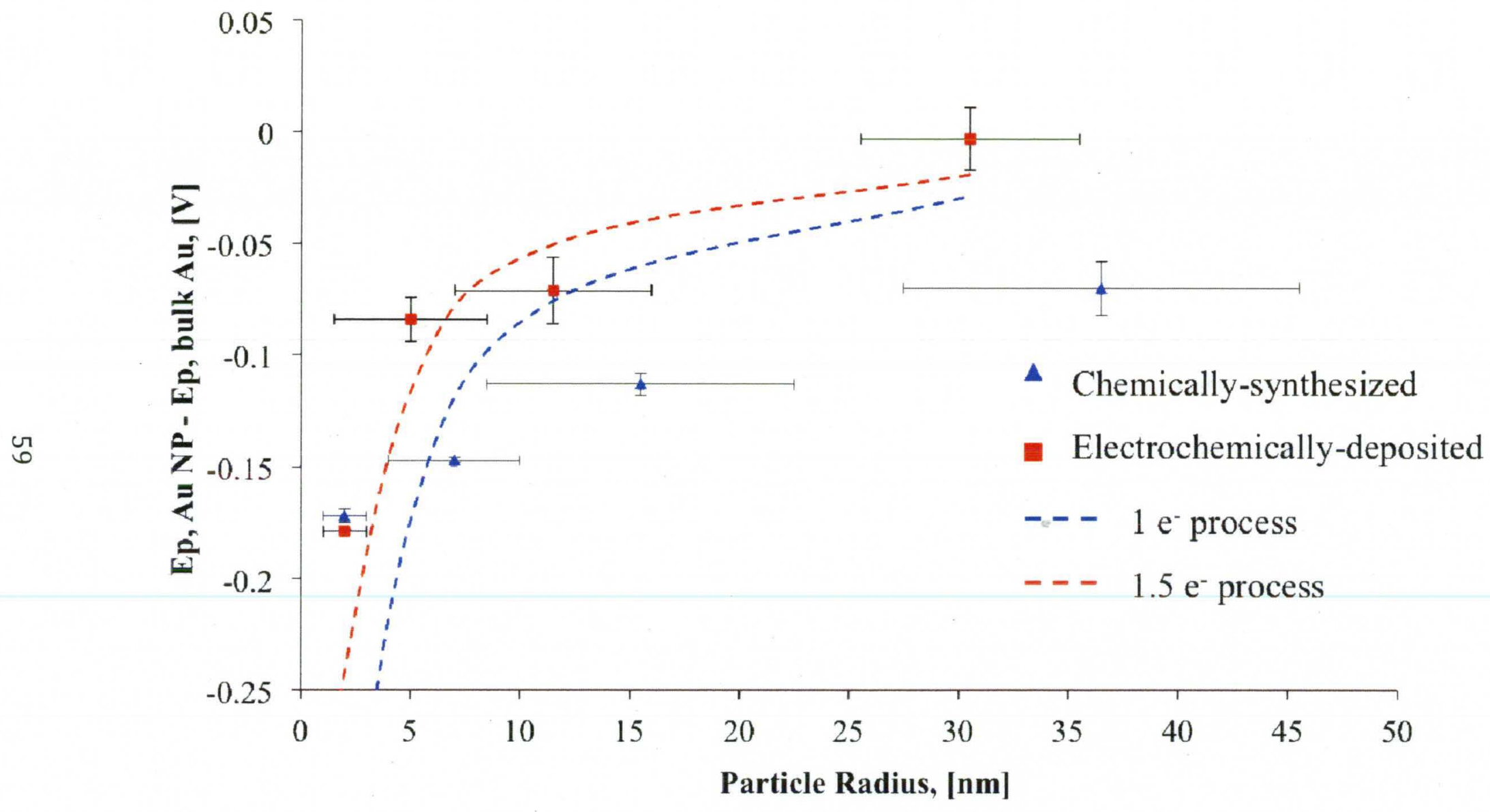

Figure 3.7. Experimentally measured shift in oxidation potential (blue triangles) for Au NPs versus bulk Au as a function of radius as compared to electrochemically-deposited Au NPs (red squares) and to theory (dashed line). Blue dashed line (1 electron process), red dashed line (1.5 electron process). 
diameter and are statistically different from one another. $\mathrm{E}_{\mathrm{p}}$ shifts $\sim 102 \mathrm{mV}$ from the smallest particles to the largest for chemically-synthesized NPs.

The theoretical values at different ratios of $\mathrm{Au}^{+} / \mathrm{Au}$ seed based on the equation:

$$
\mathrm{D}_{\mathrm{p}}=\mathrm{d}_{\mathrm{p} 0}\left(1+\mathrm{n}_{+} / \mathrm{n}_{\mathrm{s}}\right)^{1 / 3} \quad(\mathrm{Eq} \cdot 3 \cdot 1)
$$

were $d_{p}$ is the final diameter of the NP, $d_{p 0}$ is the diameter of the Au seed, and $n_{+} / n_{s}$ is the $\mathrm{Au}^{+} / \mathrm{Au}$ seed mole ratio used in the synthesis. The actual size of the Au NPs prepared with the $\mathrm{Au}^{+} / \mathrm{Au}$ seed mole ratio 10 is agree well with theoretical size, while the ratio $\mathrm{Au}^{+} / \mathrm{Au} 100$ theoretically is much bigger than the experimentally prepared.

For reversible systems, it has been shown that Ep for stripping an array of metal NPs shifts linearly with $\ln$ (metal coverage) in terms of metal atoms $/ \mathrm{cm}^{2}$, not metal NPs $/ \mathrm{cm}^{2}$. We also observed experimentally that for a constant NP size, Ep was directly proportional to $\ln (\mathrm{Au}$ coverage). Figure 3.8 shows the LSVs of Glass/ITO/APTES electrodes coated with $4 \pm 1 \mathrm{~nm}$ diameter Au seed NPs as a function of the coverage of $\mathrm{Au}$ controlled by varying the soaking time in $\mathrm{Au}$ seed solution. Table 3.2 shows the corresponding data obtained for Ep as a function of Au coverage as determined by charge under the stripping peak. The inset of Figure 3.8 shows a plot of Ep versus $\ln$ (coverage). The experimental plot is linear. We tested different times of soaking from 1 to 15 minutes and different dilutions of $\mathrm{Au}$ seed solution with water $(1: 9,1: 25 ; 1: 50)$. The summation of all experiments is presented in the inset of Figure 3.8 .

We kept the total coverage of $\mathrm{Au}$ on the electrode surface constant within $\sim 3 \times 10^{-4}$ coulombs (C) and also observed that Ep shifts positive with increasing scan rate, as predicted previously. Figure 3.9 shows LSVs of glass/ITO/APTES functionalized electrodes covered with $4 \mathrm{~nm}$ Au NPs recorded in $10 \mathrm{mM} \mathrm{KBr}$ plus $0.1 \mathrm{M} \mathrm{HClO}_{4}$ at 


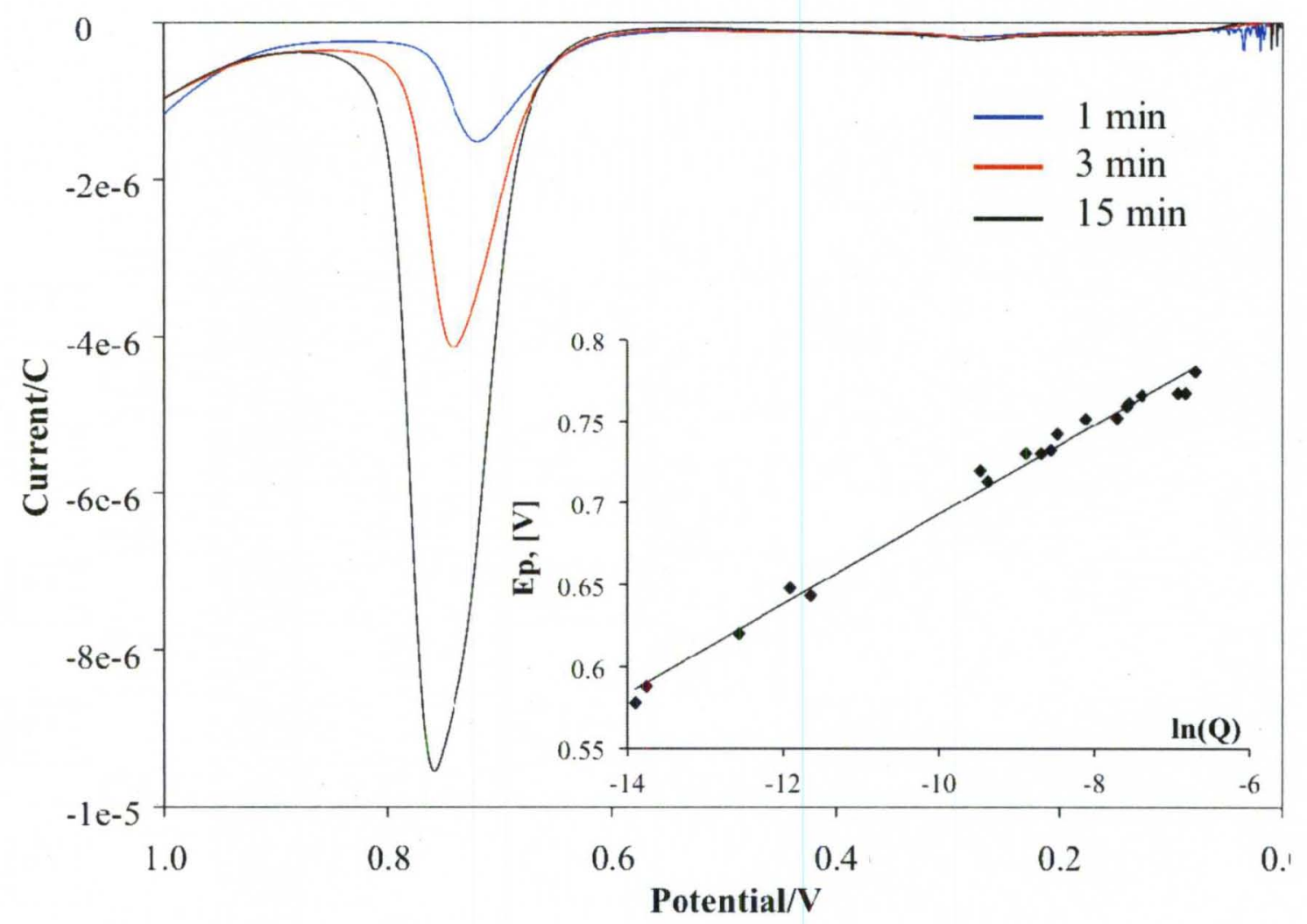

Figure 3.8. $\mathrm{LSV}$ in $10 \mathrm{mM} \mathrm{KBr}$ plus $0.1 \mathrm{M} \mathrm{HClO}_{4}$ electrolyte at $1 \mathrm{mV} / \mathrm{s}$ from $0 \mathrm{~V}$ to $1.0 \mathrm{~V}$ of Glass/ITO/APTES electrodes coated with $4 \pm 1 \mathrm{~nm}$ diameter Au NPs by soaking in the solution for $1 \mathrm{~min}$ (blue), $3 \mathrm{~min}$ (red) and $15 \mathrm{~min}$ (black). Inset shows the plot of Ep versus $\ln (\mathrm{Q})$, which is expected to be linear for reversible kinetics. 
Table 3.2. Ep for Au seed NPs as a function of coverage.

\begin{tabular}{|c|c|c|c|}
\hline $\begin{array}{l}\text { Soaking time in Au } \\
\text { seed solution, [min] }\end{array}$ & Coverage or Charge $(\mathbf{Q})$ in Coulombs $(C)$ & $\ln (\mathbf{Q})$ & $\begin{array}{c}\text { Ep, } \\
{[\mathrm{mV}]}\end{array}$ \\
\hline 1 & $7.68( \pm 0.10) \times 10^{-5}$ & -9.47 & 720 \\
\hline 3 & $2.06( \pm 0.02) \times 10^{-4}$ & -8.49 & 742 \\
\hline 15 & $5.08( \pm 0.05) \times 10^{-4}$ & -7.59 & 759 \\
\hline
\end{tabular}




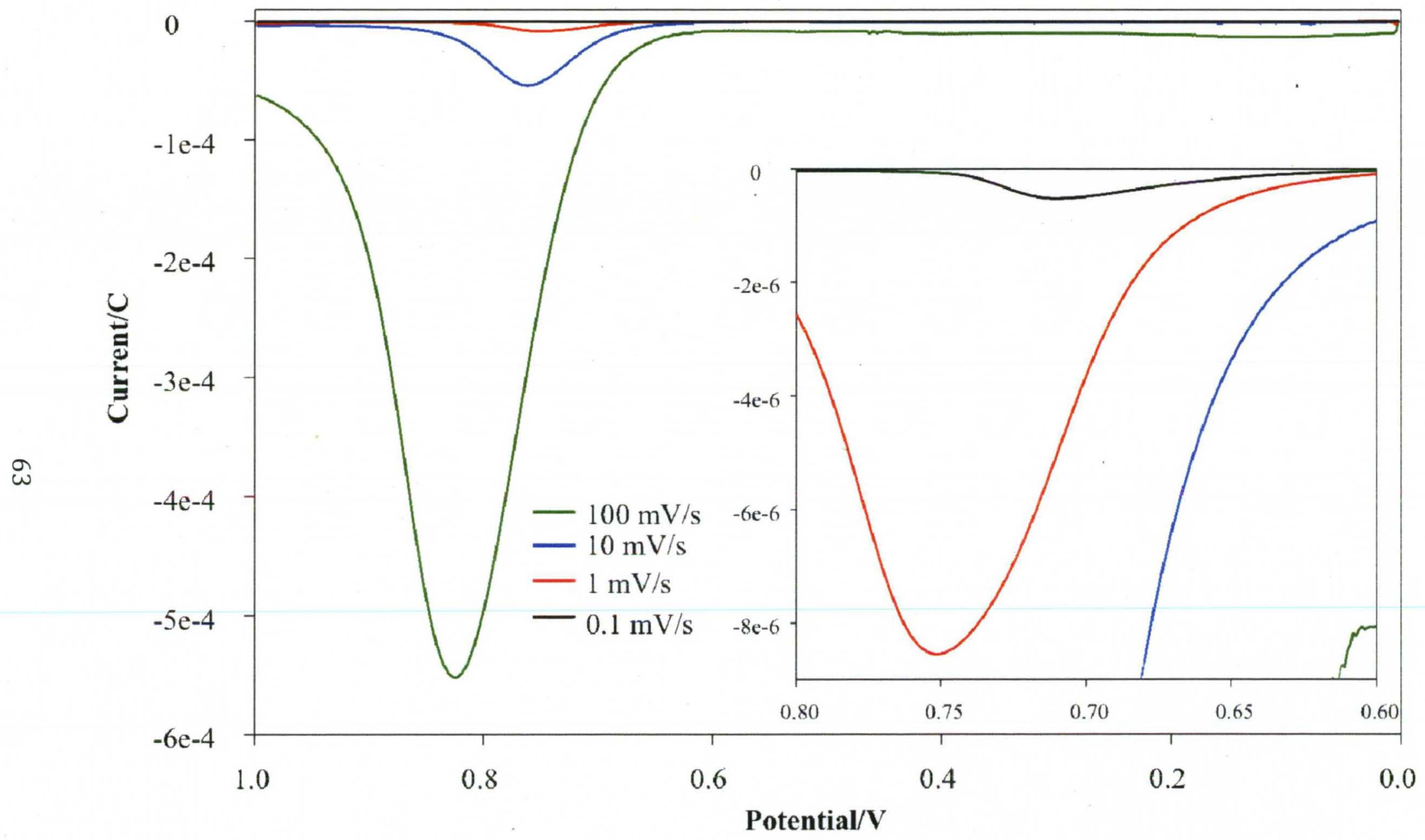

Figure 3.9. LSVs in $10 \mathrm{mM} \mathrm{KBr}$ plus $0.1 \mathrm{M} \mathrm{HClO}_{4}$ from $0.6 \mathrm{~V}$ to $1.0 \mathrm{~V}$ of Glass/ITO/APTES electrodes coated with Au seed NPs (soaking time 15 minutes obtained at different scan rates: $100 \mathrm{mV} / \mathrm{s}$ (green), $10 \mathrm{mV} / \mathrm{s}$ (blue), $1 \mathrm{mV} / \mathrm{s}$ (red), $0.1 \mathrm{mV} / \mathrm{s}$ (black). Inset shows the zoomed in area of the Figure 3.9. 
Table 3.3. Ep for Au NPs as a function of scan rate.

\begin{tabular}{|c|c|c|c|}
\hline Scan rate, $\mathbf{m V} / \mathbf{s}$ & In (scan rate) & Ep, $[\mathbf{m V}]$ & Charge, $\mathbf{Q},[\mathbf{C}]$ \\
\hline 0.1 & -2.30 & 710 & $2.635 \times 10^{-4}$ \\
\hline 1 & 0 & 752 & $3.195 \times 10^{-4}$ \\
\hline 10 & 2.30 & 762 & $2.781 \times 10^{-4}$ \\
\hline 100 & 4.61 & 824 & $2.826 \times 10^{-4}$ \\
\hline
\end{tabular}



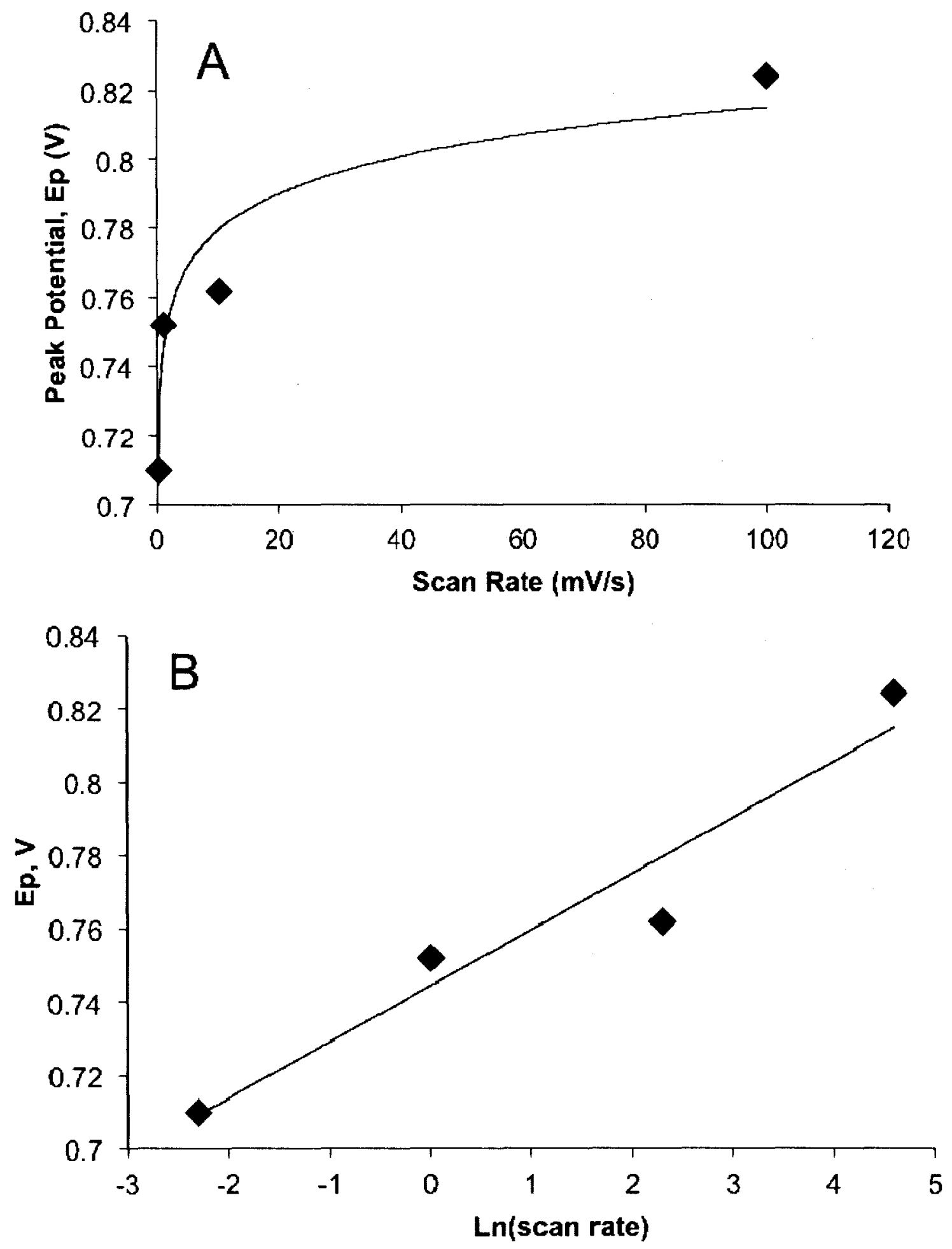

Figure 3.10. Plot of peak potential (Ep) versus (A) scan rate and (B) $\ln ($ scan rate) for Glass/ITO/APTES electrodes covered with Au seed NPs. 
different scan rates. Table 3.3 displays the relevant data and Figure 3.10A show exponential dependence of Ep on the scan rate and Figure 3.10B shows that Ep is directly proportional to $\ln ($ scan rate).

A slow scan rate was chosen in order to ensure electrochemical reversibility and conditions of planar diffusion. The diffusion layer thickness $(\delta)$ was calculated by:

$$
\Delta=2(\mathrm{Dt})^{1 / 2} \quad \text { (Eq. 3.2) }
$$

\subsection{CONCLUSIONS}

We described here the direct voltammetric measurement of the oxidation potential $\left(E_{p}\right)$ for the oxidation of Au as a function of the size of Au NPs, which were chemically synthesized in solution. The experimental shift $(\sim 102 \mathrm{mV})$ shows that the oxidation potential has a dependence on the size of Au NPs, which was described previously by theory ${ }^{58,57}$ and in previous works, where Au NPs with different sizes were directly electrochemically deposited on the surface of a glass/ITO electrode with controlled size and coverage ${ }^{62}$ and for different metals. ${ }^{13}$ The properties of the chemically-synthesized Au NPs in terms of the shift of the oxidation potential was similar to the properties of chemically-synthesized Ag NPs and different from electrochemically-deposited Au NPs. The negative shift in the oxidation potential for small Au NPs is not due to diffusion effects or electron transfer kinetics. We believe it is due to athermodynamic shift in $\mathrm{E}^{0}$, We believe that these results will be very useful for future studies about the electrochemical properties of metal nanoparticles and their potential applications. 


\section{CHAPTER IV}

\section{SIZE DEPENDENCE OF UNDERPOTENTIAL DEPOSITED COPPER ON GOLD NANOPARTICLES}

\subsection{INTRODUCTION}

Here we describe copper underpotential deposition (Cu-UPD) on gold nanoparticles (Au NPs) of different sizes attached to glass/indium-tin-oxide (ITO) electrodes. Au NPs of 14 to $312 \mathrm{~nm}$ diameter were synthesized by electrodeposition from $\mathrm{HAuCl}_{4}$ in $\mathrm{H}_{2} \mathrm{SO}_{4}$ solution using chronocoulometry. Also, Au NPs of 4 to $73 \mathrm{~nm}$ diameter were prepared chemically and attached to amino-functionalized glass/ITO electrodes. Cyclic voltammograms (CVs) obtained in $0.01 \mathrm{M} \mathrm{Cu}\left(\mathrm{ClO}_{4}\right)_{2}$ plus $0.1 \mathrm{M} \mathrm{HClO}_{4}$ in the region from 0.1 to $1.6 \mathrm{~V}$ vs. $\mathrm{Hg} / \mathrm{HgO}$ show that the $\mathrm{Cu}$ UPD peaks are highly sensitive to the size of the Au NPs and their magnitude is inversely proportional to the size of the $\mathrm{Au}$ NPs. The amount of $\mathrm{Cu}$ deposited onto the $\mathrm{Au}$ surface relative to the number of surface $\mathrm{Au}$ atoms is inversely proportional to the size of the NPs. CVs obtained in the region from 0.8 to $-0.7 \mathrm{~V}$ reveal small changes in the reduction potential of bulk $\mathrm{Cu}^{2+}$ deposition for different sized Au NPs. The potential decreases from $-508 \mathrm{mV}$ to $-553 \mathrm{mV}$ with increasing the NP size, showing that smaller NPs catalyze metal deposition better than larger NPs. 
Underpotential deposition (UPD) is one of the scientifically and practically attractive systems. The process of underpotential deposition involves the electrodeposition of a monolayer or submonolayer of one metal on a second metal substrate at potentials more positive than that for the bulk deposition of the first metal. ${ }^{106}$ The UPD process is widely studied in many technologically important processes, including electrochemical nanotechnology. ${ }^{107,108}$

The UPD phenomenon of metals in many electrochemical processes is very sensitive to the presence of defects and edge sites as active centers. Accordingly, UPD can be used for defining the behavior of complex polycrystalline surfaces ${ }^{109} \mathrm{Cu}$ UPD on $\mathrm{Au}$ is one of the most well-studied systems by various electrochemical and surface techniques. ${ }^{110,111,112}$ The properties of $\mathrm{Au} / \mathrm{Cu}-\mathrm{UPD}$ are different from the properties of bulk $\mathrm{Cu}$. $\mathrm{Cu}$ UPD has been widely studied with a variety of different substrates, such as single crystal $\mathrm{Au}$, includes $\mathrm{Au}$ (111), polycrystalline $\mathrm{Au}$, and nanostructures. ${ }^{112} \mathrm{The} \mathrm{Cu}$ adsorbate lattice structure has been studied by various techniques, such as $\mathrm{X}$-ray diffraction, ${ }^{113} \mathrm{X}$-ray absorption spectroscopy, ${ }^{14,115}$ atomic force microscopy, ${ }^{116}$ scanning tunnelling microscopy, ${ }^{117}$ and different electrochemical and spectroscopic methods. ${ }^{118}$ Unfortunately, there is less information about $\mathrm{Cu}$ UPD on $\mathrm{Au}(110)$ and $\mathrm{Au}(100)$ compared to $\mathrm{Au}(111)$ and also the $\mathrm{Cu}$ UPD phenomenon is less studied on high index surfaces. ${ }^{119}$

In this work, $\mathrm{Cu}$ UPD has been studied on Au NPs which were chemicallysynthesized and electrochemically-deposited on the surface of glass/ITO electrodes with different sizes and crystallinity. 


\subsection{EXPERIMENTAL DETAILS}

The experimental procedure consisted of 3 steps in the case of chemicallysynthesized Au NPs): 1) synthesis of Au NPs, 2) attachment of Au NPs to aminofunctionalized glass/ITO electrodes, and 3) characterization of the nanostructures by SEM and CV to determine the dimensions of the Au NPs and electrochemical properties, respectively. Alternatively, $\mathrm{Au}$ NPs were electrodeposited directly and then characterized by SEM and CV.

The electrochemical deposition of Au NPs, chemical synthesis of Au NPs, oxidation of Au NPs and their characterization by UV-vis and SEM is described in Chapter II.

\subsection{RESULTS AND DISCUSSION}

\subsubsection{Electrochemical deposition of Au NPs of different size on Glass/ITO}

electrodes. Figure 4.1 shows a cyclic voltammogram (CV) of a glass/ITO electrode in a solution of $5 \times 10^{-3} \mathrm{M} \mathrm{HAuCl}_{4}$ plus $0.5 \mathrm{M} \mathrm{H}_{2} \mathrm{SO}_{4}$ scanned from $1.5 \mathrm{~V}$ to $-1 \mathrm{~V}$ at a scan rate of $100 \mathrm{mV} / \mathrm{s}$. The reduction of $\mathrm{AuCl}_{4}{ }^{-}$to $\mathrm{Au}^{0}$ starts at a potential of $\sim 290 \mathrm{mV}$ with a peak at $\sim 100 \mathrm{mV}$ on the forward scan. The reaction of the reduction process is:

$$
\mathrm{AuCl}_{4}^{-}+3 \mathrm{e}^{-}=\mathrm{Au}^{0}+4 \mathrm{Cl}^{-} E^{0}=0.994 \mathrm{~V} \text { vs NHE (1) }
$$

The reduction process at $\sim-600 \mathrm{mV}$ is due to hydrogen evolution. On the reverse scan, a reduction current remains until $0.8 \mathrm{~V}$, which is due to the ability of Au to catalyze $\mathrm{AuCl}_{4}{ }^{-}$reduction once $\mathrm{Au}^{0}$ deposits form on the forward scan. 


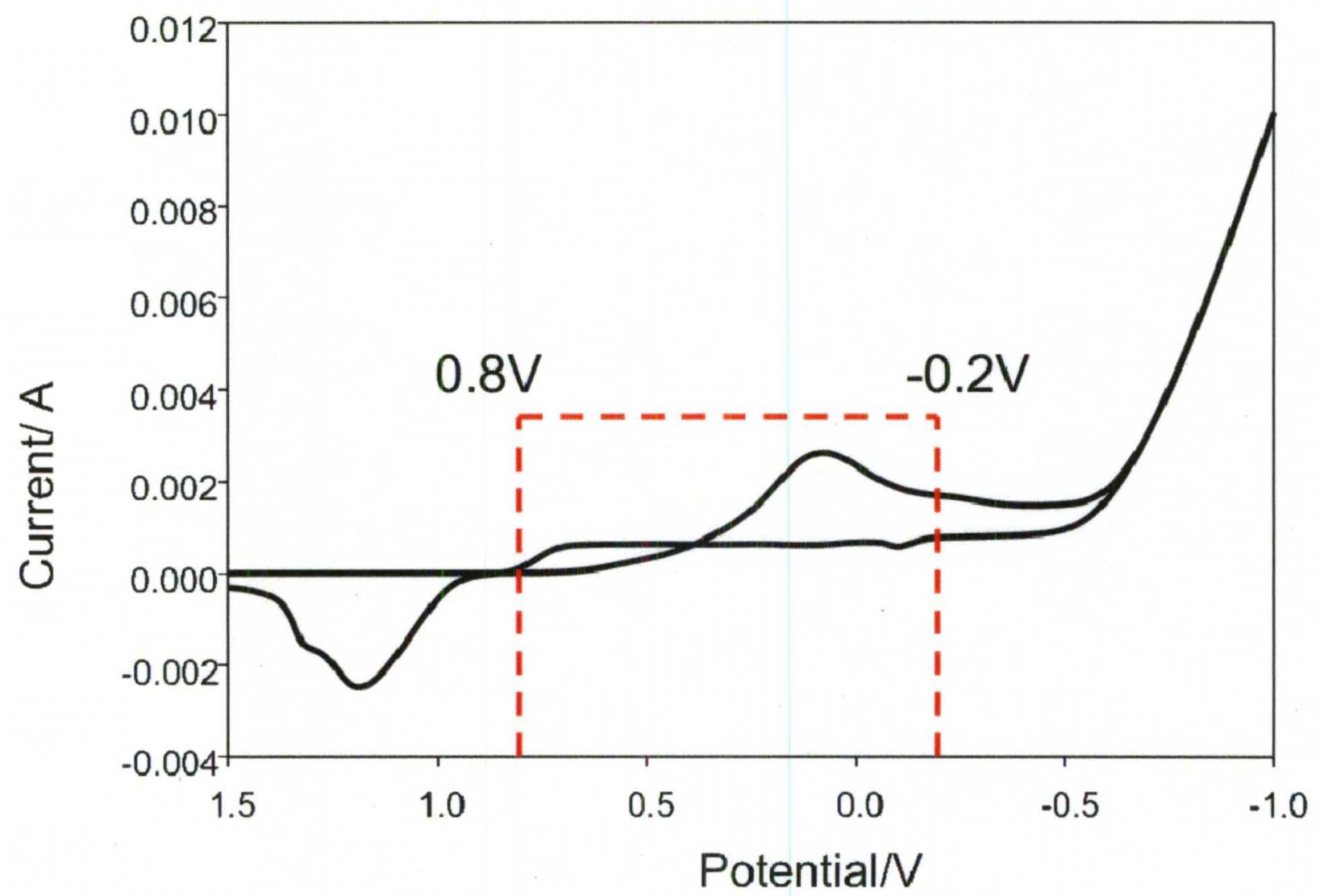

Figure 4.1. Cyclic voltammogram of glass/ITO electrode in a solution of $5 \times 10^{-3} \mathrm{M} \mathrm{HClO}_{4}$ plus $0.5 \mathrm{M} \mathrm{H}_{2} \mathrm{SO}_{4}$ at a scan rate of $100 \mathrm{mV} / \mathrm{s}$ with a potential range from $1.5 \mathrm{~V}$ to $-1.0 \mathrm{~V}$. The red dashed box indicates the range of potentials where the Au NP deposition was made. 
There is an Au oxidation peak starting at $\sim 900 \mathrm{mV}$, achieving a maximum at $\sim 1250$ $\mathrm{mV}$. The gap between $900 \mathrm{mV}$ and $600 \mathrm{mV}$ is due to the nucleation and growth phenomenon described previously. ${ }^{120}$ The red square indicates the range of potentials used for the deposition of Au NPs in this study.

Figure 4.2 shows scanning electron microscopy (SEM) images of glass/ITO before deposition (inset in Figure 4.2(C)) and after Au deposition of: (A) $6 \times 10^{-4} \mathrm{C}$ at a potential of $-0.2 \mathrm{~V}(\sim 53 \mathrm{sec}),(\mathrm{B}) 1 \times 10^{-3} \mathrm{C}$ at a potential of $0.4 \mathrm{~V}(\sim 800 \mathrm{sec})$, and $(\mathrm{C}) 6.5 \times 10^{-3} \mathrm{C}$ at a potential of $0.8 \mathrm{~V}(\sim 2100 \mathrm{sec})$. The dark grainy background corresponds to the glass/ITO electrode surface, and bright spherical and irregular shaped structures correspond to the Au NPs. Based on the images, the average diameter of the Au NPs increased with increasing deposition potential and time. Also, the density decreased with increasing potential (and size) of NPs, while the total coverage in terms of surface area of $\mathrm{Au}$ NPs was constant as determined by the reduction peak of $\mathrm{Au}$ in the $\mathrm{Cu}$ UPD experiments. It was crucial to keep the surface area constant in order to determine the size-dependent UPD properties. The average diameters of Au NPs deposited onto the glass/ITO electrodes according to the SEM images were: $20 \pm 6 \mathrm{~nm}, 105 \pm 6 \mathrm{~nm}$ and 312 $\pm 37 \mathrm{~nm}$ for the deposition of $6 \times 10^{-4} \mathrm{C}$ at $-0.2 \mathrm{~V}(\sim 53 \mathrm{sec}), 1 \times 10^{-3} \mathrm{C}$ at $0.4 \mathrm{~V}(\sim 800 \mathrm{sec})$, and $6.5 \times 10^{-3} \mathrm{C}$ at $0.8 \mathrm{~V}(\sim 2100 \mathrm{sec})$, respectively. Most of the Au NPs have a spherical, irregular shape, or flower-like morphology. The density of the Au NPs ranged from 50 to $2 \mathrm{NP}$ per $1 \mu \mathrm{m}^{2}$ at -0.2 and $0.8 \mathrm{~V}$, respectively. 


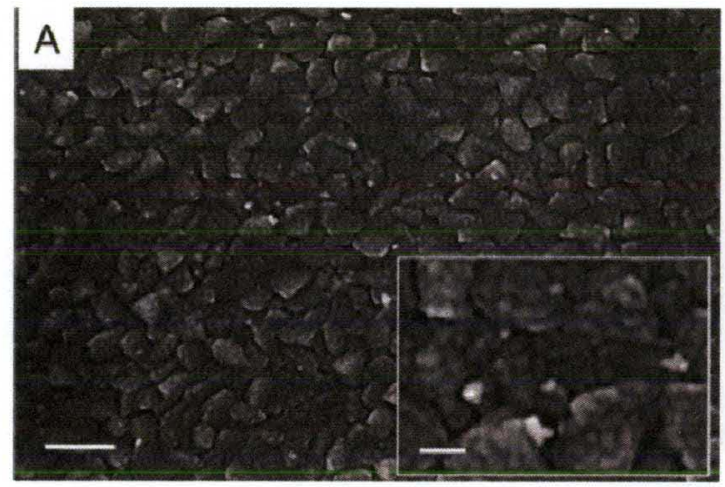

$20 \pm 6 \mathrm{~nm}$

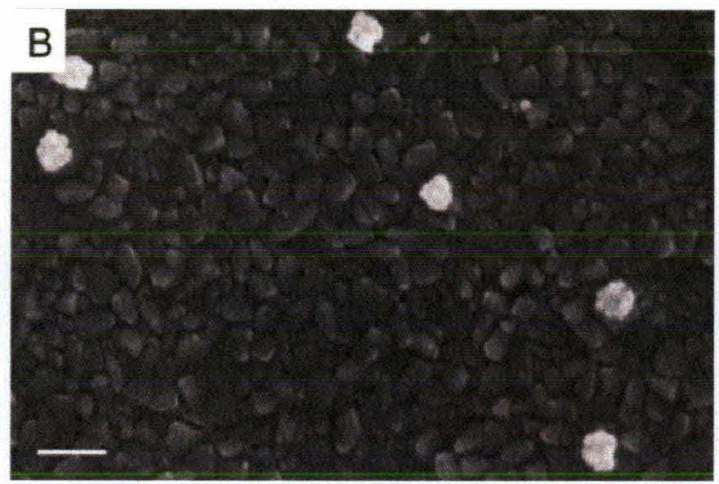

$105 \pm 6 \mathrm{~nm}$

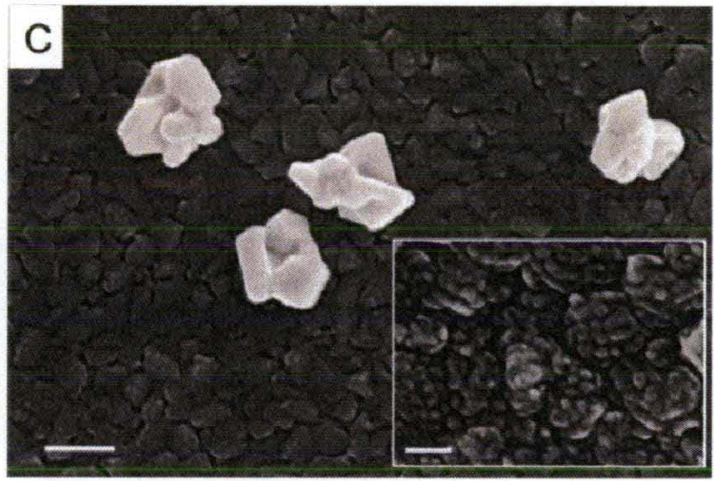

$312 \pm 37 \mathrm{~nm}$

Figure 4.2. SEM images of Glass/ITO/Au NPs deposited at different potentials and coulombs (C): (A) $-0.2 \mathrm{~V}, 6 \times 10^{-4} \mathrm{C}$; (B) 0.4 $\mathrm{V}, 1 \times 10^{-3} \mathrm{C}$; (C) $0.8 \mathrm{~V}, 6.5 \times 10^{-3} \mathrm{C}$. The scale bar is $200 \mathrm{~nm}$ in the large images and $50 \mathrm{~nm}$ in the inset. 


\subsubsection{Chemical synthesis and attachment of Au NPs of different size on amino-}

functionalized Glass/ITO electrodes. Four different syntheses were performed for the chemical preparation of $4 \pm 1 \mathrm{~nm}, 15 \pm 7 \mathrm{~nm}, 31 \pm 14 \mathrm{~nm}$ and $73 \pm 19 \mathrm{~nm}$ diameter $\mathrm{Au}$ NPs as described in Chapter II.

4.3.3. Copper underpotential deposition measurements on Au NPs. Figure 4.3 shows cyclic voltammograms (CVs) of glass/ITO and glass/ITO/APTES/Au NP (chemically-synthesized) electrodes with different size NPs measured from $0.8 \mathrm{~V}$ to -0.7 $\mathrm{V}$ in a solution of $0.01 \mathrm{M} \mathrm{Cu}\left(\mathrm{ClO}_{4}\right)_{2}$ and $0.1 \mathrm{M} \mathrm{HClO}_{4}$. The cathodic peak starting near $0.1 \mathrm{~V}$ (Frame $\mathrm{B}$ ) in the $\mathrm{CV}$ s corresponds to $\mathrm{Cu}^{2+}$ reduction by the following reaction:

$$
\mathrm{Cu}^{2+}{ }_{(\mathrm{aq})}+2 \mathrm{e}^{-}=\mathrm{Cu}_{(\mathrm{s})}^{0}
$$

The peak potential (Frame C) for bulk $\mathrm{Cu}^{2+}$ reduction follows the order of $\mathrm{Au}_{4 \mathrm{~nm}}(-509$ $\mathrm{mV})>\operatorname{Au}_{15 \mathrm{~nm}}(-512 \mathrm{mV})>\operatorname{Au}_{31 \mathrm{~nm}}(-525 \mathrm{mV})>\operatorname{Au}_{73 \mathrm{~nm}}(-529 \mathrm{mV})>$ Glass $/ \mathrm{ITO}(-554$ $\mathrm{nm})$.

The same behavior occurred for Au NPs which were electrochemically deposited on glass/ITO electrodes as shown in Figure 4.4. The potential for bulk $\mathrm{Cu}^{2+}$ reduction increased with decreasing NPs diameter as $\mathrm{Au}_{20 \mathrm{~nm}}(-513 \mathrm{mV})>\mathrm{Au}_{105 \mathrm{~nm}}(-538 \mathrm{mV})>$ $\mathrm{Au}_{312 \mathrm{~nm}}(-554 \mathrm{mV}) \approx$ bare glass/ITO $(-554 \mathrm{mV})$. All the statistical data are presented in Table 4.1. They based on at least 3 trials.

This experiment shows that smaller Au NPs can better catalyze bulk Cu deposition. It is more energetically favored as the size of the Au NPs decreased. This is due to the well-known phenomenon of nucleation and growth. The growth of the bulk $\mathrm{Cu}$ is more favorable at small Au nucleation sites due to the lower stability of small Au NPs. The growth is favored since it lowers their surface area. Interestingly, large Au NPs do not 

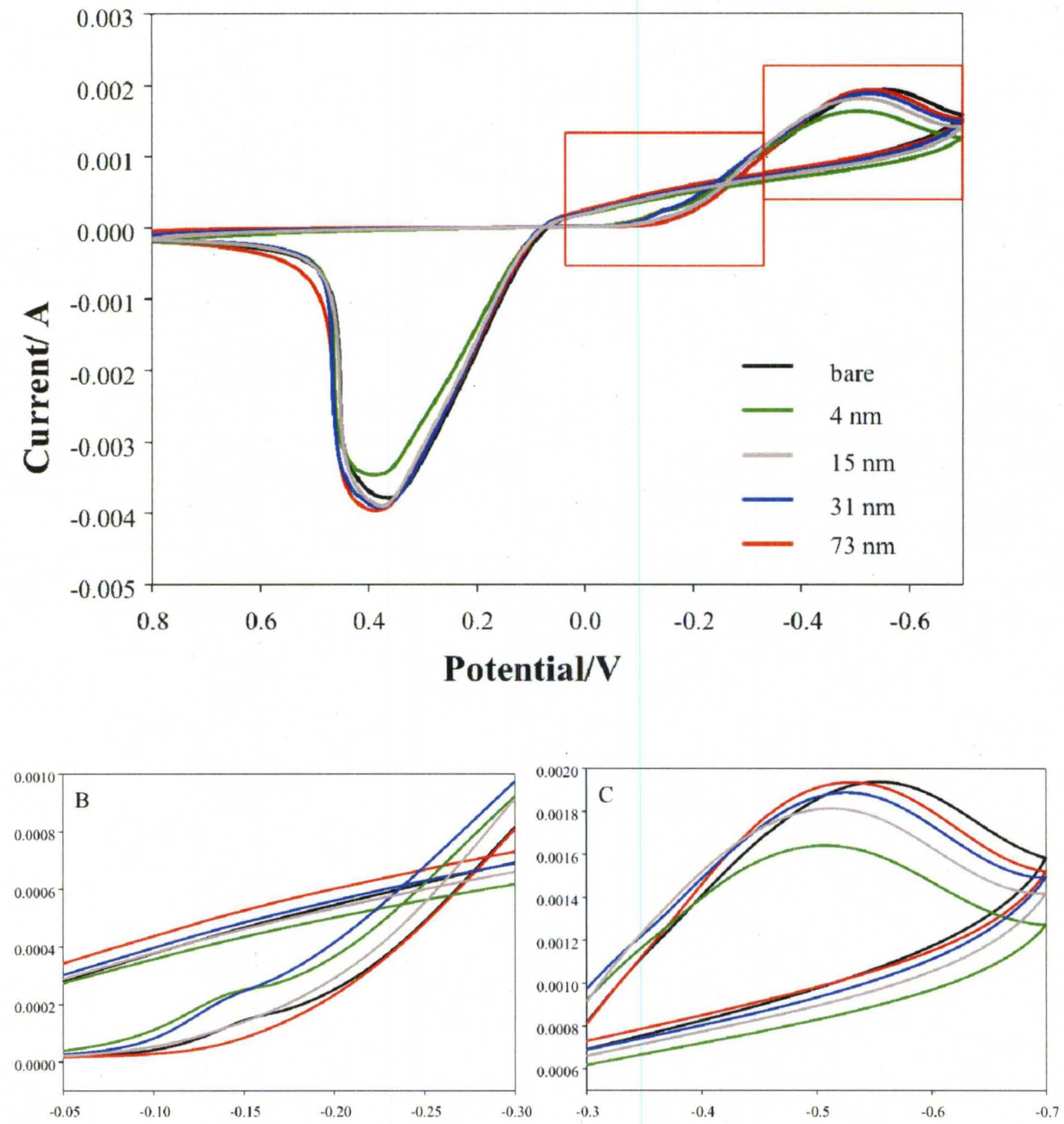

Figure 4.3. $\mathrm{CV}$ s of Glass/ITO/APTES and Glass/ITO/APTES/Au NPs in $0.01 \mathrm{M} \mathrm{Cu}\left(\mathrm{ClO}_{4}\right)_{2}$ and $0.1 \mathrm{M} \mathrm{HClO}_{4}$ (A), (B) and (C) - blow up regions of the Figure 4.3 (A). 

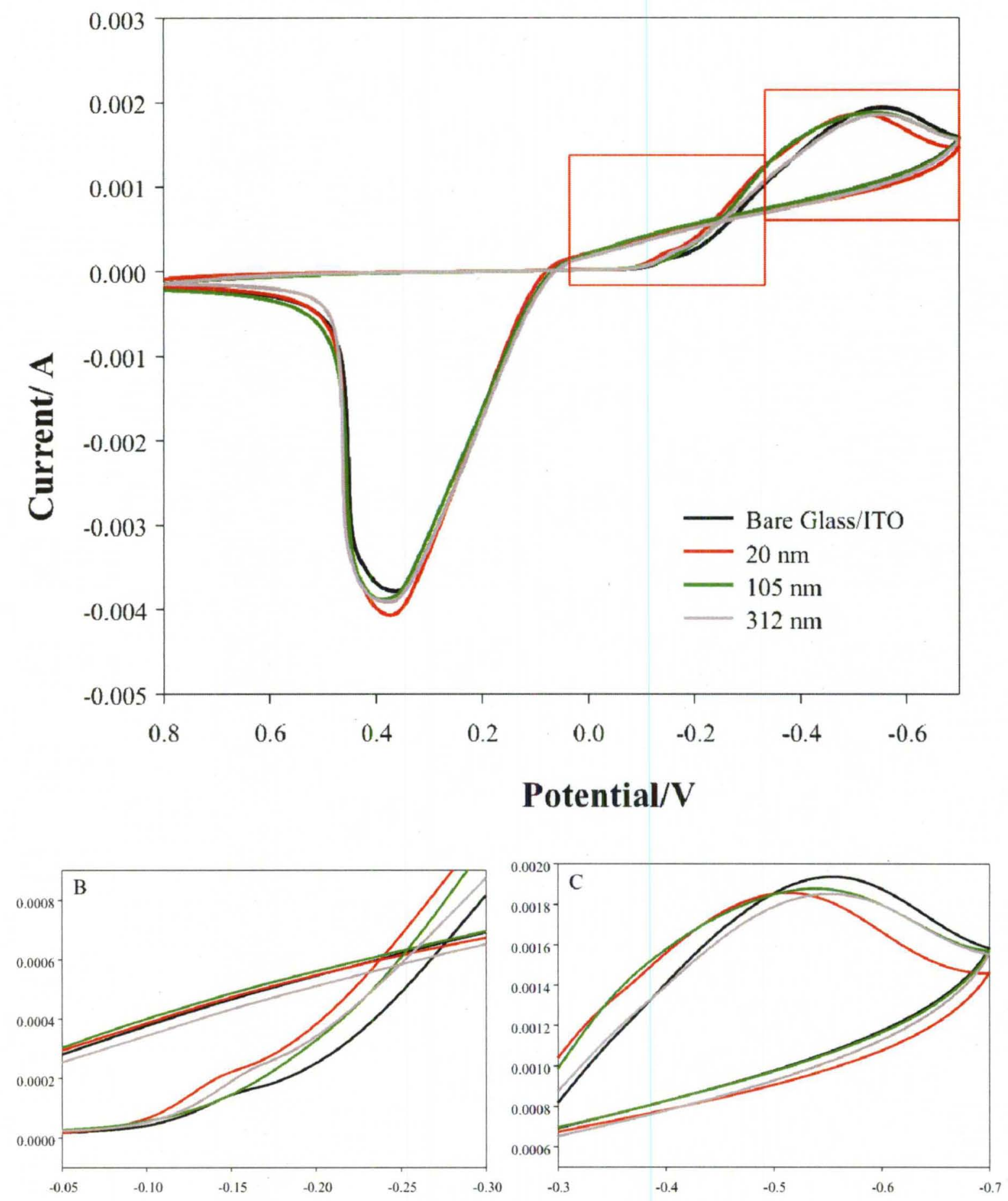

Figure 4.4. $\mathrm{CVs}$ of Glass/ITO and Glass/ITO/Au NPs deposited at potentials from $-0.2 \mathrm{~V}$ to 0.8 $\mathrm{V}$ and a charge of $6 \times 10^{-4} \mathrm{C}$ to $6.6 \times 10^{-3} \mathrm{C}$ in $0.01 \mathrm{M} \mathrm{Cu}\left(\mathrm{ClO}_{4}\right)_{2}$ and $0.1 \mathrm{M} \mathrm{HClO}_{4}(\mathrm{~A}),(\mathrm{B})$ and (C) - blow up regions of the Figure 4.4 (A). 


\begin{tabular}{|c|c|c|}
\hline Size of Au NP, nm & $\begin{array}{c}\text { Potential for bulk } \mathrm{Cu}^{2+} \\
\text { reduction, } \mathrm{mV}\end{array}$ & $|\mathrm{C}(\mathrm{Cu}) / \mathrm{C}(\mathrm{Au})|$ \\
\hline$* 4 \pm 1$ & -509 & $0.22 \pm 0.02$ \\
\hline$* 15 \pm 7$ & -512 & $0.18 \pm 0.01$ \\
\hline $20 \pm 6$ & -513 & $0.11 \pm 0.03$ \\
\hline$* 31 \pm 14$ & -525 & $0.08 \pm 0.01$ \\
\hline$* 73 \pm 19$ & -529 & $0.07 \pm 0.02$ \\
\hline $105 \pm 6$ & -538 & $0.07 \pm 0.02$ \\
\hline $312 \pm 37$ & -554 & - \\
\hline Bare Glass/ITO & -554 & \\
\hline
\end{tabular}

* - chemically synthesized Au NPs

Table 4.1. Statistical data of size, bulk $\mathrm{Cu}^{2+}$ reduction peak potential, and the ratio of the charge of $\mathrm{Cu}$ UPD peak to Au reduction peak on electrodes with the same surface area of $\mathrm{Au}$ NPs. 
catalyze $\mathrm{Cu}$ deposition any better than bare glass/ITO. The corresponding stripping peak for bulk $\mathrm{Cu}$ is at $\sim 390 \mathrm{mV}$ for all sizes.

Figure 4.5 shows CVs of glass/ITO/APTES and glass/ITO/APTES/Au NPs in 0.01 $\mathrm{M} \mathrm{Cu}\left(\mathrm{ClO}_{4}\right)_{2}$ and $0.1 \mathrm{M} \mathrm{HClO}_{4}$ measured from $0.1 \mathrm{~V}$ to $1.6 \mathrm{~V}$ with a $\mathrm{Hg} / \mathrm{HgO}$ reference electrode. We focused on the Cu UPD oxidation peak that occurs around $370 \mathrm{mV}$. The same is shown in Figure 4.6 for glass/ITO and glass/ITO/Au NPs electrochemically deposited with different sizes measured in the same solutions over the same potential range. These CVs show the Cu UPD region near $370 \mathrm{mV}$, the Au oxidation near $1.3 \mathrm{~V}$ and $\mathrm{Au}$ reduction near $0.9 \mathrm{~V}(907 \pm 19 \mathrm{mV})$. The Au reduction peaks all have approximately the same peak area $(2.05 \pm 0.12) \times 10^{-5} \mathrm{C}$ showing a similar Au surface area.

Figures 4.5 and 4.6 show that the Cu UPD oxidation and corresponding reduction peaks occurred at $\sim 370 \mathrm{mV}$ and $\sim 330 \mathrm{mV}$, respectively. The peaks are well-pronounced and visible above the background charging current. The area under the Cu UPD oxidation peak $(\sim 370 \mathrm{mV})$ relative to the size of the Au NP reduction peak $(\sim 900 \mathrm{mV})$ increases with decreasing Au NP size. The bigger area of the Cu UPD oxidation peaks corresponds to the glass/ITO/Au $\mathrm{Am}_{8}$ and glass/ITO/APTES/Au ${ }_{4 n m}$. The glass/ITO/Au $312 \mathrm{~nm}$ and glass/ITO/APTES/Au ${ }_{73} \mathrm{~nm}$ Cu UPD oxidation peaks have smaller area, they are less pronounced, and exhibit less charge. The potential and shape of the UPD peaks also vary with the size of Au NPs. For smaller sizes ( $\mathrm{Au} 4 \pm 1 \mathrm{~nm}$ and $\mathrm{Au} 8 \mathrm{~nm}$ ), the peak potentials (Ep) are positively shifted to $378 \mathrm{mV}$ and appears as one solid peak. For Au NPs with sizes of $73 \mathrm{~nm}$ or $312 \mathrm{~nm}$, the Cu UPD oxidation peaks are 


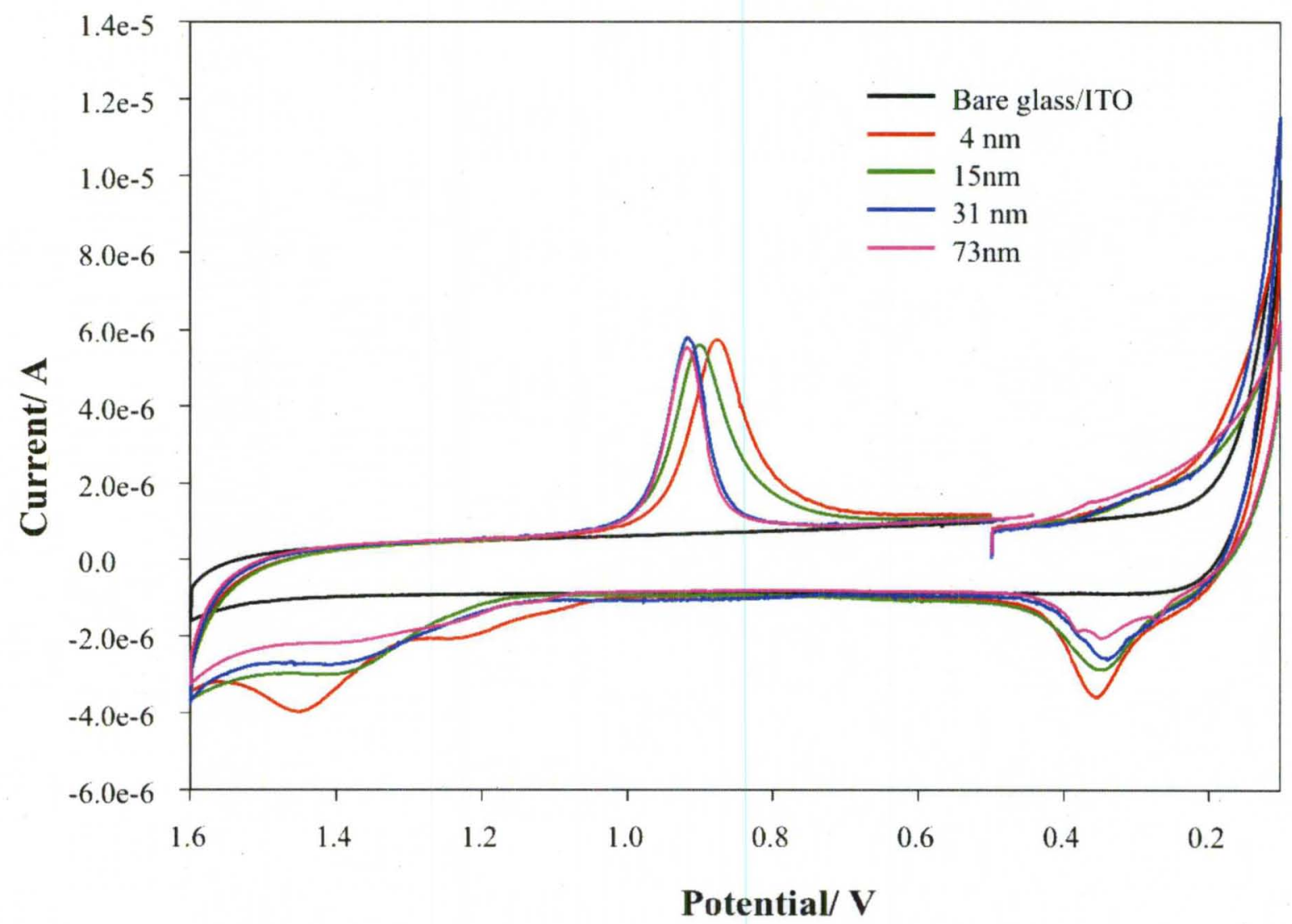

Figure 4.5. $\mathrm{CV}$ of chemically-synthesized glass/ITO/APTES/Au NPs in $0.01 \mathrm{M} \mathrm{Cu}\left(\mathrm{ClO}_{4}\right)_{2}$ and $0.1 \mathrm{M} \mathrm{HClO}_{4}$. 


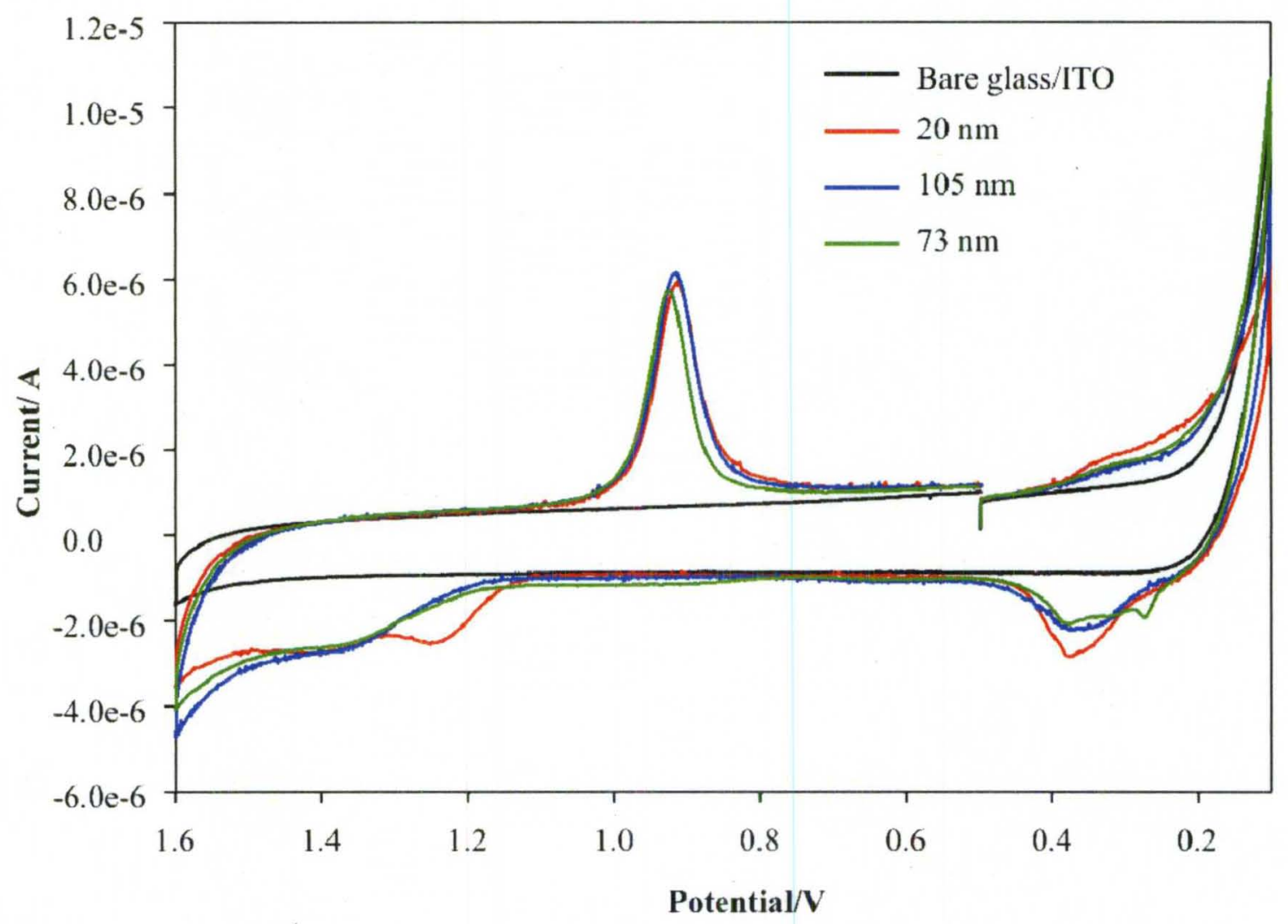

Figure 4.6. $\mathrm{CV}$ of electrochemically-deposited glass/ITO/Au NPs in $0.01 \mathrm{M} \mathrm{Cu}\left(\mathrm{ClO}_{4}\right)_{2}$ and $0.1 \mathrm{M} \mathrm{HClO}_{4}$. 
around $350 \mathrm{mV}$, are less pronounced, and there are two or three peaks. This can be explained by the presence of Au NPs with different crystallographic structures.

The surface area of the Au NPs deposited on the surface of glass/ITO and glass/ITO/APTES electrodes was kept constant, but the amount of Au was not the same for all electrodes. It increases with increasing size of the Au NPs. We studied the phenomenon of the different Au NPs, which have different sizes but the same surface area. We also studied their behavior after applying a layer of $\mathrm{Cu}$ at a potential much smaller than is necessary for deposition of bulk $\mathrm{Cu}$.

Based on the data from the CVs, we calculated the ratio of the $\mathrm{Cu}$ UPD oxidation peak to the $\mathrm{Au}$ reduction peak. It ranged from 0.22 to 0.07 as shown in Table 4.1 and Figure 4.7. The glass/ITO/Au electrodes with different sized Au NPs are statistically different in terms of the $\mathrm{Cu} / \mathrm{Au}$ ratio. The ratio decreases exponentially with diameter for the sizes below $73 \mathrm{~nm}$ and stabilizes above $73 \mathrm{~nm}$. Figure 4.9 explains why Au NPs with smaller sizes have more $\mathrm{Cu}$ deposited on the Au surface relative to Au. Au NPs with larger sizes have more terrace sites relative to edge sites. As a result, most of the $\mathrm{Cu}$ deposits on the terrace sites. This leads to lower coverage relative to smaller NPs because the coverage of $\mathrm{Cu}$ on a terrace site is lower than the coverage on edge sites and other high energy defect sites. Au NPs with smaller sizes (below $73 \mathrm{~nm}$ ) have more edges and defects and fewer terrace cites. More $\mathrm{Cu}$ accumulated on the edges and defects results in a higher amount and coverage of $\mathrm{Cu}$ relative to $\mathrm{Au}$ on the surface. There is also a logarithmic decrease in the Au reduction peak potential with decreasing of NP size as shown in Figure 4.8. 


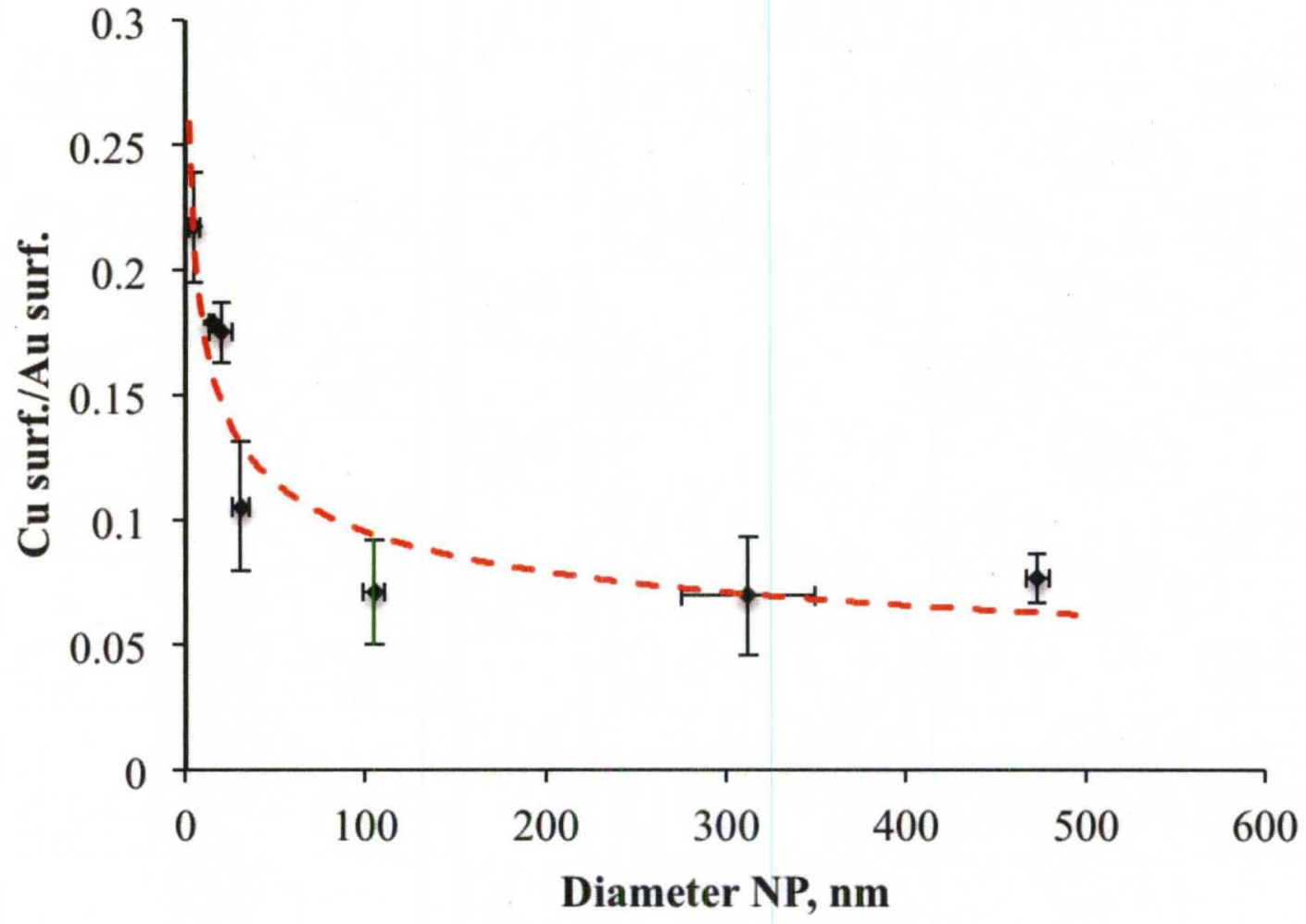

Figure 4.7. Cu-UPD dependence of size of Au NPs. 


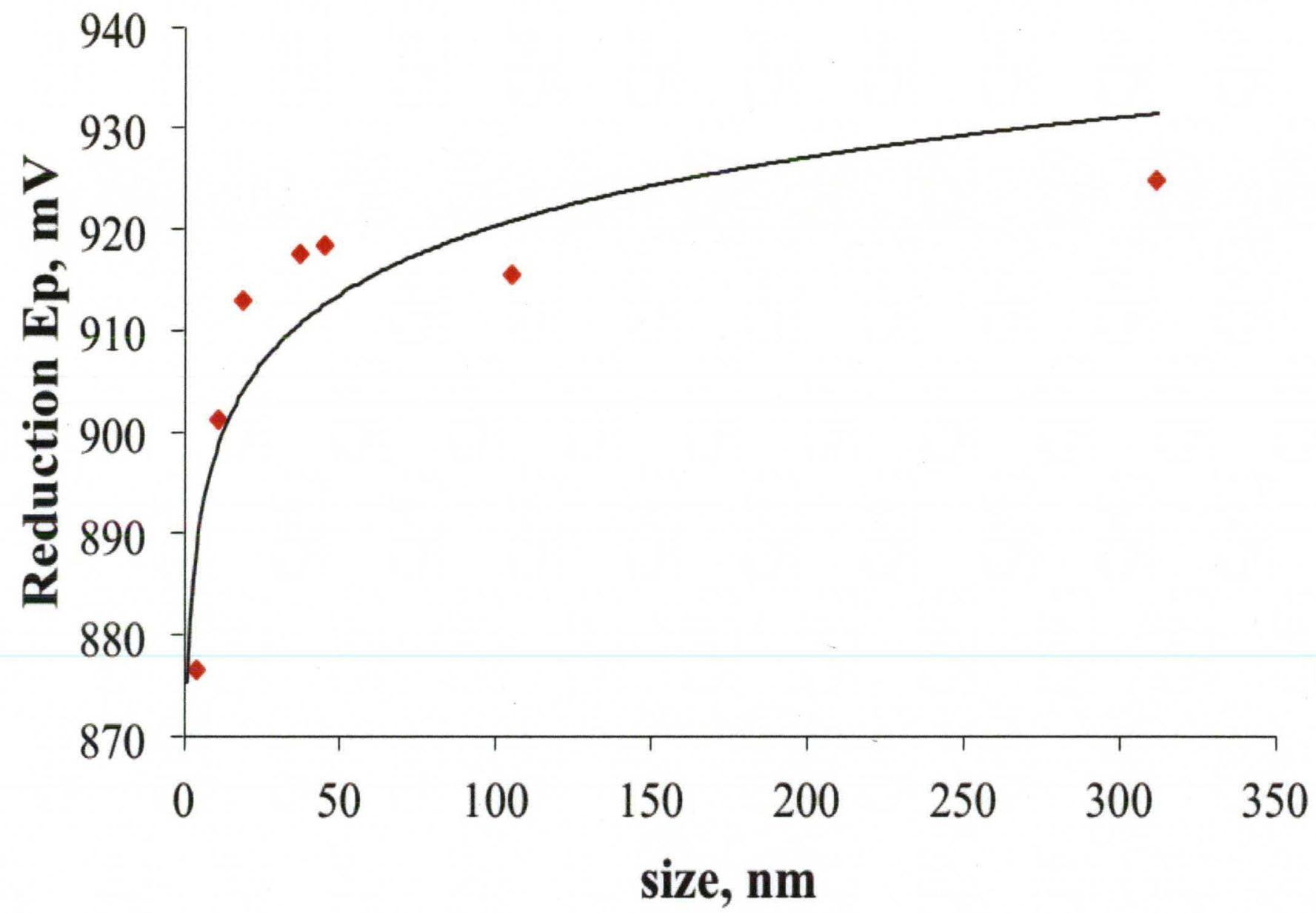

Figure 4.8. Dependence of the Au reduction peak potential on the size of the Au NP. 

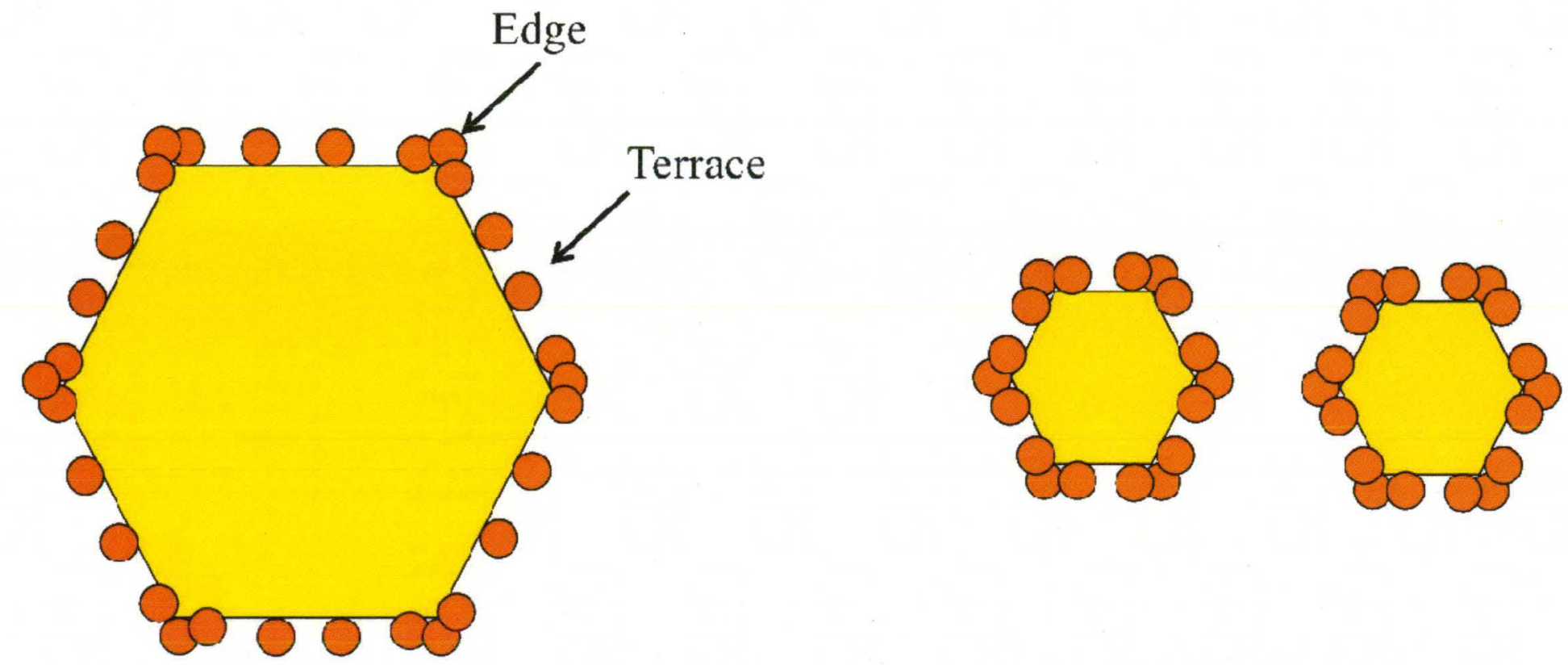

More terrace sites - less coverage relative to surface $\mathrm{Au}$ atoms

More edge and defects, less terrace sites - higher coverage relative to surface $\mathrm{Au}$ atoms

Figure 4.9. Scheme of the distribution of $\mathrm{Cu}$ atoms on the top of large and small Au NPs. 
Au NPs, which were chemically prepared and then attached to the surface of a glass/ITO/APTES electrode had the same surface area, but the total amount of Au atoms was not the same. To show this, the Au NPs were electrochemically oxidized by linear sweep voltammetry in $10 \mathrm{mM} \mathrm{KBr}$ plus $0.01 \mathrm{M} \mathrm{HClO}_{4}$ at a scan rate of $1 \mathrm{mV} / \mathrm{s}$ from 0.0 V to $1.6 \mathrm{~V}$. Figure 4.10 shows LSVs of the oxidation of Au NPs with different sizes. The calculated amount of Au based on the area under the oxidation peak is shown in Table 4.2

Our initial goal was to determine if the oxidation peak of the $\mathrm{Cu}$ UPD layer depends on the size of the Au NPs, since our group recently showed that the oxidation potential of Au and Ag NPs depends on size. ${ }^{62,13}$ We performed Cu UPD on the different sized Au NPs keeping the surface area constant as described. We also measured the UPD coverage with $4 \mathrm{~nm}$ diameter Au NPs which had different NP coverage as shown in Figure 4.11 . The coverage varied by varying the soaking time from 1 to 30 minutes as indicated. Figure 4.11 shows the CVs of glass/ITO/APTES/Au NPs (4 nm) from $0.1 \mathrm{~V}$ to $1.6 \mathrm{~V}$ as a function of soaking time (coverage). The surface area of the Cu UPD increases with increasing area under the Au reduction peak at $0.9 \mathrm{~V}$. This linear dependence is plotted in Figure 4.12. This shows that the $\mathrm{Cu} / \mathrm{Au}$ ratio depends on the $\mathrm{Au}$ NP size, but not on the Au NP coverage. 


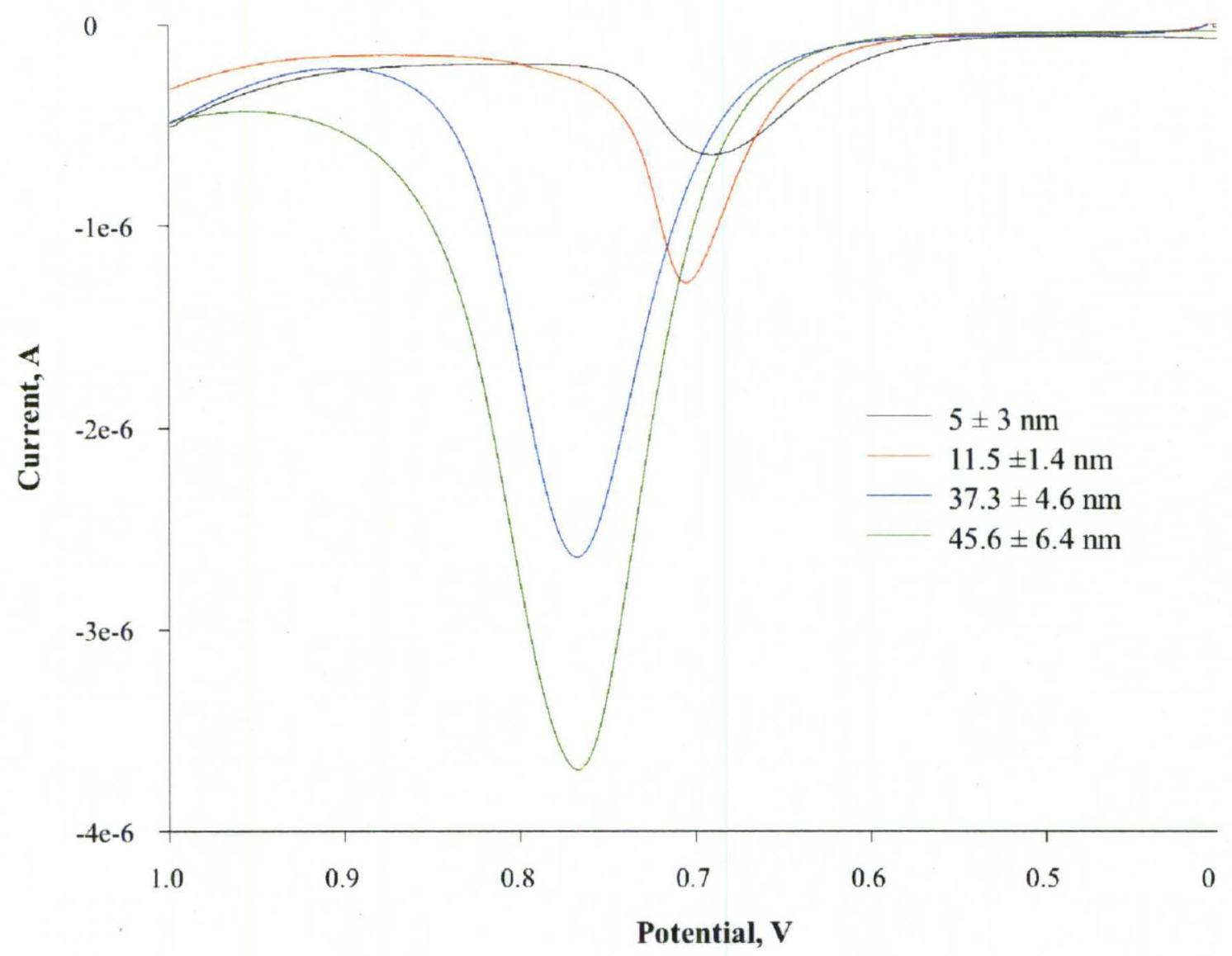

Figure 4.10. Linear Sweep Voltammograms obtained in $10 \mathrm{mM} \mathrm{KBr}$ plus $0.1 \mathrm{M}$ $\mathrm{HClO}_{4}$ electrolyte at $1.0 \mathrm{mV} / \mathrm{s}$ of $1.4 \mathrm{~cm}^{2}$ glass/ITO/APTES electrodes coated with chemically synthesized Au NPs. The surface area of the Au NPs was kept constant as determined by $\mathrm{Au}$ oxide reduction peak obtained in $\mathrm{H}_{2} \mathrm{SO}_{4}$. 


\begin{tabular}{|c|c|c|c|c|c|}
\hline Size, nm & $\begin{array}{c}\text { Experimental } \\
\text { peak potential, } \\
\mathbf{E}_{\mathrm{p}, \exp }[\mathrm{mV}]\end{array}$ & $\begin{array}{c}\text { Charge under } \mathrm{Au} \\
\text { reduction peak }\left(\times 10^{-5} \mathrm{C}\right) \\
\text { "Surface Au" }\end{array}$ & $\begin{array}{c}\text { Charge under the } \\
\text { oxidation peak }\left(\times 10^{-4} \mathrm{C}\right) \\
\text { "Total Au" }\end{array}$ & $\begin{array}{c}\text { Surface } \\
\text { Au/Total Au }\end{array}$ & $\begin{array}{r}\text { Surf. Cu/Surf. Au } \\
\text { (based on CV) }\end{array}$ \\
\hline $4 \pm 1$ & 691 & 1.23 & 0.357 & 0.344 & $0.217 \pm 0.022$ \\
\hline $15 \pm 7$ & 705 & 1.12 & 0.511 & 0.109 & $0.179 \pm 0.001$ \\
\hline $31 \pm 14$ & 768 & 1.12 & 1.327 & 0.042 & $0.105 \pm 0.026$ \\
\hline $73 \pm 19$ & 768 & 1.11 & 1.906 & 0.029 & $0.076 \pm 0.010$ \\
\hline
\end{tabular}

Table 4.2 Electrochemical Data of the Oxidation of glass/ITO/APTES/Au NP Electrodes. 


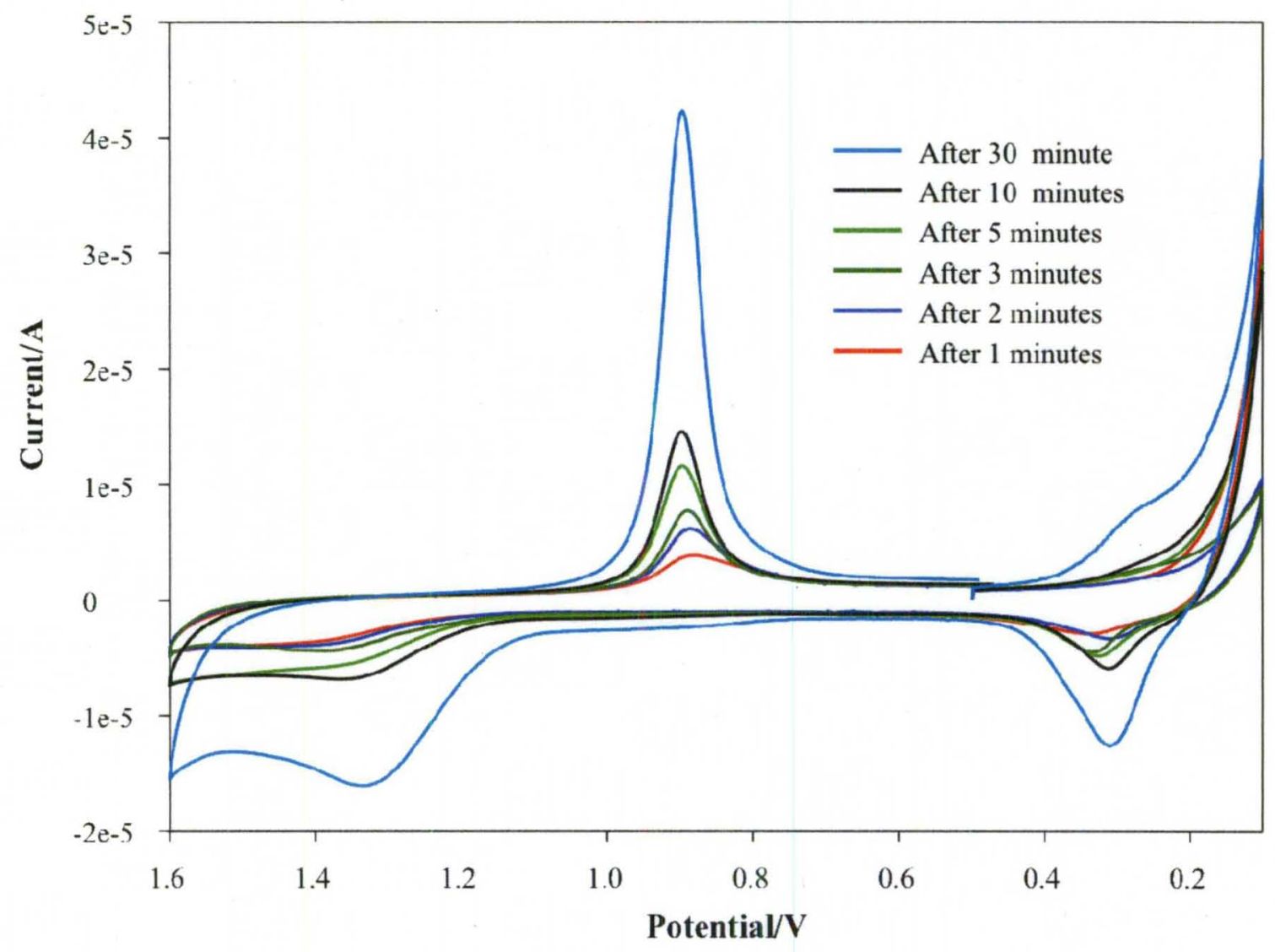

Figure 4.11. $\mathrm{CV}$ of glass/TTO/APTES/Au 4 nm in $0.01 \mathrm{M} \mathrm{Cu}\left(\mathrm{ClO}_{4}\right)_{2}$ and $0.1 \mathrm{M} \mathrm{HClO}_{4}$ with different coverage of Au NPs. 


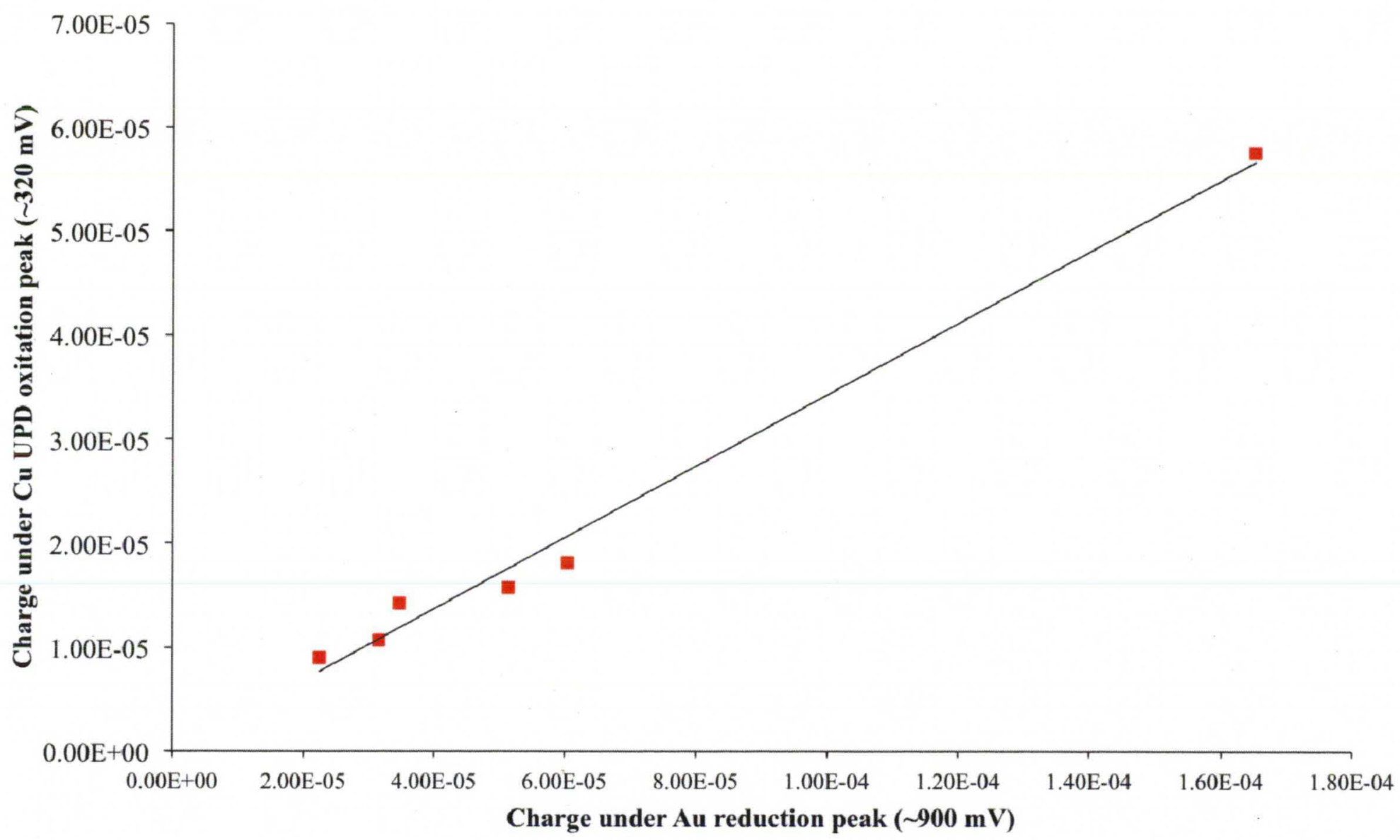

Figure 4.12. Plot of $\mathrm{Cu}$ : $\mathrm{Au}$ ratio in different deposition time of $\mathrm{Au}$ seeds. 


\subsection{CONCLUSIONS}

In summary, we demonstrated here the properties of the UPD of $\mathrm{Cu}$ on Au NPs of different size. Au NPs of different size were directly deposited on the glass/ITO electrodes by electrochemical deposition and by electrostatic attachment of chemicallysynthesized Au NPs. We controlled the size and coverage of the Au NPs. The NPs were studied by CV, LSV and SEM. The growth of bulk $\mathrm{Cu}$ is more favorable at small Au NPs because they possess lower stability and can better catalyze bulk $\mathrm{Cu}$ deposition. The area and shape of the Cu UPD oxidation peak is different for Au NPs of different size. The area of the $\mathrm{Cu}$ UPD peak relative to the Au reduction peak increases with decreasing $\mathrm{Au}$ NP size. The shape of the UPD peaks for smaller sizes ( $\mathrm{Au} 4 \mathrm{~nm}$ and $\mathrm{Au} 8 \mathrm{~nm}$ ) is a wellpronounced solid single peak and for NPs larger than $73 \mathrm{~nm}$, there are two or three peaks. The peak potentials (Ep) are more positively shifted $(\sim 378 \mathrm{mV})$ for smaller NPs and negatively shifted $(\sim 350 \mathrm{mV})$ for bigger NPs $(73 \mathrm{~nm}$ and higher). This is explained by the formation of Au NPs with different crystallographic structures for different sizes and higher stability of Cu UPD on small Au. The amount of $\mathrm{Cu}$ deposited on the Au surface was measured by $\mathrm{CV}$, and the oxidation peak area of $\mathrm{Cu}$ UPD was inversely proportional to the Au NPs size due to the differences in the crystal structure of the different sized NPs. The amount of $\mathrm{Cu}$ increased with decreasing size of $\mathrm{Au}$ NPs. There is also a logarithmic dependence showing a decrease Au reduction peak potential with a decreasing of NP size. 


\section{CHAPTER V}

\section{ELECTROCHEMICAL GROWTH OF GOLD TRIANGULAR AND HEXAGONAL SHAPED NANOPLATES DIRECTLY ON A SURFACE OF GLASS/ITO ELECTRODE}

\subsection{INTRODUCTION}

Here we report a new method to synthesize triangular and hexagonal shaped nanoplates by electrochemical deposition onto indium-tin oxide-coated glass electrodes (glass/ITO) from a solution of $\mathrm{HAuCl}_{4}$ and $\mathrm{H}_{2} \mathrm{SO}_{4}$. We control the shape of the nanostructures by varying the charge and keeping the deposition potential constant at 0.8 $\mathrm{V}$ versus an $\mathrm{Ag} / \mathrm{AgCl}$ reference electrode. UV-vis spectroscopy, underpotential deposition (UPD) of $\mathrm{Cu}$ on the Au nanoplates, and SEM imaging confirm the presence of the nanoplates which had a $40-50 \%$ yield under optimal conditions. SEM imaging obtained at different stages of the deposition reveal that the plates form by the formation of highly branched structures which evolve into irregular shaped plates. Aggregation of nanoparticles (NPs) on the plates followed by ripening leads to larger, more regular shaped plates.

The preparation of noble metallic nanoplates with triangular and hexagonal shapes has been described using various methods. Zhang et al. synthesized nanoplates in 
aqueous solution at room temperature with the use of tannic acid. ${ }^{121}$ The seedmediated growth ${ }^{122}$ of nanoplates was used by Roh et. al. and Beeram. ${ }^{123}$ Also, other methods were reported for the preparation of nanoplates, such as a chemical and photoreduction method, ${ }^{124}$ galvanic displacement preparation, ${ }^{125}$ electrochemical reduction method, ${ }^{126}$ and by electrodeposition of $\mathrm{Au}$ nanoplates from $\mathrm{Au}(\mathrm{CN})_{2}{ }^{-}$on $\mathrm{Au}$ surfaces. ${ }^{127}$ Most of the methods occur in solution and not directly on the surface of the electrode. Interestingly, there are no reports on the preparation of triangular and hexagonal gold nanoplates by using an electrochemical method directly on the surface of the working electrode.

Our group recently developed a method of electrochemical deposition of Au nanorods (NRs). ${ }^{98}$ Au NRs were electrodeposited from a solution containing $2.5 \times 10^{-4} \mathrm{M}$ $\mathrm{AuCl}_{4}{ }^{-}$and $0.1 \mathrm{M}$ cetyltrimethylammonium bromide (CTAB) onto Au-nanoparticle (NP)seeded mercaptopropyltrimethoxysilane (MPTMS)-functionalized glass/indium tin oxide (glass/ITO) electrodes. The yield of NRs depends on the presence of Au seeds, the electrode potential, and on deposition time. In general, the length, aspect ratio, and yield of the Au NRs increase with increasing potential and increasing deposition time up to 120 min. Ivanova and Zamborini was developed a method to control the size of Au NPs electrochemically deposited directly on the surface of a glass/ITO working electrode by controlling the deposition potential while keeping the amount of Au deposited constant by monitoring the charge with chronocoulometry. ${ }^{62}$ The diameter of the NPs ranged from 8 to $250 \mathrm{~nm}$ at potentials of -0.2 to $0.8 \mathrm{~V}$ versus an $\mathrm{Ag} / \mathrm{AgCl}$ reference electrode. 


\subsection{EXPERIMENTAL DETAILS}

Electrochemical deposition of Gold Nanoplates (Au NPLs). Glass/ITO electrodes were used as working electrodes after cleaning them in acetone, ethanol, and 2-propanol by sonication for 20 minutes. Then they were dried under a stream of $\mathrm{N}_{2}$. Au NPLs were electrochemically deposited onto the $1.4 \mathrm{~cm}^{2}$ clean glass/ITO working electrode using A $\mathrm{CH}$ Instruments (Austin, TX) 660C electrochemical workstation in chronocoulometry mode with an $\mathrm{Ag} / \mathrm{AgCl}(3 \mathrm{M} \mathrm{KCl})$ reference electrode and Pt counter electrode to complete the cell. The solution used for the deposition was $5 \times 10^{-5} \mathrm{M} \mathrm{HAuCl}_{4}$ plus $0.5 \mathrm{M}$ $\mathrm{H}_{2} \mathrm{SO}_{4}$. The potential was stepped from $1.0 \mathrm{~V}$ to $0.8 \mathrm{~V}$ and held constant at $0.8 \mathrm{~V}$ until a certain amount of charge was passed through the electrode, ranging from $3 \times 10^{-3}$ Coulombs (C) to $1.2 \times 10^{-2} \mathrm{C}$ with a deposition time of $\sim 1000$ to $4000 \mathrm{~s}$, respectively. Figure 5.1 shows an illustration of the setup.

Cu Underpotential Deposition measurements. The electrochemical cell consisted of glass/ITO/Au as the working electrode, a Pt wire counter electrode, and an $\mathrm{Ag} / \mathrm{AgCl}$ reference electrode. The electrolyte solution was $0.01 \mathrm{M} \mathrm{Cu}\left(\mathrm{ClO}_{4}\right)_{2}$ plus $0.1 \mathrm{M} \mathrm{HClO}_{4}$. Cyclic voltammograms were obtained by scanning from $0.0 \mathrm{~V}$ to $1.6 \mathrm{~V}$ at $20 \mathrm{mV} / \mathrm{s}$.

Electrochemical oxidation Measurements. The electrochemical cell consisted of a glass/ITO/Au working electrode, a Pt wire counter electrode, and an $\mathrm{Ag} / \mathrm{AgCl}$ reference electrode. The oxidation of $\mathrm{Au}$ was montored by scanning from 0.4 to $1.1 \mathrm{~V}$ in a solution of $10 \mathrm{mM} \mathrm{KBr}$ plus $0.1 \mathrm{M} \mathrm{HClO}_{4}$ at a scan rate of $1 \mathrm{mV} / \mathrm{s}$ in linear sweep voltammetry (LSV) mode. 


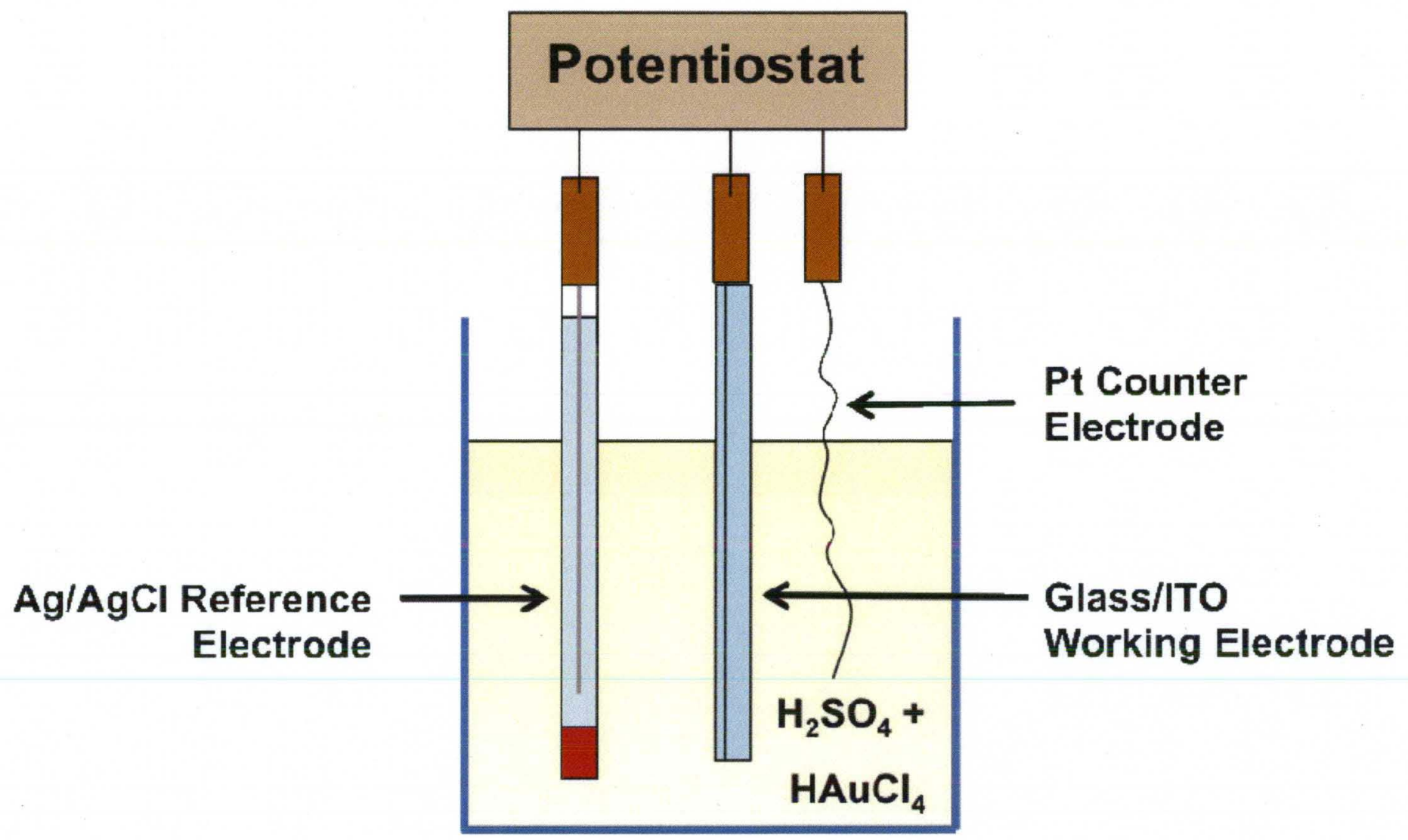


UV-vis characterization. UV-Vis spectroscopy data were obtained using a Varian Cary 50 Bio UV-Visible Spectrophotometer from 300 to $1100 \mathrm{~nm}$ in fast scan mode. The glass/ITO/Au absorbance was measured by placing the slide over the window and was referenced to the same glass/ITO slide before Au electrodeposition.

Scanning Electron Microscopy (SEM) Characterization. The same as that described in Chapter II.

\subsection{RESULTS AND DISCUSSION}

\subsubsection{Electrochemical deposition of Au nanoplates and nanoparticles on} glass/ITO electrodes. Figure 5.2 shows a cyclic voltammogram (CV) of a clean glass/ITO electrode from $1.5 \mathrm{~V}$ to $-1.0 \mathrm{~V}$ in a solution of $5 \times 10^{-3} \mathrm{M} \mathrm{HAuCl}_{4}$ plus $0.5 \mathrm{M}$ $\mathrm{H}_{2} \mathrm{SO}_{4}$ at a scan rate of $100 \mathrm{mV} / \mathrm{s}$. The cathodic peaks at $\sim 290 \mathrm{mV}$ and $-600 \mathrm{mV}$ correspond to the reduction of $\mathrm{AuCl}_{4}^{-}$to metallic $\mathrm{Au}^{0}$ and reduction of $\mathrm{H}^{+}$to $\mathrm{H}_{2}$, respectively. The reduction of $\mathrm{AuCl}_{4}{ }^{-}$can occur as follows:

$$
\begin{gathered}
\mathrm{AuCl}_{4}{ }^{-}+3 \overline{\mathrm{e}} \leftrightarrow \mathrm{Au}^{0}+4 \mathrm{Cl}^{-} \mathrm{E}^{0}=0.994 \mathrm{~V} \text { vs NHE } \\
\mathrm{AuCl}_{4}{ }^{-}+2 \overline{\mathrm{e}} \rightleftarrows \mathrm{AuCl}_{2}{ }^{-}+2 \mathrm{Cl}^{-} \mathrm{E}^{0}=0.926 \mathrm{~V} \text { vs NHE }
\end{gathered}
$$

The peak near $1.3 \mathrm{~V}$ corresponds to the re-oxidation of $\mathrm{Au}$.

We deposited Au nanostructures at a potential of $0.8 \mathrm{~V}$ as indicated by the red line in Figure 5.2. On the forward scan, there is no cathodic (reduction) current from $0.8 \mathrm{~V}$ to $\sim 0.6 \mathrm{~V}$. On the return scan there is a larger cathodic current from 0.5 to $0.8 \mathrm{~V}$ than on the 


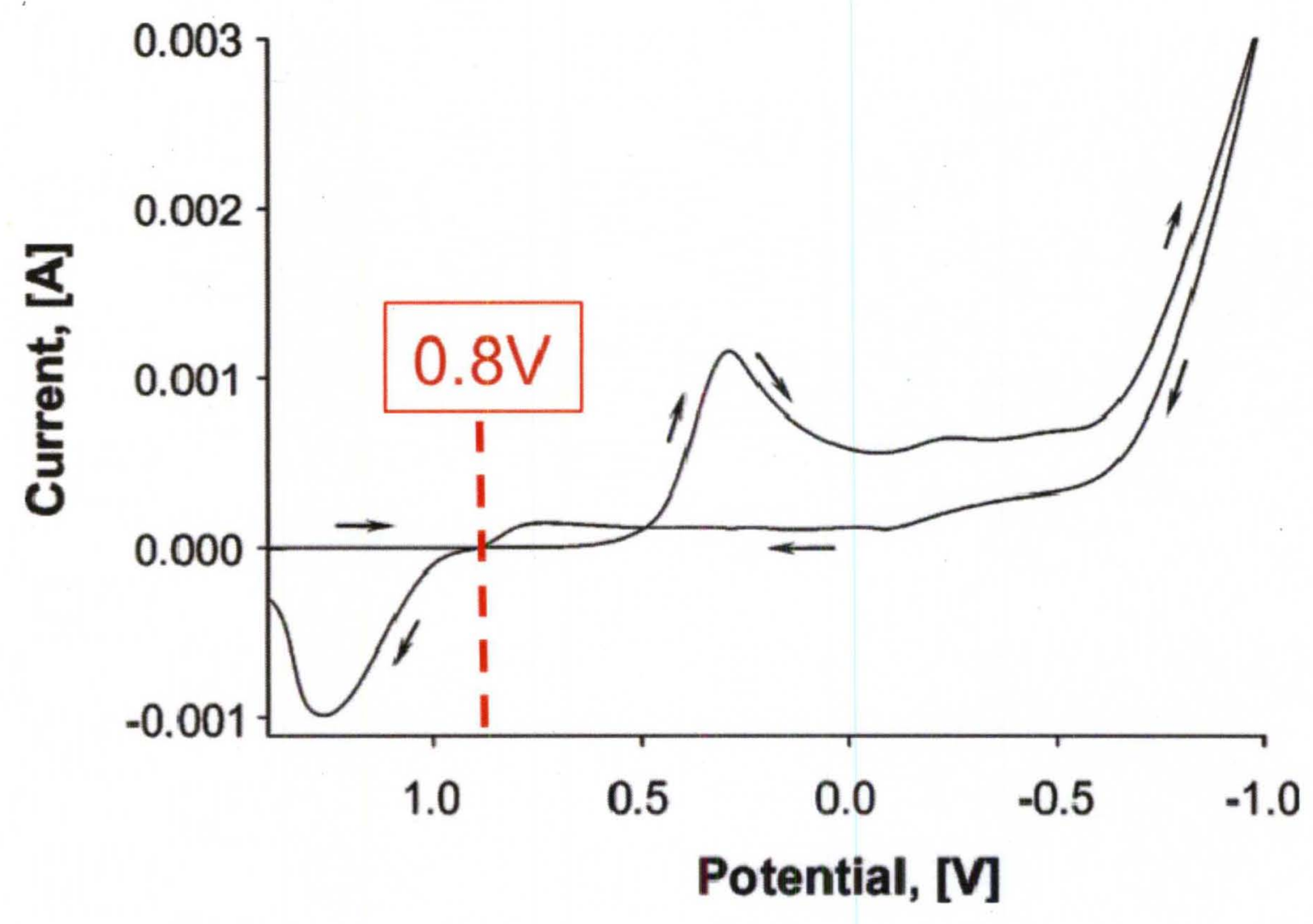

Figure 5.2. Cyclic Voltammogram (CV) of a glass/ITO electrode obtained in $5 \times 10^{-3} \mathrm{M}$ $\mathrm{HAuCl}_{4}$ plus $0.5 \mathrm{M} \mathrm{H}_{2} \mathrm{SO}_{4}$ at a scan rate of $100 \mathrm{mV} / \mathrm{s}$. The arrows show the direction of the forward and reverse scan beginning at $1.5 \mathrm{~V}$ and ending at $-1.0 \mathrm{~V}$. The deposition was made at $0.8 \mathrm{~V}$ for all synthesis. 
forward scan. The potential at $0.8 \mathrm{~V}$ is well before the Ep at $0.3 \mathrm{~V}$. At this potential the reduction is too slow to observe the current, but it still occurs. On the return scan, one can observe current because the Au deposited at more negative potential catalyzes deposition at more positive potential on the return scan. The amount of charge passed during the deposition was varied to observe the effect of charge on the size and shape of the deposited nanostructures. The charge varied from $3 \times 10^{-3}$ Coulombs (C) to $1.2 \times 10^{-2} \mathrm{C}$ with times ranging from $\sim 1000$ to $4000 \mathrm{~s}$, respectively. After each deposition cycle (approximately each 1000 seconds or each $3 \times 10^{-3} \mathrm{C}$ ), we obtained a CV in a solution of $0.01 \mathrm{M} \mathrm{Cu}\left(\mathrm{ClO}_{4}\right)_{2}$ plus $0.1 \mathrm{M} \mathrm{HClO}_{4}$ from $0.0 \mathrm{~V}$ to $1.6 \mathrm{~V}$ at a scan rate of $20 \mathrm{mV} / \mathrm{s}$. Overall, four deposition and four CV cycles were ran in order to synthesize $\mathrm{Au}$ nanoplates.

Figure 5.3 shows scanning electron microscopy (SEM) images of glass/ITO electrodes after the Au electrochemical deposition. For each sample, the deposition occurred in increments of $3 \times 10^{-3} \mathrm{C}$ until the final amount of charge was reached. Between each increment, a $\mathrm{CV}$ was obtained in $0.01 \mathrm{M} \mathrm{Cu}\left(\mathrm{ClO}_{4}\right)_{2}$ plus $0.1 \mathrm{M} \mathrm{HClO}_{4}$ from 0.0 to $1.6 \mathrm{~V}$ to observe the $\mathrm{Cu} \mathrm{UPD}$ region and $\mathrm{Au}$ oxidation/reduction region as discussed later. The dark, grainy background in the SEM images corresponds to the glass/ITO surface and the bright gray and white features correspond to the various Au nanostructures. Figure $5.3 \mathrm{~A}$ shows an SEM image after passing $3 \times 10^{-3} \mathrm{C}$ in 1000 seconds. The image shows flower-like Au nanostructures with an average diameter of $407 \pm 51 \mathrm{~nm}$. Figure 5.3B shows images of the surface after the second deposition of $3 \times 10^{-3} \mathrm{C}\left(\right.$ total $\left.=6 \times 10^{-3} \mathrm{C}\right)$. The surface contains flat structures, described as the 


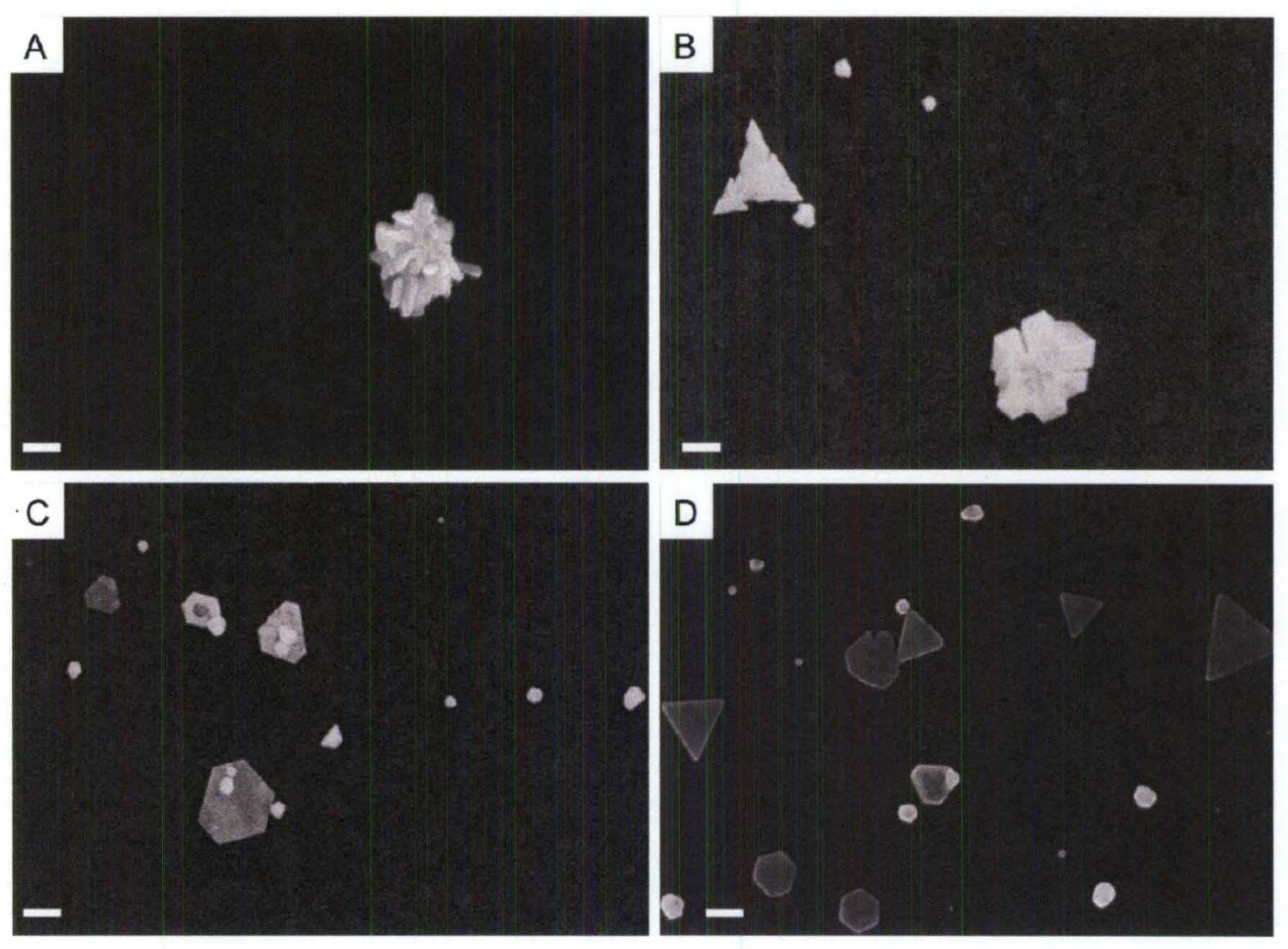

5.3. SEM images of glass/ITO electrodes after Au deposition at a potential of $0.8 \mathrm{~V}$ with a different amount of passed charge: (A) $3 \times 10^{-3} \mathrm{C}$; (B) $6 \times 10^{-3} \mathrm{C}$; (C) $9 \times 10^{-3} \mathrm{C}$; (D) $1.2 \times 10^{-2} \mathrm{C}$. The charge was passed in increments of $3 \times 10^{-3} \mathrm{C}$ and a $\mathrm{CV}$ was obtained from 0 to $1.6 \mathrm{~V}$ in $0.01 \mathrm{M} \mathrm{Cu}\left(\mathrm{ClO}_{4}\right)_{2}$ plus $0.1 \mathrm{M} \mathrm{HClO}_{4}$ solution (as described in the text) between each increment. The scale bars are $200 \mathrm{~nm}$. 
smashing of the flower-like structures. The average size was $410 \pm 92 \mathrm{~nm}$. Other smaller particles that are $114 \pm 34 \mathrm{~nm}$ are also present. Figures $5.3 \mathrm{C}\left(9 \times 10^{-3} \mathrm{C}\right)$ shows nanoplates that are better defined, but also coated with $\mathrm{Au}$ spheres on their surface. In Figure 5.4D $\left(1.2 \times 10^{-2} \mathrm{C}\right)$ the nanostructures became smoother and rounded or formed triangular plates.

We also studied Au deposition after passing charges of $6 \times 10^{-4} \mathrm{C}, 6 \times 10^{-3} \mathrm{C}$ and $1.2 \times 10^{-2} \mathrm{C}$. In this case, the deposition potential was constant at $0.8 \mathrm{~V}$ and we did not obtain a $\mathrm{CV}$ in $\mathrm{Cu}\left(\mathrm{ClO}_{4}\right)_{2}$ solution after each increment. Figure 5.4 shows the corresponding SEM images. According to the images and statistical calculations, the yield of nanoplates increased with increasing deposited charge, which was $0 \%$ after $6 \times 10^{-}$ ${ }^{4} \mathrm{C}, 5 \pm 2 \%$ after $6 \times 10^{-3} \mathrm{C}$ and $35 \pm 11 \%$ after $1.2 \times 10^{-2} \mathrm{C}$. The nanoplates appear to grow at the expense of the nanospheres as the amount of charge increased. These images show that the $\mathrm{CV}$ in $\mathrm{Cu}^{2+}+0.1 \mathrm{M} \mathrm{HClO}_{4}$ is not necessary to grow Au nanoplates.

Prior to obtaining the results in Figures 5.3 and 5.4, we tested many different concentrations of the $\mathrm{HAuCl}_{4}$ solution and different charge. The concentration of $\mathrm{H}_{2} \mathrm{SO}_{4}$ was kept constant at $0.5 \mathrm{M}$ while the concentration of $\mathrm{HAuCl}_{4}$ was varied as $5 \times 10^{-6} \mathrm{M}$, $2.5 \times 10^{-5} \mathrm{M}, 5 \times 10^{-5} \mathrm{M}, 5 \times 10^{-4} \mathrm{M}$ and $5 \times 10^{-3} \mathrm{M}$. The deposition potential was always stepped from $1.0 \mathrm{~V}$ to $0.8 \mathrm{~V}$. We tested three charges of $6 \times 10^{-4} \mathrm{C}, 6 \times 10^{-3} \mathrm{C}$ and $1.2 \times 10^{-2}$ $\mathrm{C}$ for each concentration. The corresponding SEM images are presented in Figure 5.5 and the statistical calculation of the size and yield of Au NPs at each condition are presented in Table 5.1. With a decreasing concentration of $\mathrm{HAuCl}_{4}$, the deposition time increases, the size of the nanostructures decreases, and the density increases. This occurs due to the fact that with increasing time of deposition, $\mathrm{Au}$ nucleation event have a greater 


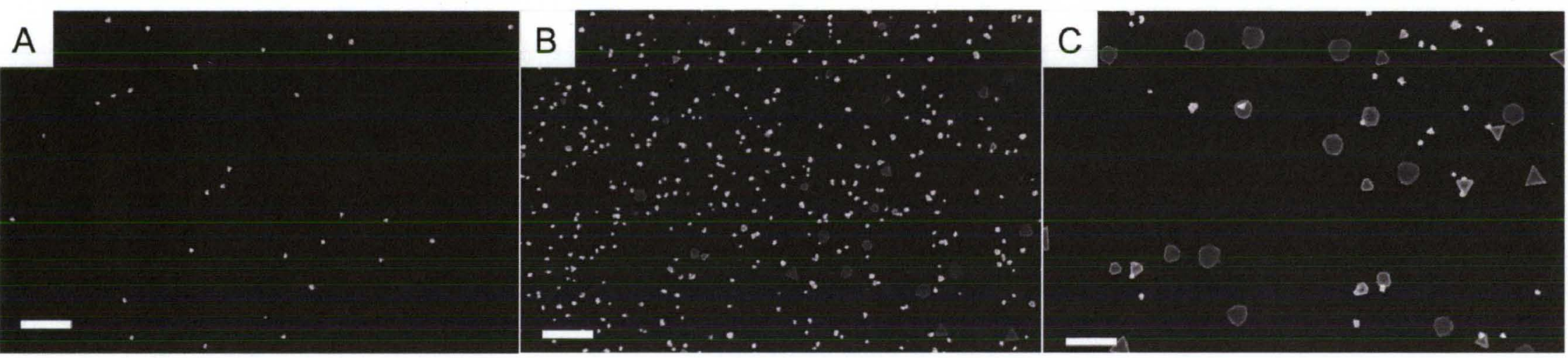

Figure 5.4. SEM images of glass/ITO/Au nanostructures deposited at a potential of $0.8 \mathrm{~V}$ with different amount of charge: (A) $6 \times 10^{-4}$ C; (B) $6 \times 10^{-3} \mathrm{C}$; and (C) $1.2 \times 10^{-2} \mathrm{C}$. The scale bars are $2 \mu \mathrm{m}$. 


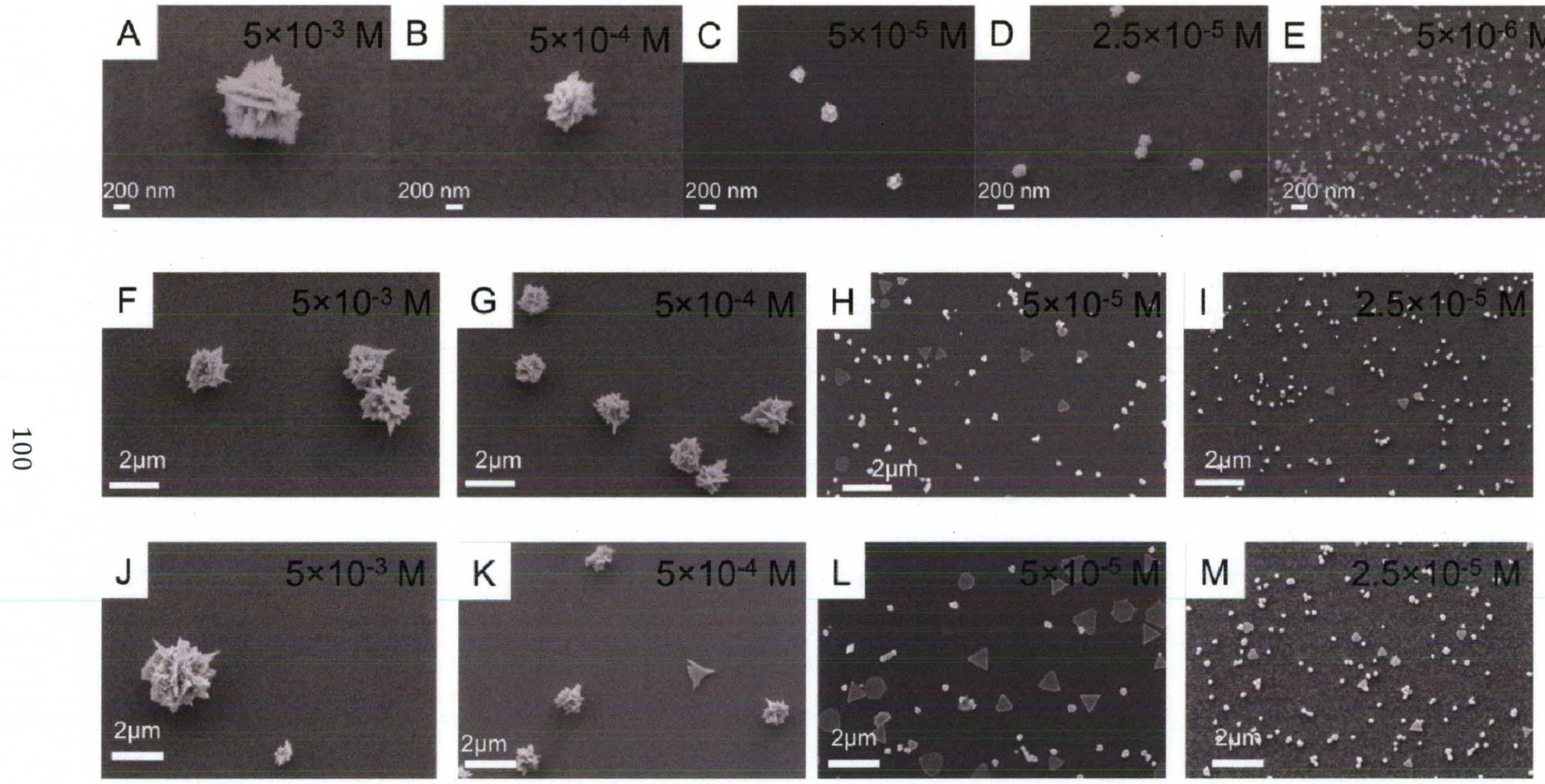

Figure 5.5. SEM images of glass/ITO/Au nanostructures deposited by a potential step from $1.0 \mathrm{~V}$ to $0.8 \mathrm{~V}$ from a solution with different concentrations of $\mathrm{HAuCl}_{4}$ (as indicated in each image) and constant $0.5 \mathrm{M}$ concentration of $\mathrm{H}_{2} \mathrm{SO}_{4}$ with different amounts of charge: (A), (B), (C), (D), (E) - $6 \times 10^{-4} \mathrm{C}$; (F), (G), (H), (I) - $6 \times 10^{-3} \mathrm{C}$; and $(\mathrm{J}),(\mathrm{K}),(\mathrm{L}),(\mathrm{M})-1.2 \times 10^{-2} \mathrm{C}$. 
Table 5.1. Statistical data of size, coverage, and yield of Au nanoplates obtained by electrochemical deposition at a potential of $0.8 \mathrm{~V}$ from solutions with different $\mathrm{HAuCl}_{4}$ concentration and different charge.

\begin{tabular}{|c|c|c|c|c|c|c|c|c|c|c|c|c|c|c|c|}
\hline $\begin{array}{c}\text { \# of } \\
\text { coulombs }\end{array}$ & \multicolumn{5}{|c|}{$6 \times 10^{-4} \mathrm{C}$} & \multicolumn{5}{|c|}{$6 \times 10^{-3} \mathrm{C}$} & \multicolumn{5}{|c|}{$1.2 \times 10^{-2} \mathrm{C}$} \\
\hline $\begin{array}{l}\mathrm{HAuCl}_{4} \\
\text { concentrati } \\
\text { on (M) }\end{array}$ & $\begin{array}{l}\text { Time. } \\
\text { sec }\end{array}$ & $\begin{array}{l}\quad \# \text { of } \\
\text { particles }+ \\
\text { plates, per } \\
2400 \mu \mathrm{m}^{2}\end{array}$ & $\begin{array}{c}\text { \# of } \\
\text { particles, } \\
\text { average } \\
\text { width }\end{array}$ & $\begin{array}{c}\text { \# of } \\
\text { plates. } \\
\text { average } \\
\text { width }\end{array}$ & $\begin{array}{l}\% \text { yield } \\
\text { of } \\
\text { plates }\end{array}$ & $\begin{array}{l}\text { Time, } \\
\text { sec }\end{array}$ & $\begin{array}{c}\text { \# of } \\
\text { particles }+ \\
\text { plates, per } \\
2400 \mu \mathrm{m}^{2}\end{array}$ & $\begin{array}{l}\text { \# of particles, } \\
\text { average width }\end{array}$ & $\begin{array}{c}\text { \# of } \\
\text { plates, } \\
\text { average } \\
\text { width }\end{array}$ & $\begin{array}{l}\% \text { yield } \\
\text { of } \\
\text { plates }\end{array}$ & $\begin{array}{l}\text { Tim } \\
\text { e, } \\
\text { sec }\end{array}$ & $\begin{array}{c}\text { \# of } \\
\text { particles } \\
\text { + plates, } \\
\text { per } \\
2400 \mu \mathrm{m}^{2}\end{array}$ & $\begin{array}{c}\text { \# of } \\
\text { particles, } \\
\text { average } \\
\text { width }\end{array}$ & $\begin{array}{l}\text { \# of plates, } \\
\text { average } \\
\text { width }\end{array}$ & $\begin{array}{l}\% \text { yield } \\
\text { of } \\
\text { plates }\end{array}$ \\
\hline $5 \times 10^{-3}$ & 66 & $8.2 \pm 3.2$ & $\begin{array}{c}8.2 \pm 3.2 \\
(1104.97 \pm \\
128.99) \mathrm{nm}\end{array}$ & 0 & 0 & 522 & $16.3 \pm 4.2$ & $\begin{array}{l}16.3 \pm 4.2 \\
(1722.09 \pm \\
490.76) \mathrm{nm}\end{array}$ & 0 & 0 & 1048 & $\begin{array}{c}13.3 \pm \\
2.1\end{array}$ & $\begin{array}{l}13.3 \pm 2.1 \\
(2324.89 \pm \\
522.49) \mathrm{nm}\end{array}$ & $\begin{array}{c}\text { kind of } \\
\text { plates } \approx 1 \text {; } \\
(1753.64 \pm \\
258.01) \mathrm{nm}\end{array}$ & $\approx 0 \%$ \\
\hline $5 \times 10^{-4}$ & 96 & $17.3 \pm 5.6$ & $\begin{array}{l}17.3 \pm 5.6 \\
(614.46 \pm \\
168.67) \mathrm{nm}\end{array}$ & 0 & 0 & 561 & $30.8 \pm 8.7$ & $\begin{array}{c}30.8 \pm 8.7 \\
(1268.40 \pm \\
96.24) \mathrm{nm}\end{array}$ & 0 & 0 & 1038 & $\begin{array}{l}63.5 \pm \\
23.5\end{array}$ & $\begin{array}{l}59.2 \pm 21.4 \\
(1045.54 \pm \\
232.57) \mathrm{nm}\end{array}$ & $\begin{array}{c}4 \pm 1 ; \\
(1322.83 \pm \\
155.33) \mathrm{nm}\end{array}$ & $6.3 \%$ \\
\hline $5 \times 10^{-5}$ & 254 & $40.3 \pm 15.0$ & $\begin{array}{c}40.3 \pm 15.0 \\
(457.83 \pm \\
66.60) \mathrm{nm}\end{array}$ & 0 & 0 & 1939 & $\begin{array}{c}86.0 \pm \\
24.0\end{array}$ & $\begin{array}{c}70.5 \pm 16.2 \\
(305.22 \pm \\
88.4) \mathrm{nm}\end{array}$ & $\begin{array}{c}15.5 \pm \\
7.7 \\
(554.35 \pm \\
108.47) \mathrm{n} \\
\mathrm{m}\end{array}$ & $\begin{array}{c}(17.43 \\
\pm \\
4.16) \%\end{array}$ & 3727 & $\begin{array}{l}72.8 \pm \\
41.62\end{array}$ & $\begin{array}{c}63.25 \pm \\
28.07 \\
(259.48 \pm \\
40.89) \mathrm{nm}\end{array}$ & $\begin{array}{c}24.5 \pm 3.87 \\
(679.71 \pm \\
46.00) \mathrm{nm}\end{array}$ & $\begin{array}{c}(35.74 \\
\pm \\
11.04) \\
\%\end{array}$ \\
\hline $2.5 \times 10^{-5}$ & 647 & $\begin{array}{c}619.5 \pm \\
75.7\end{array}$ & $\begin{array}{c}619.5 \pm \\
75.7 \\
(156.58 \pm \\
23.63) \mathrm{nm}\end{array}$ & 0 & 0 & 3848 & $\begin{array}{c}1071.8 \pm \\
129.56\end{array}$ & $\begin{array}{c}1038 \pm 137.5 \\
(153.37 \pm \\
41.7) \mathrm{nm}\end{array}$ & $\begin{array}{c}44 \pm \\
14.23 \\
(381.82 \pm \\
50.29) \mathrm{nm}\end{array}$ & $\begin{array}{l}(4.02 \pm \\
0.95) \%\end{array}$ & 9018 & $\begin{array}{c}1575.5 \pm \\
433.7\end{array}$ & $\begin{array}{c}1283.3 \pm 434 \\
7 ;(254.33 \pm \\
47.35) \mathrm{nm}\end{array}$ & $\begin{array}{c}291.7 \pm \\
62.9 \\
(480.55 \pm \\
167.7) \mathrm{nm}\end{array}$ & $\begin{array}{c}(19.35 \\
\pm \\
6.65) \%\end{array}$ \\
\hline $5 \times 10^{-6}$ & 5980 & $\begin{array}{c}(252.8 \pm 35 \\
1)^{*} 400\end{array}$ & $\begin{array}{c}(222 \pm 34.7) \\
* 400 \\
(50.64 \pm 17 \\
79) \mathrm{nm}\end{array}$ & $\begin{array}{c}(31 \pm 3.4)^{*} \\
400 ; \\
(107.48 \pm 2 \\
7.79) \mathrm{nm}\end{array}$ & $\begin{array}{l}12.3 \pm \\
2.4 \%\end{array}$ & & & & & & & & & & \\
\hline
\end{tabular}


probability to occur. Also, this method can be used as a method to prepare of Au NPs with controlled size because most of the nanoparticles have uniform size and they are equally distributed on the surface of the glass/ITO. The appearance of plates occured from the solution with a concentration of $5 \times 10^{-6} \mathrm{M}$ (Figure $\left.5.5(\mathrm{E})\right)$. The average yield of the nanoplates was $12.3 \pm 2.4 \%$. The other trial which has a comparatively larger yield of nanoplates $(45 \pm 11 \%)$ was deposited from a solution with a concentration of $5 \times 10^{-5} \mathrm{M}$ and the charge was $1.2 \times 10^{-3} \mathrm{C}$ (Figure $5.5(\mathrm{~L})$ ). According to the statistical data of the sample, the average diameter of the nanoplates was $679 \pm 41 \mathrm{~nm}$ and the average diameter of nanoparticles was $259 \pm 46 \mathrm{~nm}$ for that sample. The area is covered mostly by nanoplates than by NPs. Unfortunately these methods did not give a high yield of plates considering the number of plates per total amount of nanostructures.

In order to obtain a higher yield of nanoplates we developed another strategy. The nanostructures were electrochemically deposited at a potential of $0.8 \mathrm{~V}$ in chronocoulometry mode till they reached the charge of approximately $3 \times 10^{-3} \mathrm{C}$ (after $1000 \mathrm{sec}$.) and then one cycle of $\mathrm{CV}$ from the potential $0.1 \mathrm{~V}$ to $1.6 \mathrm{~V}$ in a solution of $\mathrm{Cu}\left(\mathrm{ClO}_{4}\right)_{2}$ or $\mathrm{HClO}_{4}$ vs. $\mathrm{Ag} / \mathrm{AgCl}$ was performed. Figure 5.6 shows typical SEM images of $\mathrm{Au}$ nanostructures obtained from $5 \times 10^{-5} \mathrm{M} \mathrm{HAuCl}_{4}$ at a deposition potential of $0.8 \mathrm{~V}$ until a total charge of $1.2 \times 10^{-2} \mathrm{C}$ was reached. In Figure $5.6(\mathrm{~A})$, the nanostructures were obtained by the simple deposition in chronocoulometry mode. The average diameter of the NPs was $179.6 \pm 58 \mathrm{~nm}$, the average diameter of nanoplates was $349 \pm 74 \mathrm{~nm}$, and the yield of the nanoplates was $35 \pm 11 \%$. Figure 5.6 (B) shows a typical image of $\mathrm{Au}$ nanostructures obtained by deposition and oxidation/reduction by $\mathrm{CV}$ in $0.1 \mathrm{M} \mathrm{HClO}_{4}$. In this case, the yield of nanoplates was $38 \pm 9 \%$, the size of the NPs was $59.3 \pm 19.6 \mathrm{~nm}$, 


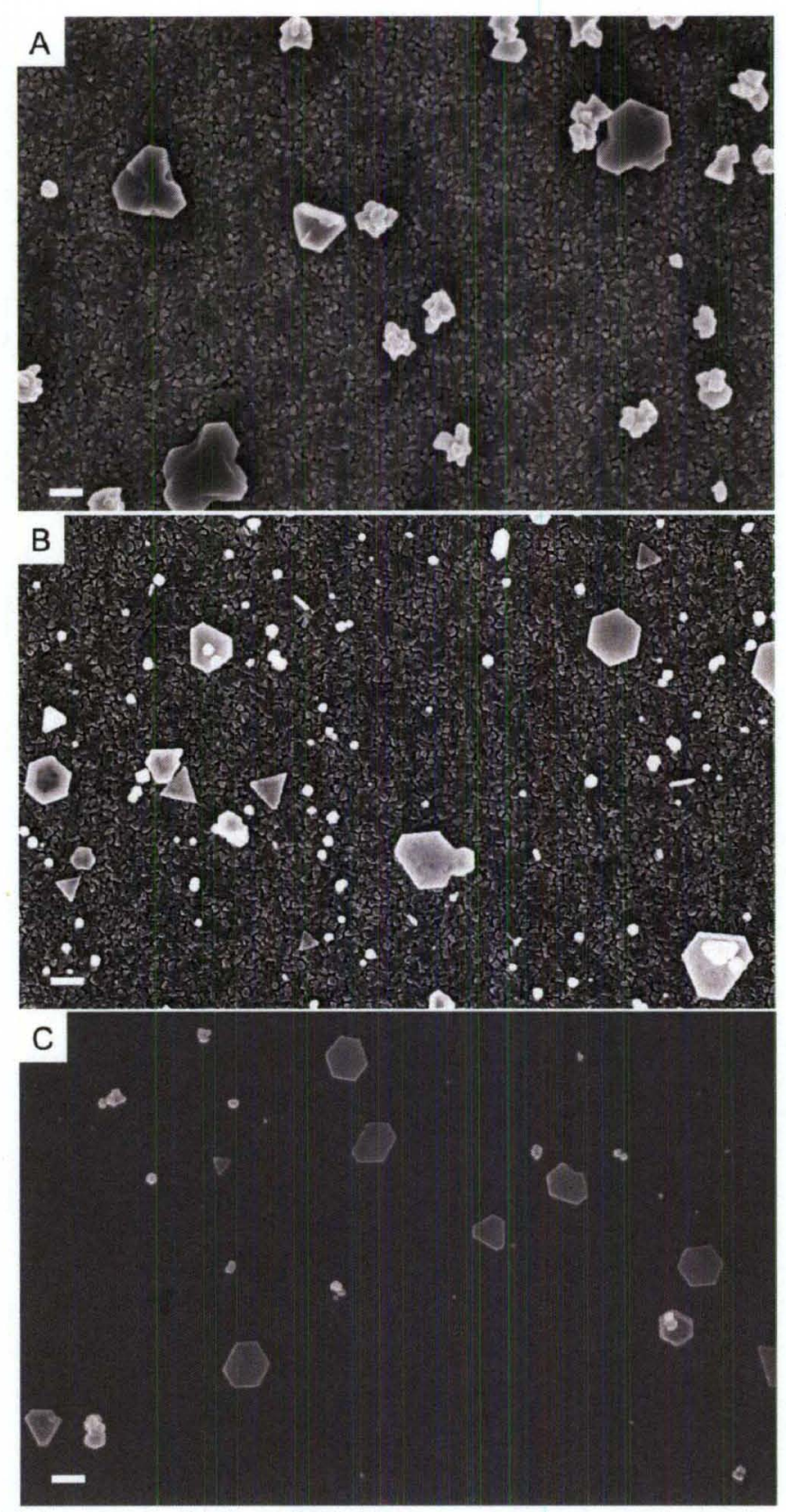

Figure 5.6. SEM images of glass/ITO/Au nanostructures deposited by stepping the potential from $1.0 \mathrm{~V}$ to $0.8 \mathrm{~V}$ in a $5 \times 10^{-5} \mathrm{M} \mathrm{HAuCl}_{4}$ plus $0.5 \mathrm{M} \mathrm{H}_{2} \mathrm{SO}_{4}$ solution with a charge of $1.2 \times 10^{-2} \mathrm{C}$ under different conditions: (A)without cycling between $3 \times 10^{-3} \mathrm{C}$ intervals; (B) with cycling in $0.1 \mathrm{M} \mathrm{HClO}_{4}$ between $3 \times 10^{-3} \mathrm{C}$ intervals, and (C) with cycling in $0.01 \mathrm{M} \mathrm{Cu}\left(\mathrm{ClO}_{4}\right)_{2}$ plus $0.1 \mathrm{M} \mathrm{HClO}_{4}$ between $3 \times 10^{-3} \mathrm{C}$ intervals. 
and the average diameter of the nanoplates was $314 \pm 151 \mathrm{~nm}$. The best results are presented in Figure $5.6(\mathrm{C})$, where the yield of nanoplates was $50 \pm 7 \%$, the average diameter of the nanoplates was $269 \pm 37 \mathrm{~nm}$, and the size of the NPs decreased to $14 \mathrm{~nm}$, which makes the nanoplates to be predominant structure in terms of the area covered by the nanostructure.

5.3.2. Spectroscopy studies. We obtained UV-vis spectra for the different glass/ITO/Au nanostructures. Au nanostructures absorb strongly in the visible region due to the localized surface plasmon absorption. Metallic Au has a characteristic localized surface plasmon resonanoce (LSPR) band in the visible/near-infrared range (520-2000 $\mathrm{nm})$, depending on the size and shape of the nanostructures. ${ }^{128,3}$ The magnitude of the LSPR band can be used to qualitively determine the amount of Au on the surface and the specifics of the Au NP shape. Au NPs with spherical shapes have a LSPR band at 520$600 \mathrm{~nm}$, and with the appearance of nanoplates, the LSPR band have additional second peak at $\sim 895 \mathrm{~nm}$ as presented in Figure 5.7. The two peaks likely present spheres and plates. Au was deposited from $5 \times 10^{-5} \mathrm{M} \mathrm{HAuCl}_{4}$ plus $0.5 \mathrm{M} \mathrm{H}_{2} \mathrm{SO}_{4}$ at a potential of 0.8 $\mathrm{V}$ until $3 \times 10^{-3} \mathrm{C}, 6 \times 10^{-3} \mathrm{C}, 9 \times 10^{-3} \mathrm{C}$ and $1.2 \times 10^{-2} \mathrm{C}$ of charge passed. With increasing charge during the deposition the peak intensity at the $600 \mathrm{~nm}$ corresponding to the $\mathrm{Au}$ NPs with spherical shape increased. Also, the addition of the second peak of the LSPR band is occurred at $6 \times 10^{-3} \mathrm{C}$ with the appearance of the nanoplates. The intensity of the LSPR band at $895 \mathrm{~nm}$, corresponding to the nanoplates, also increased with increasing the amount of nanoplates.

5.3.3. Cu underpotential deposition (Cu-UPD) studies. The position of the $\mathrm{Cu}$ UPD peaks on Au depends on the Au crystal face exposed and therefore the 


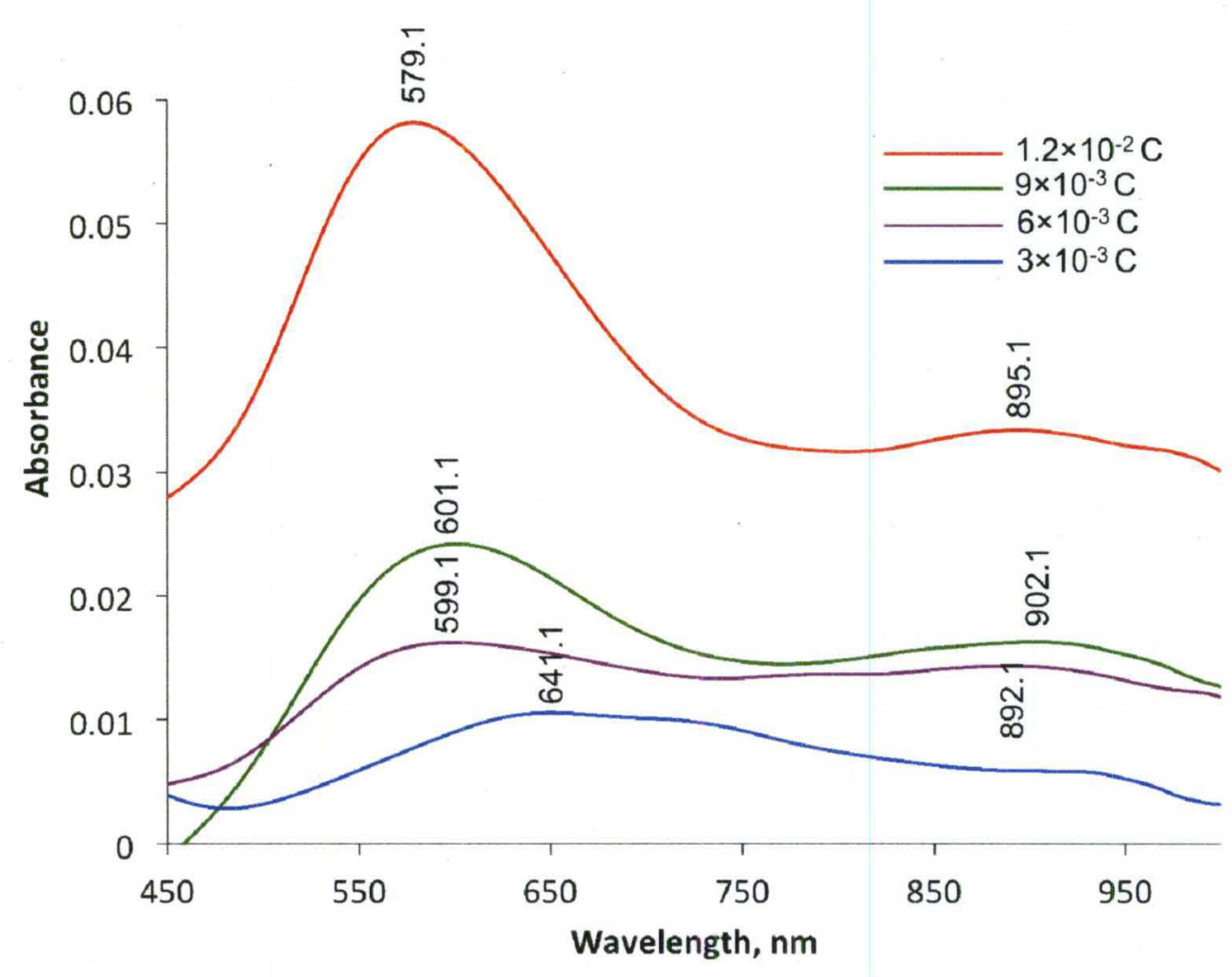

Figure 5.7. UV-vis spectra of glass/ITO/Au electrodes deposited at $0.8 \mathrm{~V}$ with a charge of (A) $3 \times 10^{-3} \mathrm{C}$ (blue), (B) $6 \times 10^{-3} \mathrm{C}$ (purple), (C) $9 \times 10^{-3} \mathrm{C}$ (green), and (D) $1.2 \times 10^{-2}$ $\mathrm{C}(\mathrm{red})$. The absorbance increased with increasing Au deposition charge in all cases. 
nanostructure shape. For this reason Cu UPD was monitored by cyclic voltammetry CV) in a $0.01 \mathrm{M} \mathrm{Cu}\left(\mathrm{ClO}_{4}\right)_{2}+0.1 \mathrm{M} \mathrm{HClO}_{4}$ solution in the range of potential from 0 to $1.6 \mathrm{~V}$ versus $\mathrm{Ag} / \mathrm{AgCl}$ at $20 \mathrm{mV} / \mathrm{s}$, in order to reveal and confirm the changes in the $\mathrm{Au}$ nanostructures. Figure 5.8 shows CVs of glass/ITO electrodes with Au nanostructures deposited at a potential of $0.8 \mathrm{~V}$ with $3 \times 10^{-3} \mathrm{C}, 6 \times 10^{-3} \mathrm{C}, 9 \times 10^{-3} \mathrm{C}$ and $1.2 \times 10^{-2} \mathrm{C}$ of charge. The Cu UPD peaks are near $300 \mathrm{mV}$ and their size increased with increasing Au. The UPD signature also changed, indicating the presence of different shaped structures. They are different from each other by their shape and size. In the case of glass/ITO/Au deposited with $3 \times 10^{-3} \mathrm{C}$, the $\mathrm{Cu}$ UPD reduction was not well-pronounced, but the subsequent oxidation was visible at $\sim 310 \mathrm{mV}$. For glass/ITO/Au deposited with $1.2 \times 10^{-2}$ $\mathrm{C}$ both oxidation and reduction $\mathrm{Cu}$ UPD peaks are very well-pronounced. Three sharp oxidation peaks at $\sim 290 \mathrm{mV}, \sim 320 \mathrm{mV}$ and $\sim 370 \mathrm{mV}$ appeared. At these conditions the yield of plates are maximum and the crystal face of the Au is primarily (111). With an increasing of the amount of deposited $\mathrm{Au}$ and with the changing of the crystal phase of deposited Au nanostructures Cu UPD peaks have the tendency to split, become sharper and more intensive.

Figure 5.9 shows the process of the formation of nanoplates from the nanoparticles with increasing the charge passed during the deposition process. According to this scheme, at the first step, which we can observe in the first 1000 seconds when the passed charge is till $3 \times 10^{-3} \mathrm{C}$, the nanoparticles with an average diameter $\sim 407 \pm 51 \mathrm{~nm}$ formed. They have a flower-like structure and are uniformly distributed over the surface of the glass/ITO working electrode. The next step is the smashing of big nanoparticles into an 


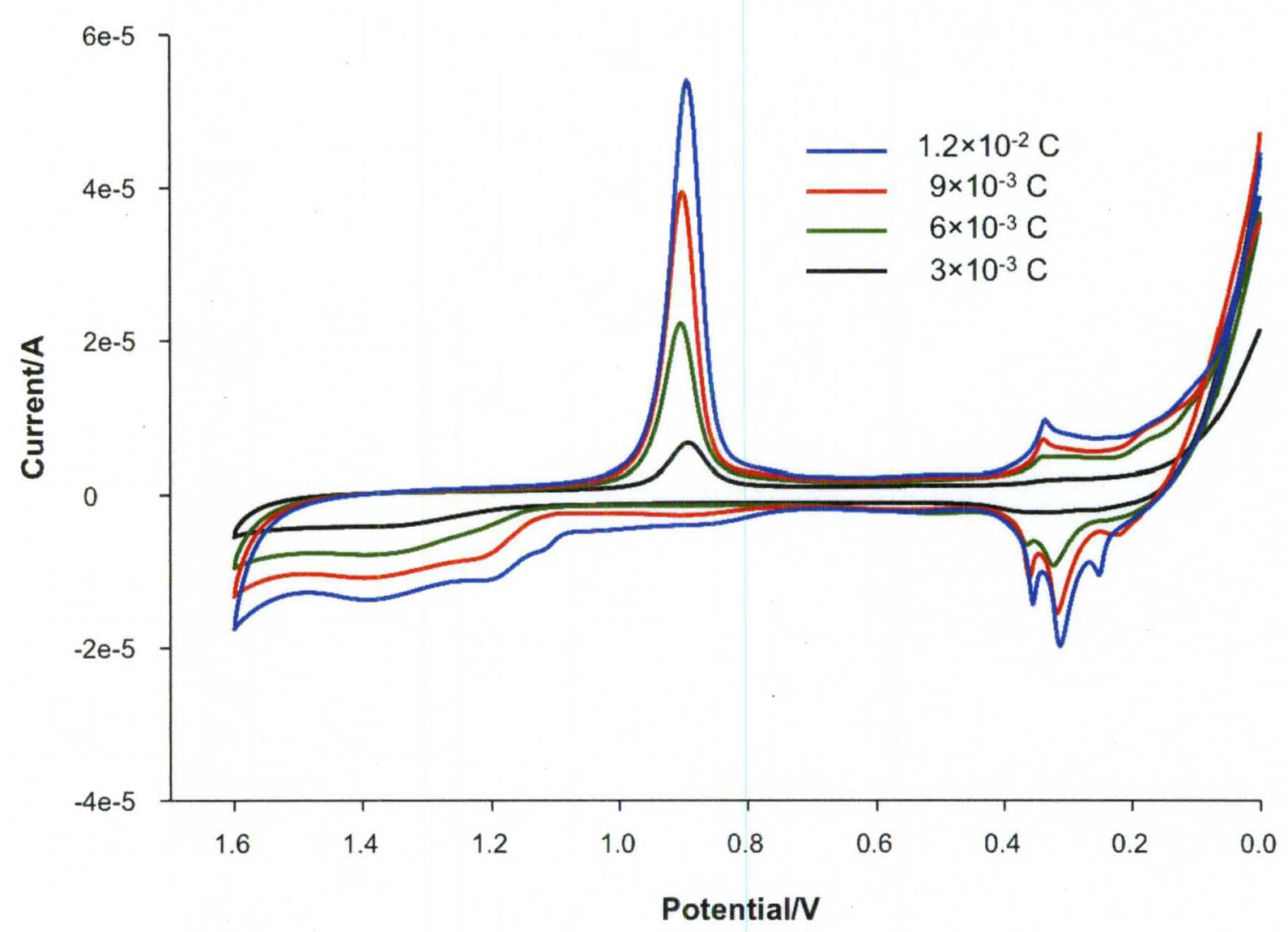

Figure 5.8. Cyclic voltammogram (CV) of Cu UPD on glass/ITO electrodes deposited with $3 \times 10^{-3} \mathrm{C}$ (black), $6 \times 10^{-3} \mathrm{C}$ (green), $9 \times 10^{-3} \mathrm{C}$ (red) and $1.2 \times 10^{-2} \mathrm{C}$ (blue) of $\mathrm{Au}$. 
irregular-shaped nanoplate and their growth. These nanostructures have relatively smooth surfaces with numerous edged borders. The average diameter of these nanostructures is $410 \pm 92 \mathrm{~nm}$. This step occurs after approximately $2000 \mathrm{sec}$ of continuous passing of charge. The total charge is $6 \times 10^{-3} \mathrm{C}$. Next, the irregular-shape nanostructures with the smooth surface began etching and converting their shape into triangular or hexagonal nanoplates. Their average diameter decreased to $271 \pm 111 \mathrm{~nm}$. At the same time some nanoparticles, which didn't converted into nanoplates, dissolve, decreasing in size to 35.7 $\pm 32 \mathrm{~nm}$ in diameter. The final process is the aggregation of nanoplates with some nanoparticles. They stick to each other, then ripen and dissolve. This was observable after approximately $9 \times 10^{-3} \mathrm{C}-1.2 \times 10^{-2} \mathrm{C}$ were passed. The nanoplates decrease a bit in size to an average diameter of $269 \pm 37 \mathrm{~nm}$ and the rest of the nanoparticles, which did not form nanoplates, decreased in size to $14 \mathrm{~nm}$.

In order to consider the features of $\mathrm{Cu}$ UPD on the high index crystal surfaces it is necessary to compare the voltammograms with those for the relevant low index surfaces. For this purpose we conducted two experiments. In the first experiment we obtained Au nanoplates by electrochemical deposition from $5 \times 10^{-5} \mathrm{M} \mathrm{HAuCl}_{4}$ plus $0.5 \mathrm{M} \mathrm{H}_{2} \mathrm{SO}_{4}$ at a potential of $0.8 \mathrm{~V}$ until $9 \times 10^{-3} \mathrm{C}$ passed. The yield was $\sim 30 \%$. The indication of plates was the two Cu UPD oxidation peaks as shown in Figure 5.10 (black) at potentials $~ 320$ and $\sim 360 \mathrm{mV}$, and the SEM image, presented in Figure 5.12A. Next, the Au was oxidized in $10 \mathrm{mM} \mathrm{KBr}$ and $0.1 \mathrm{M} \mathrm{HClO}_{4}$ solution by LSV. The oxidation potential of the Au NPs used in our study is $\sim 920 \mathrm{mV}$ as shown in Figure 5.11 (black). The initial potential was $0.5 \mathrm{~V}$ and the scan was stopped at $0.8 \mathrm{~V}$ to partially oxidize the Au to determine which shapes were more stable against dissolution. After the glass/ITO/Au was 


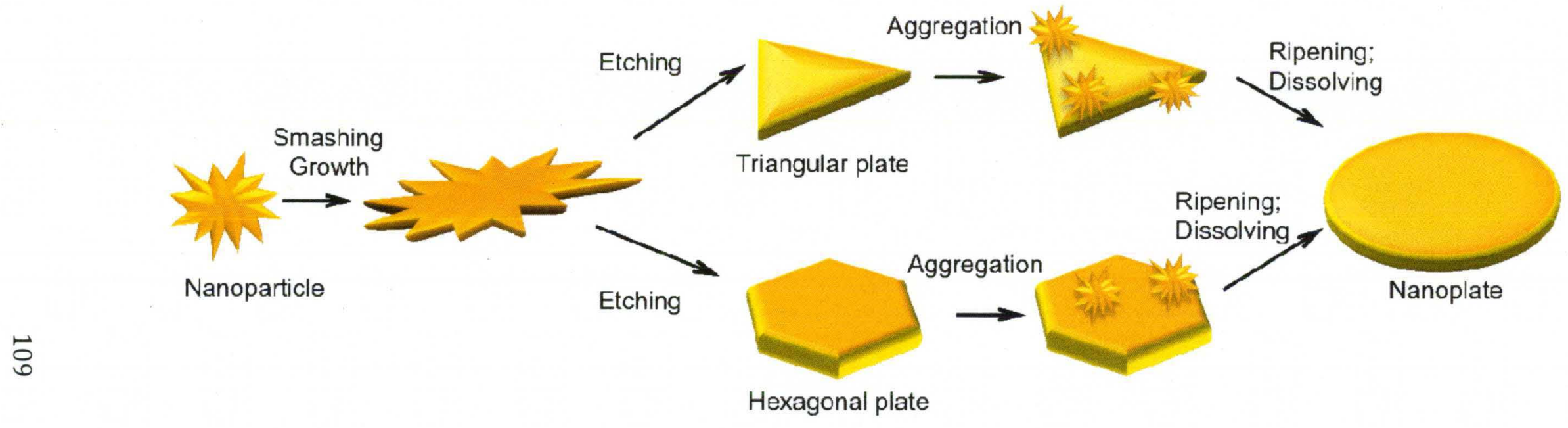

Figure 5.9. Scheme of nanoplates formation. 


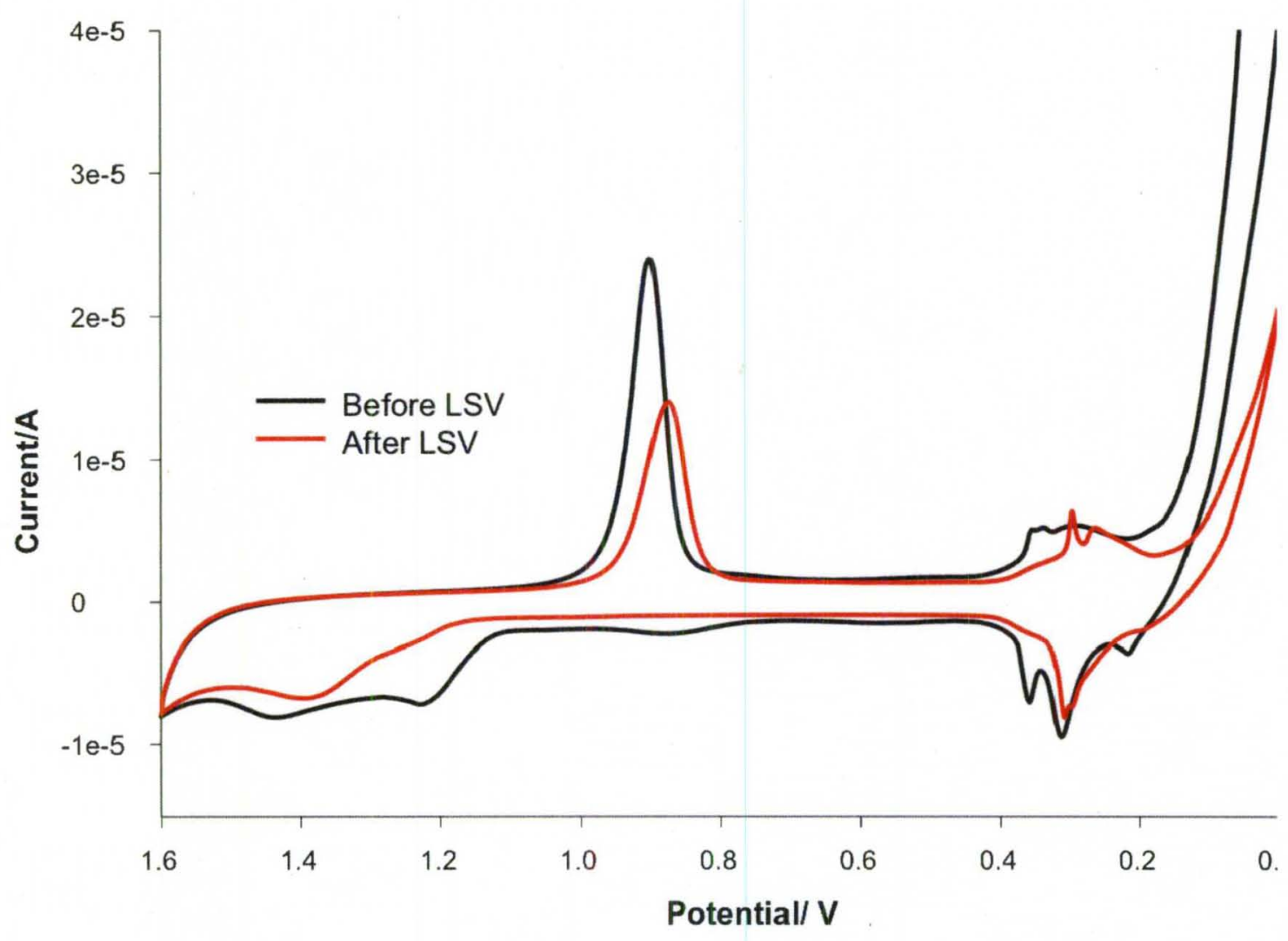

Figure 5.10. Cyclic voltammograms of $\mathrm{Cu}$ UPD on glass/ITO/Au obtained from $0.01 \mathrm{M} \mathrm{Cu}\left(\mathrm{ClO}_{4}\right)_{2}$ plus $0.1 \mathrm{M} \mathrm{HClO}_{4}$ before (black) and after (red) oxidation of $\mathrm{Au}$. Scan rate $20 \mathrm{mV} / \mathrm{s}$. 


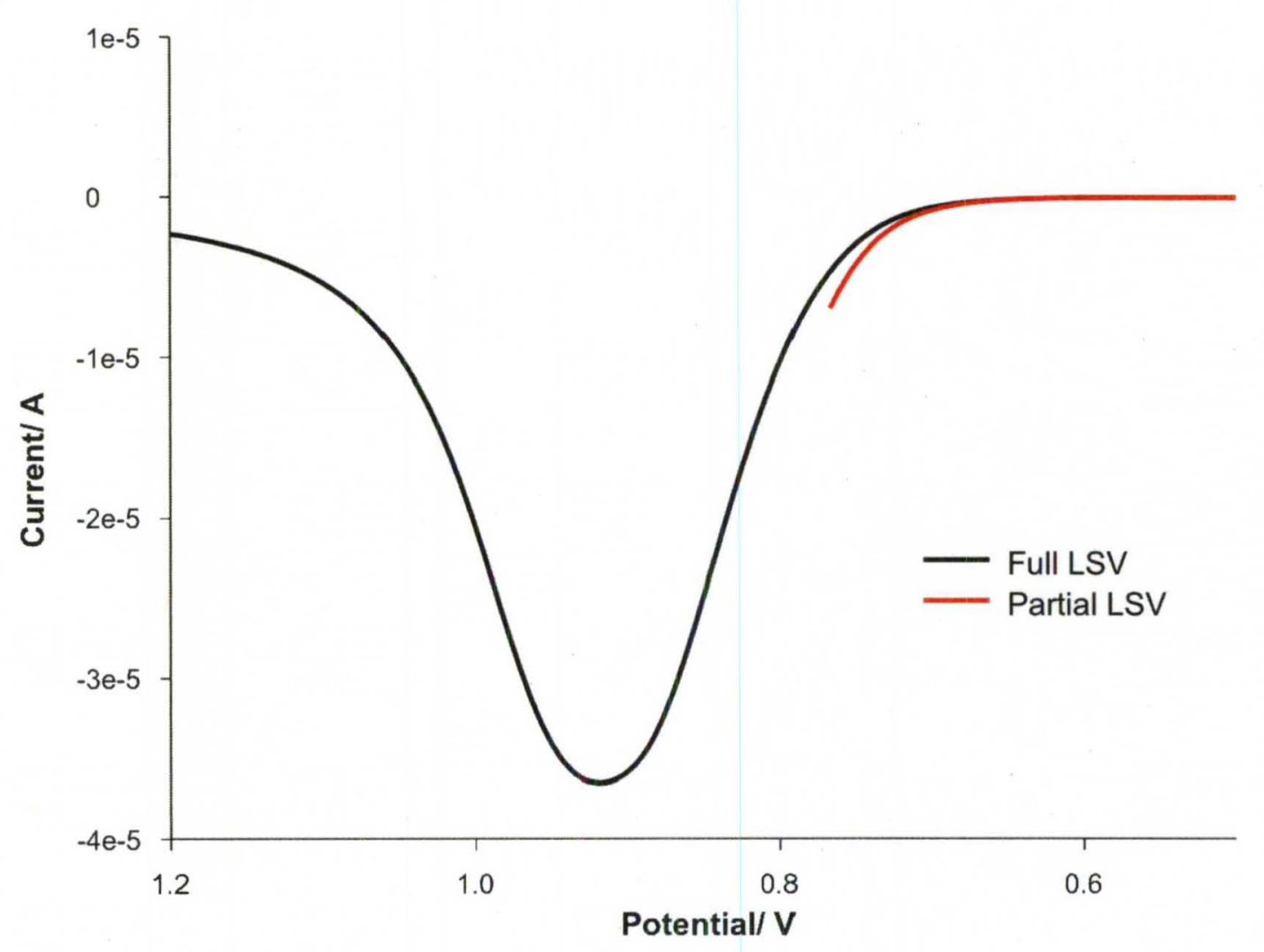

Figure 5.11. Linear Sweep Voltammograms (LSVs) of glass/ITO coated with electrochemically deposited Au NPs and nanoplates obtained in $10 \mathrm{mM}$ KBr plus 0.1 $\mathrm{M} \mathrm{HClO}_{4}$ electrolyte at $1 \mathrm{mV} / \mathrm{s}$. Black - full oxidation, red - partial oxidation. 


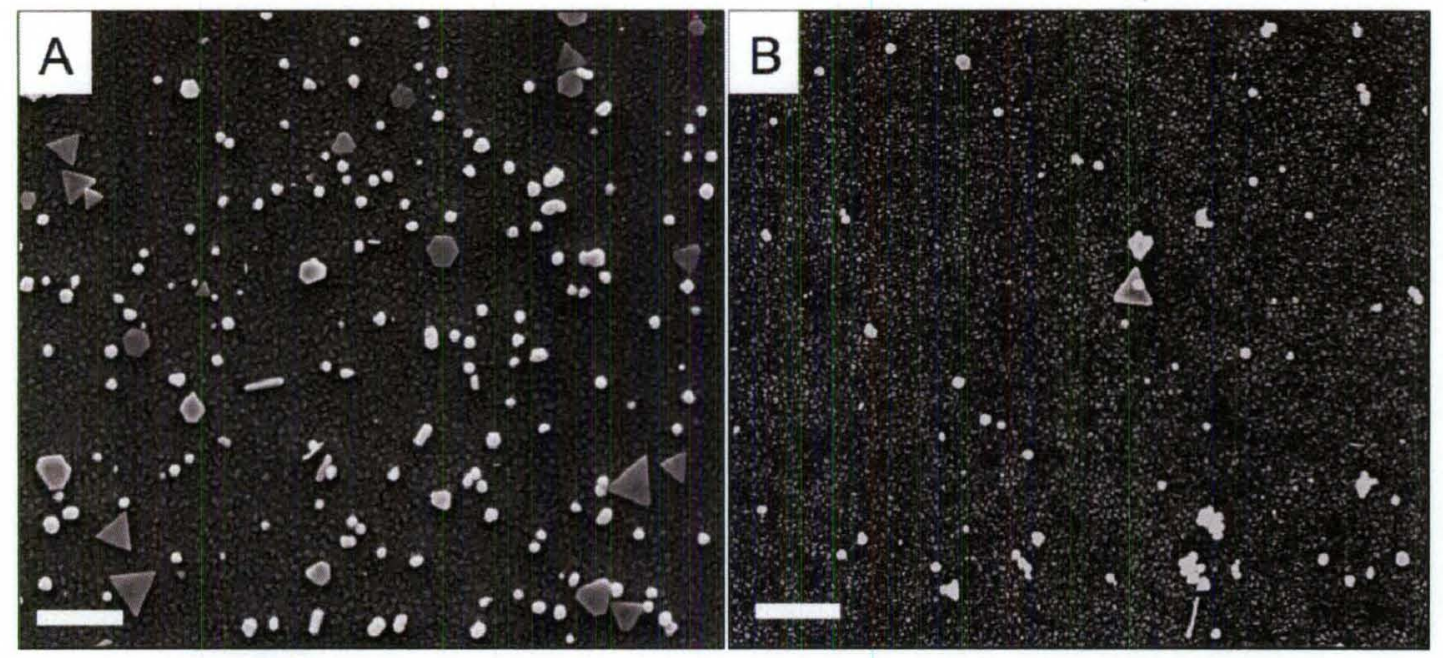

Figure 5.12. SEM images of glass/ITO/Au deposited at a potential of $0.8 \mathrm{~V}$ before (A) and after (B) oxidation in $10 \mathrm{mM} \mathrm{KBr}$ plus $0.1 \mathrm{M} \mathrm{HClO}_{4}$. The scale bars are $1 \mu \mathrm{m}$. 
partially oxidized by LSV, the number of nanoplates dramatically decreased as shown in the SEM image of Figure 5.12B. The yield of nanoplates after the oxidation was $\sim 3 \%$. The remaining $\mathrm{Au}$ nanostructure were spherical shapes. This shows that nanoplates are less stable compared to nanoparticles since they oxidize first. After the partial oxidation of glass/ITO/Au, a CV of the Cu UPD was obtained as shown in Figure 5.10 (red). It is obvious that the amount of $\mathrm{Au}$ decreased, and as a result, the $\mathrm{Au}$ reduction peak became smaller and the potential shifted from $\sim 901 \mathrm{mV}$ to $\sim 870 \mathrm{mV}$ due to the decreasing size of the Au NPs. The Au oxidation peak at $1.2 \mathrm{~V}$ also changed its shape and intensity. Also, from this figure, we can conclude that the disappearance of the two $\mathrm{Cu}$ UPD oxidation peak, which indicated the presence nanoplates. Cu UPD have various features on the surfaces with different crystal phases.

In another experiment, Au NPs with a flower-like structure and average diameter of $180.5 \pm 33.4 \mathrm{~nm}$ were electrochemically deposited from a solution of $5 \times 10^{-5} \mathrm{M} \mathrm{HAuCl}_{4}$ plus $0.5 \mathrm{M} \mathrm{H}_{2} \mathrm{SO}_{4}$ at potential of $0.6 \mathrm{~V}$ until $4 \times 10^{-3} \mathrm{C}$ as shown in Figure $5.13 \mathrm{~A}$. On another glass/ITO electrode, Au nanoplates were deposited, which is shown in Figure 5.13B. The surface area of the deposited Au was constant for the comparison of Cu UPD oxidation peaks so that the amount of surface Au would not affect the shape and magnitude of the $\mathrm{Cu}$ UPD oxidation peak. After electrochemical deposition of the $\mathrm{Au}$ nanostructures with different crystallographic structures, but the same surface area the $\mathrm{CVs}$ of $\mathrm{Cu}$ UPD from 0.0 to $1.6 \mathrm{~V}$ Versus $\mathrm{Ag} / \mathrm{AgCl}$ at $20 \mathrm{mV} / \mathrm{s}$. were obtained as shown in Figure 5.13. According to the Au reduction peak at $\sim 900 \mathrm{mV}$ the surface area of the $\mathrm{Au}$ nanostructures are very close to each other because the areas and shapes of these peaks are almost the same, but the Au oxidation peaks are different. For Au NPs, the 


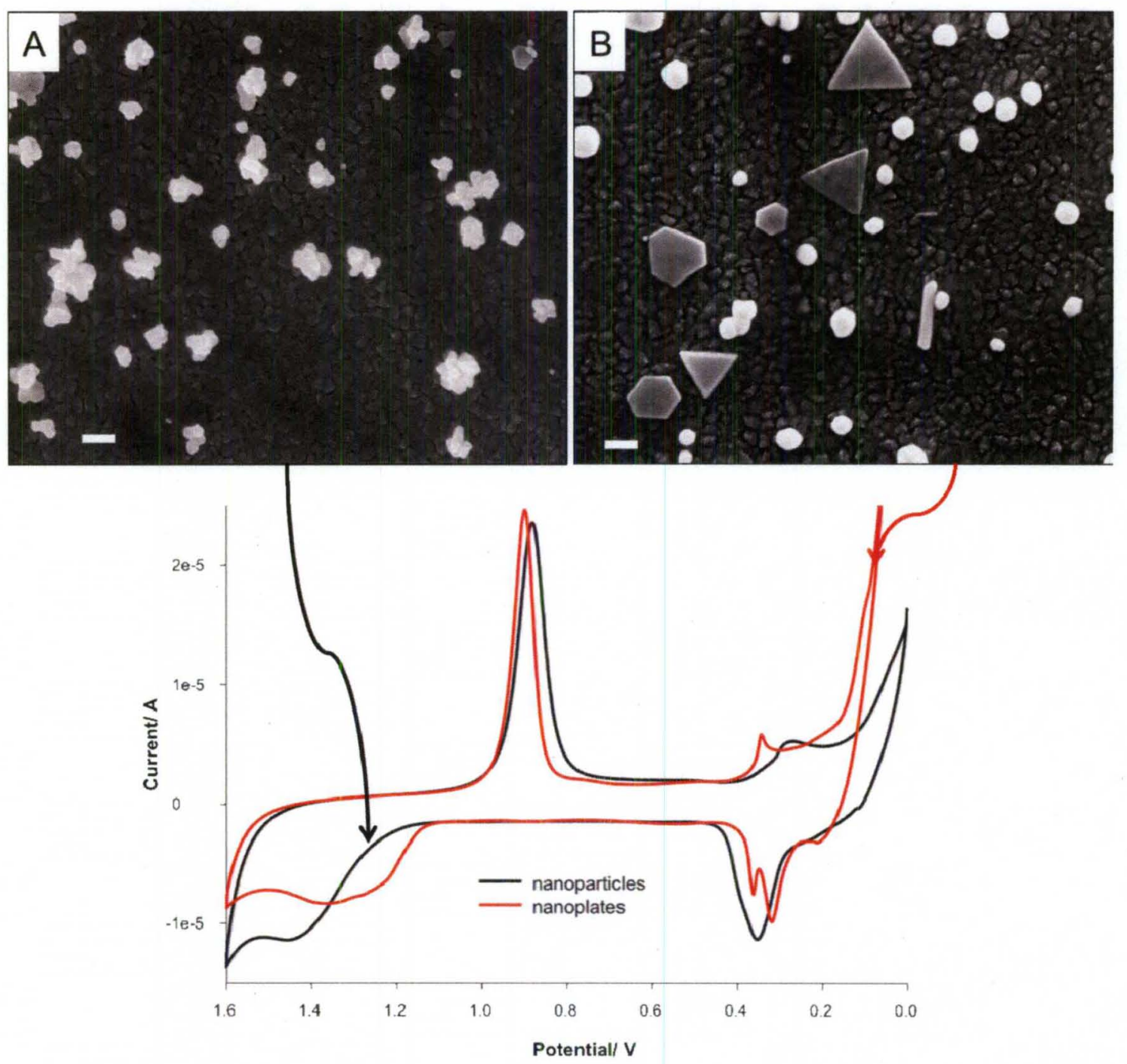

Figure 5.13. SEM images of Glass/ITO/Au NPs (A) and Glass/ITO/Au NPs plus nanoplates (B). Scale bars $200 \mathrm{~nm}$. Cyclic voltammograms of $\mathrm{Cu}$ UPD on Glass/ITO/Au NPs (black) and Glass/ITO/Au nanoplates (red) obtained from $0.01 \mathrm{M}$ $\mathrm{Cu}\left(\mathrm{ClO}_{4}\right)_{2}$ plus $0.1 \mathrm{M} \mathrm{HClO}_{4}$ at $20 \mathrm{mV} / \mathrm{s}$. 
oxidation peak is located at $\sim 1.4 \mathrm{~V}$, while for nanoplates it is around 1.2 V. As for the $\mathrm{Cu}$ UPD oxidation peaks, they are also very different. In the sample with a predominant amount of $\mathrm{Au}$ NPs with the flower-like structures, the Cu UPD oxidation peak is a singe peak at a potential of $\sim 360 \mathrm{mV}$ (Figure 5.13, black). In the glass/ITO/Au nanostructures with nanoplates, the $\mathrm{Cu}$ UPD oxidation peak has a characteristic doubled shape, with one peak at $\sim 370 \mathrm{mV}$ and a second at $\sim 320 \mathrm{mV}$ (Figure 5.13, red). From these CVs, we conclude that $\mathrm{Cu}$ UPD oxidation peaks and $\mathrm{Au}$ oxide peaks are sensitive to the shapes of the Au due to the different crystal faces exposed.

\subsection{CONCLUSIONS}

In summary, we demonstrated an electrochemical method for the preparation of $\mathrm{Au}$ nanoplates directly on the surface of glass/ITO electrodes by chronocoulometry. The properties and the mechanism of the formation of nanoplates were studied by microscopic, optical, and electrochemical techniques. The process of the formation of the nanoplates involves the transformation from branched nanoparticles into irregularly shaped flat nanostructures with edged borders and finally into smooth nanoplates with triangular and hexagonal shapes. After testing the different conditions, such as concentration of $\mathrm{HAuCl}_{4}$ solution and charge passed, we found parameters, which give the maximum yield of the nanoplates of $45 \pm 9 \%$. The deposition potential of $0.8 \mathrm{~V}$, the final amount of passed charge of $1.2 \times 10^{-2} \mathrm{C}$, and a concentration of $5 \times 10^{-5} \mathrm{M} \mathrm{HAuCl}_{4}$ plus $0.5 \mathrm{M} \mathrm{H}_{2} \mathrm{SO}_{4}$ solution were found as optimal conditions for this experiment. The

formation and presence of different structures of $\mathrm{Au}$ were monitored using 
electrochemical, optical and microscopic techniques such as Cu UPD, UV-vis, and SEM, respectively. UV-vis spectra detected the formation of the $\mathrm{Au}$ nanoplates by the appearance of the peak at $\sim 895 \mathrm{~nm}$. In Cu UPD measurements, the presence of two or three Cu UPD oxidation peaks from $\sim 290 \mathrm{mV}$ to $\sim 370 \mathrm{mV}$ indicated the presence of nanoplates. This method can be very useful for a better understanding of nanoparticle transformations during the process of electrochemical reduction, and it will allow researchers to pursue various applications in electrochemistry, catalysis, and sensing with well-defined metal nanostructures. 


\section{CHAPTER VI}

\section{SUMMARY AND CONCLUSIONS}

In summary, this thesis shows that the electrochemical properties of Au NPs, such as electrochemical oxidation, underpotential deposition of other metals, and optical properties, directly depend on their size, shape, and crystallographic structure. Understanding these properties is very important in metal nanomaterials research.

In summary we performed the:

1) chemical synthesis of Au NPs in solution with different sizes and studied their electrochemical oxidation.

2) chemical synthesis of Au NPs in solution with different sizes and studied the underpotential deposition of $\mathrm{Cu}$ on their surface.

3) electrochemical growth of $\mathrm{Au}$ NPs of various sizes and studied the underpotential deposition of $\mathrm{Cu}$ on their surface.

4) electrochemical growth of triangular- and hexagonal-shaped $\mathrm{Au}$ nanoplates directly on glass/ITO electrodes.

5) UV-vis spectroscopy and SEM characterization of Au nanostructures of different size and shape prepared chemically or electrochemically.

In this thesis we showed three different methods to prepare Au NPs in solution, including the direct chemical synthesis of Au NPs with an average diameter of $4 \mathrm{~nm}, 15$ 
$\mathrm{nm}, 31 \mathrm{~nm}$, and $73 \mathrm{~nm}$. After electrostatic attachment of the NPs we measured their electrochemical and optical properties. We also performed electrochemical deposition in chronocoulometry mode to synthesize various Au nanostructures directly on electrode surfaces. We varied the concentration of $\mathrm{HAuCl}_{4}$ solution, deposition potential, and the amount of charge passed. We studied the optical and electrochemical properties of the electrochemically-synthesized nanostructures.

The following are the conclusions drawn from the electrochemical and optical experiments of $\mathrm{Au}$ NPs chemically synthesized in solution:

- The Au oxidation potential in bromide-containing electrolyte decreased with decreasing size of the Au NPs.

- The shift is due to a thermodynamic shift in $E^{0}$.

- The shift is different from that of similar size Au NPs electrochemically synthesized.

- The UV-vis and SEM data were consistent with the sizes synthesized.

The following are conclusions about $\mathrm{Cu}$ deposition on $\mathrm{Au}$ NPs as a function of size.

- Smaller Au NPs can better catalyze the growth of bulk $\mathrm{Cu}$ deposition. It is more energetically favored as the size of the Au NPs decreased. This is due to the lower stability (higher surface energy) of small Au NPs.

- The amount of $\mathrm{Cu}$ deposited in the UPD region relative to the surface $\mathrm{Au}$ atom decreased as the Au NP diameter increased. This is due to a greater number of defects and higher energy of Au NPs as the size decreases, which allow a greater $\mathrm{Cu}$ coverage. 
- The amount of $\mathrm{Cu}$ relative to $\mathrm{Au}$ increases linearly with increasing coverage of Au for the same sized Au NPs, showing no effect of NP coverage on Cu UPD coverage.

The following are conclusions drawn from the experiments with Au nanoplates:

- Varying the concentration of $\mathrm{HAuCl}_{4}$ solution and the amount of charge passed during deposition controls the size and shape of the Au nanostructures that are electrochemically deposited directly on the glass/ITO surface.

- The Cu UPD region on $\mathrm{Au}$ is sensitive to the shape due to the different exposed Au crystal faces for different shapes.

- A peak appeared at $\sim 895 \mathrm{~nm}$ in the UV-vis spectra that was consistent with the formation of a higher yield of Au nanoplates on the surface.

- Au NPs are more stable than nanoplates in terms of electrochemical oxidation.

- The optimal conditions for obtaining a high $\sim 45 \%$ yield of nanoplates is a potential of $0.8 \mathrm{~V}$, charge of $1.2 \times 10^{-2} \mathrm{C}$, and a solution of $5 \times 10^{-5} \mathrm{M}$ $\mathrm{HAuCl}_{4}$ plus $0.5 \mathrm{M} \mathrm{H}_{2} \mathrm{SO}_{4}$.

\section{FUTURE DIRECTIONS:}

In the future it would be interesting to finish the studies about the size-dependent electrochemical stability of NPs. For this purpose it is necessary to determine all of the parameters for the electrochemical deposition of Ag NPs with different sizes and then 
measure their oxidation properties with comparison to previously obtained oxidation of chemically-synthesized Ag NPs. The same study can be performed with Pd or Pt NPs chemically-synthesized and electrochemically deposited to determine if different metals exhibit different behavior. Also, it would be interesting to study the oxidation properties of a mixture of two different sizes and shapes of metal NPs.

Another possible extension of this work would be to study the effect of various organic molecules attached to the metal NPs on their oxidation. The molecules could be thiols or amines such as - 1,6 hexanedithiol, 1,2 ethanedithiol, or aminomethil-3.5dimethoxyphenoxy. It will be interesting to study the properties of different metal NPs covered by various SAMs.

Also, discovering new chemical and electrochemical methods for the preparation of metal nanostructures comprised of $\mathrm{Ag}, \mathrm{Pd}, \mathrm{Ni}$, and $\mathrm{Cu}$ with different shapes, such as spheres, nanorods, nanodiscs, flower-like structures, and nanoplates with triangular hexagonal shapes, will be interesting in the future.

In the future, it would be interesting to study the UPD of other systems on nanostructures such as $\mathrm{Au} / \mathrm{Ag}, \mathrm{Pd} / \mathrm{Cu}$, and $\mathrm{Ag} / \mathrm{Cu}$. The study would focus on the effect of NP size and shape on the UPD signature. Other variables that could be changed during the experiment would be the concentration of the metal salt solution, which is used for underpotential deposition, the size, the various shapes of the metal NPs (spherical, flower-like, triangular, hexagonal, nanorods), and the temperature. With the different conditions, we would expect differences in the UPD characteristics. 


\section{REFERENCES}

1. Rao, C. N. R.; Cheetham, A. K. J. Materials Chem. 2001, 11, 2887-2894.

2. Rao, C. N. R.; Kulkarni, G. U.; Thomas, P. J.; Edwards, P. P. Chem. Eur. J. 2002, 8, 29-35.

3. Mulvaney, P. Langmuir 1996, 12, 788-800.

4. Jain, P. K.; Huang, X.; El-Sayed, M. A. Acc. Chem. Res. 2008, 41, 1578-1586.

5. Bansmann, J.; Baker, S. H.; Binns, C.; et al. SURFACE SCIENCE REPORTS, 56, 2005, 189-275.

6. Rustau, R.; Tiruvalam, R.; Clasen, P.L.; Gorowski, E. P.; Harmer, P. M.; Kiely, C. J.; Hussain, I.; Brust, M. Gold Bull. 2009, 42, 133-143.

7. Andres, R. P.; Bein, T.; Dorogi, M.; Feng, S.; Henderson, J. I.; Kubiak, C. P.; Mahoney, W.; Osifchin, R. G.; Reifenberger, R. Science 1996, 272, 1323-1325.

8. Feldheim, D. L.; Keating, C. D. Chem. Soc. Rev. 1998, 27, 1-12.

9. Chen, M.; Goodman, D. W. Chem. Soc. Rev. 2008, 37, 1860-1870.

10. Chen, M.; Goodman, D. W. Acc. Chem. Res. 2006, 39, 739-746.

11. Guerin, S.; Hayden, B. E.; Pletcher, D.; Rendall, M. E.; Suchsland, J. P. J. Comb. Chem. 2006, 8, 679-686.

12. Hayden, B. E.; Pletcher, D.; Rendall, M. E.; Suchsland, J.-P. J. Phys. Chem. C 2007, $111,17044-17051$. 
13. Ivanova, O. S.; Zamborini, F. P. J. Am. Chem. Soc. 2010, 132, 70-72.

14. Brust, M.; Kiely, C. J. Colloids Surf. A: Physicochem. Eng. Asp. 2002, 202, 175-186.

15. M. H. Rashid, R. R. Bhattacharjee, A. Kotal, T. K. Mandal Langmuir 2006, 22, 71417143.

16. Kimling, J.; Maier, M.; Okenve, B.; Kotaidis, V.; Ballot, H.; Plec, A. J. Phys. Chem. $B$ 2006, 110, 15700-15707.

17. Brust, M.; Walker, M.; Bethell, D.; Schiffrin, D. J.; Whyman, R. Chem. Commun. 1994, 7, 801.

18. Perrault, D. S.; Chan, W. C. W. J. Am. Chem. Soc. 2009, 47, 131.

19. Martin, M. N.; Basham,J. I.; Chando, P.; Eah, S.-K. Langmuir 2010, 26, 7410.

20. Sau, T. K.; Pal, A.; Jana, N. R.; Wang, Z. L.; Pal, T. J. Nanopart. Res. 2001, 3, 257 261

21. Meltzer, S.; Resch, R.; Koel, B. E.; Thompson, M. E.; Madhukar, A.; Requicha, A. A. G.; Will, P. Langmuir 2001, 17, 1713-1718.

22. Mallick, K.; Wang, Z. L.; Pal, T. J. Photochem. Photobiol. 2001, 140, 75-80.

23. Zhou, Y.; Wang, C. Y.; Zhu, Y. R.; Chen, Z. Y. Chem. Mater. 1999, 11, 2310-2312.

24. Niidome, Y.; Hori, A.; Sato, T.; Yamada, S. Chem. Lett. 2000, 310-311.

25. Henglein, A.; Meisel, D. Langmuir 1998, 14, 7392-7396.

26. Dawson, A.; Kamat, P. V. J. Phys. Chem. B 2000, 104, 11842-11846.

27. Nakamoto, M.; Yamamoto, M.; Fukusumi, M. Chem. Commun. 2002, 1622-1623.

28. Shimizu, T.; Teranishi, T.; Hasegawa, S.; Miyake, M. J. Phys. Shem. B 2003, 107, 2719-2724.

29. Galvagno, S.; Parravano, G. J. Catal. 1978, 55, 178-190. 
30. Haruta, M. Catal. Today, 1997, 36, 153-166.

31. Ueda, A.; Oshima, T.; Haruta, M. Appl. Catal. B 1997, 12, 81-93.

32. Andreeva, D.; Tabakova, T.; Idakiev, V.; Chistov, P.; Giovanoli, R. Appl. Catal. A 1998, $169,9-14$.

33. Richrd, D.; Roussignol, Ph.; Flytzanis, C. Opt. Lett. 1985, 10, 511-513.

34. Ansari, A. A.; Alhoshan, M.; Alsalhi, M. S.; Aldwayyan, A. S. Sensors 2010, 10, $6535-6581$

35. Brown, K. R.; Fox, A. P.; Natan, M. J. J. Am. Chem. Soc. 1996, $118,1154$.

36. Castañeda, M. T.; Alegret, S.; Merkoçi, A. Electroanalysis 2007, 19, 743.

37. Dequaire, M.; Degrand, C.; Limoges, B. Anal. Chem. 2000, 72, 5521.

38. Chen, J.; Tang, J.; Yan, F.; Ju, H. Biomaterials 2006, 27, 2313.

39. Yongxin, L.; Cox, J. T.; Bo, Z. J. Am. Chem. Soc. 2010, 132, 3047-3054

40. Sun, X.; Du, Y.; Dong, S.; Wang, E. Anal. Chem. 2005, 77, 8166.

41. Murray, R. W. Chem. Rev. 2008, 108, 2688-2720.

42. Sardar, R.; Funston, A. M.; Mulvaney, P.; Murray, R. W. Langmuir 2009, 25 (24) 13840-13851.

43. Ung, T.; Giersign, M.; Dunstan, D.; Mulvaney, P. Langmuir 1997, 13, 1773.

44. Kolb, D. M.; Englemann, G. E.; Ziegler, J. C. Angew. Chem., Int. Ed. 2000, 39, 1123 1125

45. Ng, K. H.; Liu, H.; Penner, R. M. Langmuir 2000, 16, 4016-4023

46. Del Pópolo, M.; Leiva, E.; Klein, H.; Meier, J.; Stimming, U.; Mariscal, M.; Schmickler, W. Appl. Phys. Lett. 2002, 81, 2635-2637 
47. Tang, L.; Han, B.; Persson, K.; Friesen, C.; He, T.; Sieradzki, K.; Ceder, G. J. Am. Chem. Soc. 2010, 132, 596-600

48. Kolb, D. M.; Simeone, F. C. Electrochem. Acta 2005, 50, 2989-2996

49. Guo, R.; Song, Y.; Wang, G.; Murray, R. W. J. Am. Chem. Soc. 2005, 127, 27522757

50. Wang, G.; Murray, R. W. Nano Lett. 2004, 4, 95-101

51. Hicks, J. F.; Zamborini, F. P.; Murray, R. W. J. Phys. Chem. B 2002, 106, 7751-7757.

52. Hicks, J. F.; Zamborini, F. P.; Osisek, A. J.; Murray, R. W. J. Am. Chem. Soc. 2001, $123,7048-7053$.

53. Zamborini, F. P.; Hicks, J. K.; Murray, R. W. J. Am. Chem. Soc. 2000, 122, 45144515.

54. Lee, D.; Donkers, R. L.; Wang, G.; Harper, A. S.; Murray, R. W. J. Am. Chem. Soc. 2004, 126, 6193-6199.

55. Menard, L. D.; Gao, S.-P. Xu, H.; Twesten, R. D.; Harper, A. S.; Song, Y.; Wang, G.; Douglas, A. D.; Yang, J. C.; Frenkel. A. I.; Nuzzo, R. G.; Murray, R. W. J. Phys. Chem. B 2006, 110, 12874-12883.

56. Miles, D. T.; Murray, R. W. Anal. Chem. 2003, 75, 1251-1257

57. Henglein, A. J. Phys. Chem. 1993, 97, 5457-5471

58. Plieth, W. J. J. Phys. Chem. 1982, 86, 3166

59. Ward Jones, S. E.; Campbell, F. W.; Baron, R.; Xiao, L.; Compton, R. G. J. Phys. Chem. C 2008, 112, 17820-17827

60. Ward Jones, S. E.; Toghill, K. E.; Zheng, S. H.; Morin, S.; Compton, R. G. J. Phys Chem C 2009, 113, 2846-2854 
61. Brainina K.Z.; Galperin, L.G.; Galperin, A.L. J. of Solid St. Electrochem. 2010, 14, $981-988$

62. Ivanova, O. S.; Zamborini, F. P. Anal. Chem. 2010, 82, 5844-5850

63. Anjos, D. M.; Rigsby, M. A.; Wieckowski, A J. Electroanal. Chem. 2010, 639, 8-14

64. Kolb, D. M.; in: Gerisher, H. (Ed.), Advances in Electrochemistry and Electrochemical Engeneering, New York, 1978, 125-271

65. Zhang, J.; Sung, Y. E.; Rikvold, P. A.; Wieckowski, A. J. Chem. Phys. 1996, 104, $5699-5712$

66. Gewirth, A. A.; Niece, B. K. Chem. Rev. 1997, 97, 1129-1162

67. Wasberg, M.; Hornyi, G. J. Electroanal. Chem. 1995, 385, 63-70

68. Aoun, B. S.; Dursun, Z.; Koga, T.; Bang, G. S.; Sotomura, T.; Taniguchi, I. $J$. Electroanal. Chem. 2004, 567, 175-183

69. Aoun, S. B.; Bang, G. S.; Koga, T.; Nonaka, Y.; Sotomura, T.; Tahiguchi, I. Electrochem. Commun. 2003, 5, 317-320

70. Abe, T.; Swain, G. M.; Sashikata, K.; Itaya, K. J. Electroanal. Chem. 1995, 382, 73 83

71. Domke, K. F.; Xiao, X. Y.; Baltruschat, H. Phys. Chem. Chem. Phys. 2008, 10, 15551561

72. Amadelli, R.; Markovic, N.; Adzic, R.; Yeager, E. J. Electroanal. Chem. 1983, 159, $391-412$

73. Sasaki, K. Mo, Y.; Wang, J. X.; Balasubramanian, M.; Uribe, F.; McBreen, L.; Adzic, R. R. Electrochemica Acta 2003, 48, 3841-3849 
74. Jerkiewicz, G.; Radovic-Hrapovic, Z. Abstracts of papers of Am. Chem. Soc. 2001, 221, 93-COLL

75. Jennings, G. K.; Laibinis, P. E. J. Am. Chem. Soc. 1996, 119, 5208

76. Vasiljevic, N.; Viyannalage, L. T.; Dimitrov, N.; Sieradzki, K. J. Electroanal. Chem. 2008, $613,118-124$

77. Toney, M.F.; Howard, J. N.; Richer, J.; Borges, G.L.; Gordon, J.G.; Melroy, O.R.; Yee, D.; Sorensen, L. B. Phys. Rev. Lett. 1995, 75, 4472-4475

78. Holzle, M. H.; Zwing, V.; Kolb, D. M. Electrochom. Acta 1995, 40, 1237-1247

79. Hotlos, J.; Magnussen, O. M.; Behm, R. J. Surf. Sci 1995, 335, 129-144

80. Ikemiya, N.; Miyaoka, S.; Hara, S. Surf. Sci. 1995, 327, 261-273

81. Moller, F.; Magnussen, O. M.; Behm, R. J. Electrochim. Acta 1995, 40, 1259-1265

82. Moller, F. A.; Magnussen, O. .; Behm, R. J. Phys. Rev. B 1995, 51, 2484-2490

83. Carino, E. V.; Crooks, R. M. Langmuir 2011, 27, 4227-4235.

84. Hernandez, J.; Solla-Gullon, J.; Herrero, E.; Aldaz, A.; Feliu, J. M. J. Phys. Chem. C 2007, 111, 14078-14083

85. Vidal-Iglesias, F. J.; Solla-Gullon, J.; Herrero, E.; Aldaz, A.; Feliu, J. M. Angew. Chem. Int. Ed. 2010, 49, 6998-7001

86. Campbell, F. W.; Compton, R. G. Int. J. Electrochem. Sci. 2010, 5, 407-413

87. Campbell, F. W.; Zhou, Y.-G.; Compton, R. G. New J. Chem. 2010, 34, 187-189

88. Liang, H. C.; Rong, M. Z.; Zhang, M. O.; Zeng, H. M. Acta Phys. Sinica 2002, 51, 49-54

89. Sun, Y. G.; Xia, Y. N.; Anal. Chem. 2002, 74, 5297-5305 
90. Zhou, H. S.; Honma, I.; Komiyama, H.; Haus, J. W. Phys. Rev. B 1994, 16, 1205212056

91. Burda, C.; Chen, X.; Narayanan, R.; El-Sayed, M. A. Chem. Rev. 2005, 105, $1025-$ 1102

92. El-Sayed, M. A. Acc. Chem. Res. 2001, 34, 257-264

93. Petroski, J. M.; Green, T. C.; El-Sayed, M. A. J. Phys. Chem. A 2001, 105, 55425547

94. Aizpurua, J.; Hanarp, P.; Sutherland, D. S.; Kall, M.; Bryant, G. W.; de Abajo, F. J. G. Phys. Rev. Lett. 2001, 90, 057401

95. Sarkar, A.; Kapoor, S.; Mukherjee, T. J. Colloid Interface Sci. 2005, 287, 496-500

96. Chen, S. H.; Fan, Z. Y.; Carroll, D. L. J. Phys. Chem. B 2002, 105, 10777-10781

97. Yu, Y. Y.; Chang, S. S.; Lee, C. L.; Wang, C. R. C. J. Phys. Chem. B 1997, 101, $6661-6664$

98. Adbelmonti, L. G.; Zamborini, F. P. Langmuir 2010, 26, 13511-13521

99. Block, B. P. Inorg. Synth. 1953, 4, 14-17

100. Jana, N. R.; Gearheart, L.; Murphy, C. J. J. Phys. Chem. B 2001, 105, 4065-4067

101. Pyatenko, A.; Yamaguchi, M.; Suzuki, M. J. Phys. Chem. C.2007, 111, 7910-7917

102. Bott, A. W.; Heineman, W. R. Current Separations, 2004, 121-126

103. http://www.charfac.umn.edu/sem_primer.pdf

104. Masitas, R. A; Zamborini, F. P J. Am. Chem. Soc. 2012, 134,5014-5017

105. http://vislab.eas.ualberta.ca/SSRM/Mie/Mie.aspx

106. Gerischer, H.; Kolb, D.M.; Sass, J.K. Adv. In Phys. 1978, 27, 437-498

107. Budevski, E., Staikov, G.; Lorenz, W. J. Abs. of papers of Am. Chem. Soc. 1996, 212 
108. Vereecken, P.M.; Binstead, R. A.; Deligianni, H.; Andricacos, P. C. IBM J. Res. Dev. 2005, 49, 3-18

109. A. Kuzume et al. J. Electroanalyt. Chem. 2004, 570, 157-161

110. Schneeweiss, M. A.; Kolb, D. M. Phys. Stat. Sol. 1999, 173, 51-71

111. Kolb, D. M. Electrochim. Acta 2000, 45, 15-16

112. Herrero, E.; Buller, L. J.; Abruña, H. D. Chem.Rev. 2001, 101, 1897-1930

113. Cappadonia, M.; Robinson, K.M.; Schmidberger, J.; Stimming, U.; J. Electroanal. Chem. 1997, 436, 73-78

114. Blum, L.; Abruna, H.D.; White, J.H.; Gordon, J.G.; Borges, G.L.; J. Chem. Phys. 1986, $85,6732-6738$

115. Melroy, O.R.; Samant, M.G.; Borges, G.L.; Gordon, J.G.; White, J.H.; Albarelli, M.J.; McMillan, M.; Abruna, H.D. Langmuir 1988, 4, 728-732

116. Manne, S.; Hansma, P.K.; Massie, J.; Elings, V.B.; Gewirth, A.A. Science 1991, $251,183-188$

117. Hachiya, T.; Honbo, H.; Itaya, K. J. Electroanal. Chem. 1991, 315, 275-291

118. Ragoisha, G. A.; Bondarenko, A.S. Electrochem. Comm. 2003, 5, 392-395

119. Cappadonia, M.; Linke, U.; Robinson, K.M.; Schmidberger, J.; Stimming, U. J.

Electroanal. Chem. 1996, 405, 227-232

120. Martin, H.; Carro, P.; Creus, A. H.; González, S.; Salvarezza, R. C.; Arvia, A. J. Langmuir 1997, 13, 100-110

121. Zhang, Y.; Chang, G.; Liu, S.; Lu, W.; Tian, J.; Sun, X. Biosensors and Bioelectronics 2011, 28, 344-348

122. Roh, J.; Yi, J.; Kim, Y. Langmuir 2010, 26(14), 11621-11623 
123. Beeram, S. R.; Zamborini, F. P. ACS Nano 2010, 4, 3633-3646

124. Takezaki, M.; Kida, R.; Kato, Y.; Tominaga, T. Chem. Lett. 2009, 38, 1022-23

125. Lee, C.-L.; Tseng, C.-M. J. Phys. Chem. C 2008, 112, 13342-13345

126. Zhou, M.; Chen, S.; Zhao, S.; Ma, H. Chem. Lett. 2005, 34, 1670-1671

127. Seo, B.; Choi, S.; Kim J. ACS Appl. Mater. Interfaces 2011, 3, 441-446

128. Schawartzberg, A. M.; Zhang, J. Z. J. Phys. Chem. C 2008, 112, 10323-10337 
CURRICILUM VITAE

Department of Chemistry

University of Louisville

Louisville, KY 40292

Telephone: (502) 852-5982

Mobile: (502) 424-8576

irinakhachian@gmail.com

\section{Objective}

Obtain a challenging position to apply my skills in analytical chemistry in a pharmaceutical, environmental or chemical company.

\section{Qualifications}

- Strong educational background in Analytical Chemistry, Electrochemistry, Physical chemistry, Surface Chemistry, and Nanomaterials synthesis and Characterization.

- Expertise in the synthesis and characterization of metal nanostructures using modern electrochemical, microscopic, and optical techniques.

\section{Instrumentation}

Electrochemistry: Cyclic Voltammetry, Linear Sweep Voltammetry, Electrochemical Impedance, Chronocoulometry.

Spectroscopy: Infrared Spectroscopy, UV-visible Spectroscopy.

Separations: Gas Chromatography, Capillary Electrophoresis.

Microscopy: Scanning Electron Microscopy (SEM), Atomic Force

Microscopy (AFM).

Materials: Thermogravimetric Analysis.

\section{Education}

M.S. Chemistry, University of Louisville,

Louisville, KY

- Advisor: Francis P. Zamborini

- Thesis: Size- and Shape-Dependent Stability of Gold Nanostructures.

B.S., Chemistry, Perm State University,

Perm, Russia

- Advisor: Shavkunov Sergej Pavlovich

- Senior project: Kinetics of Aluminum Electrodeposition from Xylene-

Durene Electrolytes.

\section{Research and Working Experience}

Graduate Research, University of Louisville,

Louisville, KY

- Chemical and electrochemical preparation of metal nanostructures.

- Electrochemical characterization of Au nanostructures - oxidation by Linear Sweep Voltammetry (LSV) and Cyclic Voltammetry (CV).

- Microscopic characterization by Scanning Electron Microscopy (SEM) and Atomic Force Microscopy (AFM). 
Undergraduate Research, Perm State University,

2005-2010

Perm, Russia

- Electrochemical characterization of electrodeposited Aluminum by $\mathrm{CV}$ and

electrochemical impedance spectroscopy.

\section{Teaching Experience}

Graduate Teaching Assistant, University of Louisville,

2010-2012

Louisville, KY

- Taught chemical analysis labs for undergraduate students, prepared chemicals and equipment, graded and evaluated student's woks, was responsible for safety.

\section{Conference presentations}

1. Plotnikova, I. V.; Zamborini, F. P. Synthesis and Characterization of Au Nanostructures, oral presentation at the Southeast Regional Meeting of the American Chemical Society (SERMACS) in Richmond, Virginia (November 2011).

2. Zamborini, F. P.; Plotnikova, I. V.; Masitas, R.; Dasari, R.; Fang, A.; Shah, N. Electrochemical Oxidation and Deposition of Metallic Nanostructures presentation at the Gordon Research Conference in Ventura, CA (January 2012) poster.

\section{Languages}

English, Russian

\section{References:}

Dr. Francis P. Zamborini (Ph.D.)

University of Louisville Department of Chemistry

2320 South Brook Street

Louisville, KY 40292

Phone: (502) 8526550

Email: f.zamborini@louisville.edu

Dr. Marta C. Yappert (Ph.D.)

University of Louisville Department of Chemistry

2320 South Brook Street

Louisville, KY 40292

Phone: (502) 8527061

Email: mcyappert@louisville.edu

Dr. Richard P. Baldwin (Ph.D.)

University of Louisville Department of Chemistry

2320 South Brook Street

Louisville, KY 40292

Phone: (502) 8525892

Email: rick.baldwin@louisville.edu 